\title{
DECENTRALIZATION OF RIVER BASIN MANAGEMENT: A GLOBAL ANALYSIS
}

\author{
Ariel Dinar \\ Karin Kemper \\ William Blomquist \\ Michele Diez \\ Gisèle Sine \\ William Fru
}

World Bank Policy Research Working Paper 3637, June 2005

The Policy Research Working Paper Series disseminates the findings of work in progress to encourage the exchange of ideas about development issues. An objective of the series is to get the findings out quickly, even if the presentations are less than fully polished. The papers carry the names of the authors and should be cited accordingly. The findings, interpretations, and conclusions expressed in this paper are entirely those of the authors. They do not necessarily represent the view of the World Bank, its Executive Directors, or the countries they represent. Policy Research Working Papers are available online at http://econ.worldbank.org.

This paper is a product of the study, "Integrated River Basin Management and the Principle of Managing Water Resources at the Lowest Appropriate Level - When and Why Does It (Not) Work in Practice?" The Research Support Budget of the World Bank provided major funding. The project was carried out by the Agriculture and Rural Development Department at the World Bank. The Water Resources Management Group and the South Asia Social and Environment Unit at the World Bank have provided additional support. The study core team includes Karin Kemper and Ariel Dinar (Co-Task Team Leaders, World Bank), William Blomquist and Anjali Bhat (consultants, Indiana University), and Michele Diez (World Bank), William Fru (consultant), and Gisèle Sine (International Network of Basin Organizations). Basin case study consultants include Maureen Ballestero (Tárcoles - Costa Rica), Ken Calbick and David Marshall (Fraser - Canada), Rosa Formiga (Alto Tietê and Jaguaribe - Brazil), Consuelo Giansante (Guadalquivir - Spain), Brian Haisman (Murray Darling - Australia), Kikkeri Ramu and Trie Mulat Sunaryo (Brantas - Indonesia), and Andrzej Tonderski (Warta - Poland). Help in the statistical analysis was provided by Pradeep Kurukulasuriya. Useful comments on this paper by Philip Keefer are acknowledged. 


\section{Contents}

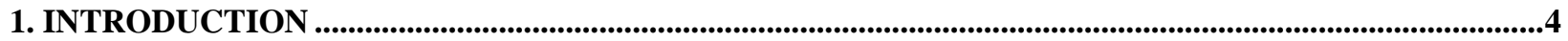

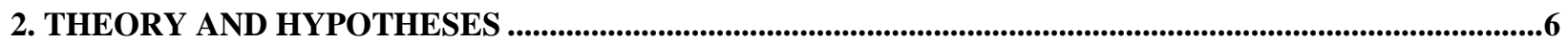

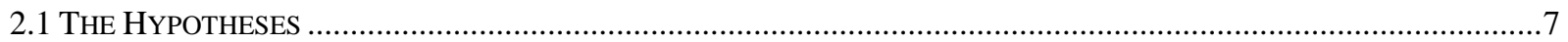

For each set we develop a list of empirical variables that could capture the expected relationship...................8

Impact of Contextual Factors and Initial Conditions.............................................................................................8

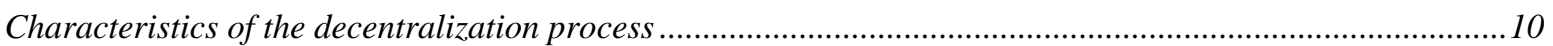

Characteristics of central government/basin-level relationships and capacities.............................................11

The internal configuration of basin-level institutional arrangements.................................................................14

3. THE DATA COLLECTION AND QUALITY ASSURANCE PROCESS...........................................................16

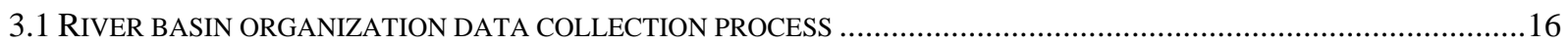

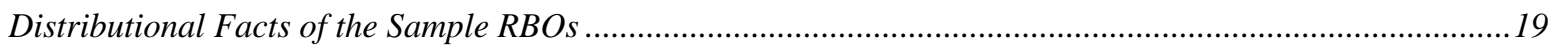

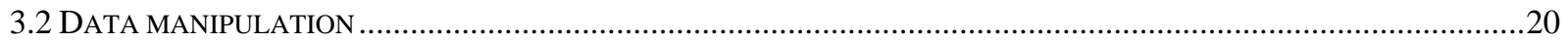

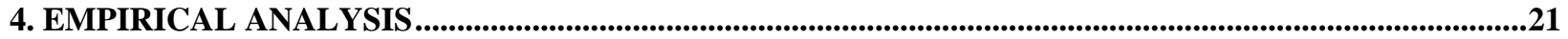

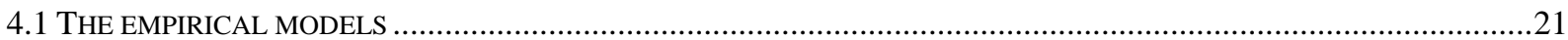

4.2 EMPIRICAL SPECIFICATIONS OF THE DECENTRALIZATION PROCESS AND ITS PERFORMANCE ...............................23

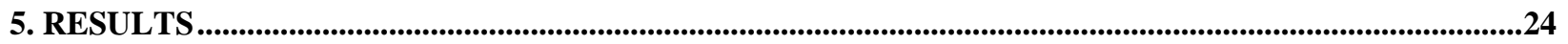

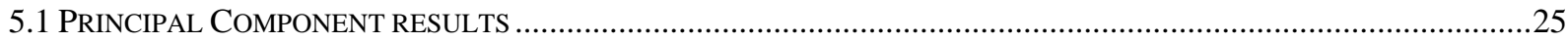

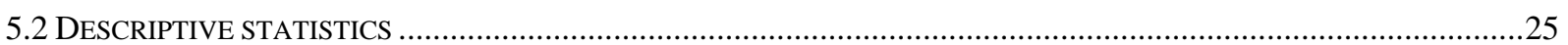

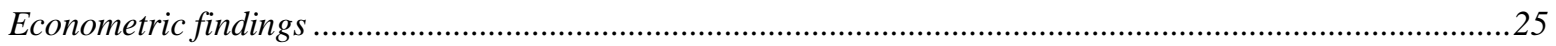

The interaction between the decentralization process and its level of performance.........................................33

6. INTERPRETATION OF THE RESULTS.........................................................................................................36

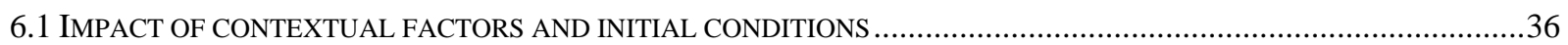

6.2 CHARACTERISTICS OF THE DECENTRALIZATION PROCESS ....................................................................................3

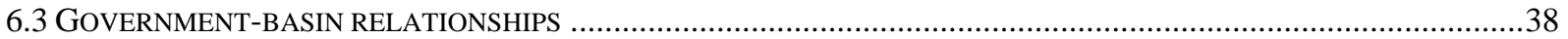

6.4 INTERNAL CONFIGURATION OF BASIN-LEVEL INSTITUTIONAL ARRANGEMENTS ..................................................39

7. CONCLUSION, POLICY IMPLICATIONS AND EXTENSION OF THE ANALYSIS.................................40

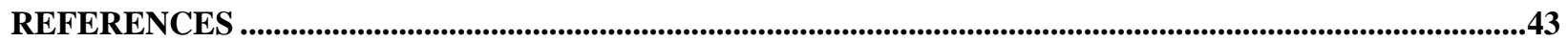

ANNEX 1: ADMINISTERING THE RIVER BASIN SURVEY (REPORT PREPARED BY INBO) ...............46

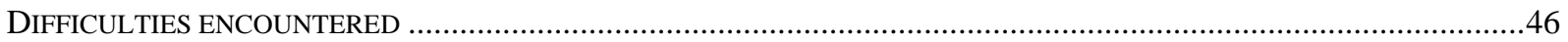

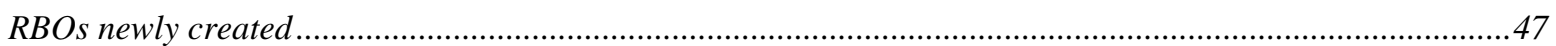

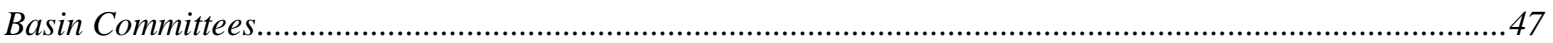


Astica

TALLY OF THE BASINS THAT WERE APPROACHED BY INBO ..........................................................................50

ANNEX 2: STRUCTURE OF VARIABLES IN DATASET …...........................................................................53

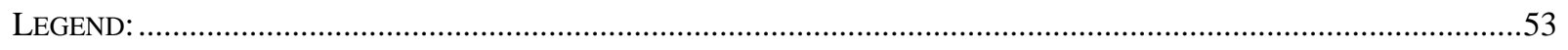

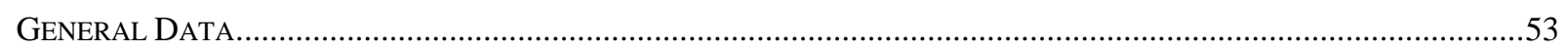

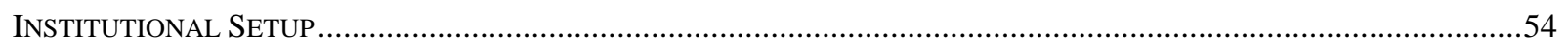

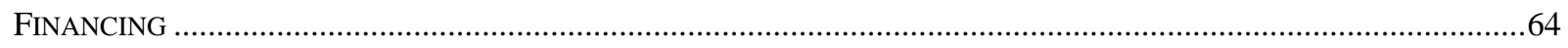

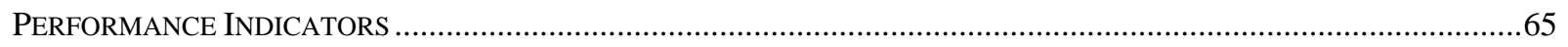

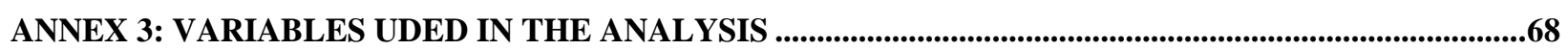

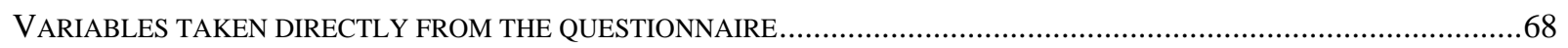

VARIABLES THAT UNDERWENT PRINCIPAL COMPONENT (PC) ANALYSIS AND EXPECTATIONS REGARDiNG THEIR

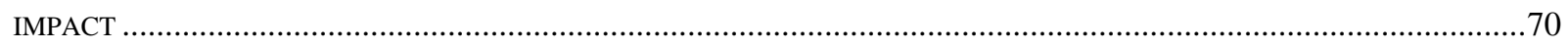

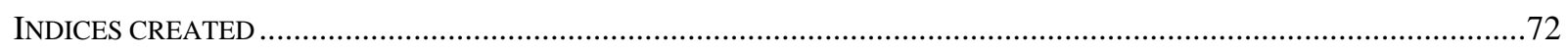

ANNEX 4: RIVER BASIN ORGANIZATION SURVEY .....................................................................................74 


\section{Introduction}

Various reforms in the water sector-including at the river basin level_-have been implemented in recent years in many countries. ${ }^{1}$ This has come following the increased awareness and concerns of both policy makers and water users regarding the state of water. One of the major components of these reforms at the basin level is the decentralization of management to the lowest appropriate level, as widely advocated in the Dublin Principles (ICWE 1992, p 4) and in the World Bank's Water Resources Policy Paper (1993, p 18), and the Global Water Partnership Working Paper (GWP, 2000). The lowest appropriate level usually implies the involvement of different stakeholders in the basin, including water users, in order to achieve a more sustainable management of the basin's water resources. $^{2}$

Early approaches to river basin management took an essentially scientific and engineering perspective to optimize water resources development and water allocation. Over time, while some efforts succeeded, many were "disappointing," as Barrow (1998) concluded. This, and the growing scope of river basin management-to include, for example, ecosystem preservation-led to the call for decentralization to the lowest appropriate level as a means for harnessing local initiatives and creating coalitions for development. In fact, of the several documented reforms of river basin management, both decentralization and performance are concepts that are hard to evaluate. A review of the literature on decentralization in the water sector (Mody, 2004) suggests that not many analyses of decentralization of river basin management functions have been undertaken yet, and that this topic is also relatively recent. Recent works have focused mainly on surveys of efforts at the national level to implement Integrated Water Resources Management (GWP, 2004).

The fact that there are only a few documented works of the experiences regarding the process and impact of decentralization in river basins around the world points to a major gap in our knowledge about the costs and benefits of the decentralization. The few analyses and case studies that particularly deal with decentralization include: the Curu, Jaguaribe and Metropolitana River Basins in Brazil (Kemper and Olson, 2000), the Yellow River Basin in China (Zusman, 1998),

\footnotetext{
${ }^{1}$ In this paper we do not question the challenges river basin management poses, and the reasons for decentralization, but take decentralization as an objective by itself. For a justification for the decentralization approach see Blomquist et al. (2005).

2 There could be several definitions for decentralization such as the general definition of delegation of decision making from higher to lower level entity. But we prefer the combination of increased transparency and involvement in decision making of stakeholders, as it provides a wider basis for measuring decentralization. Our definition of decentralization and it rationale are elaborated in the theory section of the paper.
} 
Lerma-Chapala Basin in Mexico (Reynoso, 2000; Merrey, 2000), the São Francisco Basin in Brazil (Ioris, 2001), the Bicol Basin in the Philippines (Koppel, 1987), the Olifants Basin in South Africa (Merrey, 2000), and the Cross Basin in Nigeria (Udofia, 1988). For a summary of major components of the decentralization reform in these basins, see Mody (2004). To address this issue in a more comprehensive manner, a research study was developed that would (i) carry out eight additional case study analyses and (ii) undertake a global survey of river basin organizations. The eight case studies were completed recently, employing a single analytical framework, as part of the study "Integrated River Basin Management and the Principle of Managing Water Resources at the Lowest Appropriate Level - When and Why Does It (Not) Work in Practice?” that was funded by the World Bank. The eight case studies are: the Guadalquivir Basin in Spain (Blomquist et al., 2004), the Warta Basin in Poland (Blomquist, et al., 2004), the Brantas Basin in Indonesia (Bhat ey al., 2004), the Tárcoles Basin in Costa Rica (Blomquist et al., 2004), the Murray Darling Basin in Australia (Blomquist et al., 2004), the Fraser Basin in Canada (Blomquist et al., 2004), and the Alto Tietê and Jaguaribe Basins in Brazil (Formiga and Kemper, 2005; and Formiga and Kemper, 2005).

While the case study analyses cited in Mody (2004) and the recent eight case studies mentioned above shed light on the direction of development in river basin decentralization, these do not yet permit the identification of generic reasons and forces behind decentralization, of process characterization and of success levels, just because the focus was on individual case study description. A more analytical approach would allow finding general relationships and patterns. For that one needs to have a framework that incorporates the political, institutional and economic variables and the paths by which they may influence decentralization outcome. Such framework also needs to take into account the initial and contextual conditions. An important consideration in this context is that "the lowest appropriate level" for integrated river basin management varies between basins, i.e. while full decentralization of decision-making can be optimal in one case, it can be destructive in another one. For this reason, the methodology necessarily needs to take into account hydrological, socio-economic, cultural and historical conditions in each basin (see also Saleth and Dinar, 2004).

In this paper we use the theory that has been developed within the research project and expand it to explain levels of success of decentralization processes in river basins and apply it to the global data collected from river basins around the world. The next section presents the theory and the hypotheses we plan to test. The third section presents the process of data collection and the 
quality assurance methods employed. As the data that were collected were very comprehensive, we also explain procedures used in manipulating the data for purposes of aggregating variables. Section 4 depicts and justifies the empirical models we constructed and section 5 reports the results of the analysis. The conclusion suggests lessons for both researchers dealing with assessing progress in institutional reform and policy makers dealing with river basin management and other related sectors.

\section{Theory and Hypotheses}

We follow the analytical framework suggested by Blomquist et al, (2005) that uses concepts such as incentives for stakeholders ${ }^{3}$ to act (e.g. the government to decentralize, the water users and other stakeholders to take on responsibilities), principal-agent relationships (referring to the transparency and enforcement possibilities in contractual agreements between the stakeholders to carry out certain functions), transaction costs (in terms of time and money to achieve institutional change) as well as the level of influence, determined inter alia by the degree of information asymmetry, between different actors and social groups.

In addition to the specific local context of the decentralization process, an important issue to be addressed is what to measure and how to measure. Decentralization of decision-making is not an aim per se. It is recommended because experience over the past decades has shown that when decision-making is centralized and local conditions are not taken appropriately into account, then accountability of decision makers is weak, and water resources management is inadequate. Thus, it is necessary to develop indicators to (a) define decentralization as a concept and (b) define and measure changes in water resources management outcomes when the institutional arrangements have changed.

We start with a proposed definition of decentralization, which is based on (a) an increase in transparency in decision making and (b) a substantial increase in stakeholder involvement in decision making, including measures to accord financial self-sufficiency. Acknowledging that each case is different, the baseline used for analysis would be the intention to decentralize as expressed by legislation in a certain country and by the initial statement of objectives of the respective organization that is being analyzed. The implementation of this intention would then be evaluated

\footnotetext{
${ }^{3}$ Stakeholders in the basin may include individuals, groups and governments (from local to federal).
} 
by taking into account (a) the existing institutional framework, (b) the process, (c) the political economy and (d) the results.

Decentralization can be seen as a reform process and as such, other processes that take place in parallel may affect it. Forces initiating and affecting the decentralization process stem from societal structure: the initiation of the process, the interests leading to the reform (top down or bottom up), rules governing the initiation and approval of organizational change, etc. These are discussed at length in Blomquist et al. (2005). Furthermore, the concept of path dependency plays a major role in the process of institutional reform (Saleth and Dinar, 2004:264). The process by which decentralization measures are introduced is expected to affect implementation, and thus performance, and therefore needs to be taken into account. The costs and benefits encountered by different stakeholders as well as power relations between them are also considered as important variables in our analytical framework (Saleth and Dinar, 2004:Chapter 4).

As institutional analysts have studied natural resource management in general—and in some instances, water resource management in particular-they have identified patterns that either encourage or inhibit the constructive coordination of individuals' behavior. Much of this work is summarized in Bromley (1989), Ostrom (1990) and Ostrom, Gardner and Walker (1994). An extensive literature review can be found in Dinar and Saleth (2004, Chapter 3). Among the key considerations identified in these literatures are: asymmetries of power, information, or other resources distribution among individuals; the history of past interactions among individuals and their anticipations concerning future interactions; the extent to which individuals are allowed or encouraged to innovate, experiment, and pursue trial-and-error learning with respect to institutional arrangements; social (or otherwise derived) norms of trust and reciprocity; and cultural or other differences among the individuals who are attempting to coordinate behavior or whose cooperation is needed. For this study, we have operationalized those broad categories into empirical variables, and formulated hypotheses about how each variable might contribute to the likelihood of successful or unsuccessful decentralization of river basin management.

\subsection{The Hypotheses}

For the purposes of the analysis in this paper, we assume that "management at the lowest appropriate level" usually implies the active involvement of different stakeholders, including users, at various levels related to the river basin. Appropriate in this context implies that not all stakeholders need to be involved in all decisions and management activities, but that this is a flexible concept, 
which would be adapted to each riverbasin, depending on local conditions. But increasing stakeholder involvement is not the end of the inquiry, and there are several important related questions. If such active involvement of stakeholders is secured, how can it be translated into effective resource management and high performance level? What factors might we expect to affect the likelihood of stakeholder involvement turning into effective basin-level resource management (as distinct from mere stakeholder consultation, or the collapse of stakeholder involvement)? If stakeholder involvement is translated into basin-level management, how can the active involvement and the effective resource management be sustained over time and changing conditions? What factors might account for the longevity of decentralized arrangements in some cases and their demise in others?

Guided by these research questions, we developed a theory, which identifies a set of empirical variables with hypotheses about their impact on the process of decentralization of river basin management and its performance. Those variables and hypotheses incorporate ideas identified in a literature review we conducted on decentralization in various sectors (Mody, 2004), as well as the literature on institutional analysis concerning collective action, central government-local government relationships, principal-agent relationships, and natural resource management. They are used here for translating the theory to empirical hypotheses. The following discussion presents our empirical hypotheses to be tested and the empirical variables. We have four sets of variables identified under the major headings:

1. Impact of contextual factors and initial conditions

2. Characteristics of the decentralization process

3. Characteristics of central government/basin-level relationships and capacities

4. The internal configuration of basin-level institutional arrangements.

For each set we develop a list of empirical variables that could capture the expected relationship.

\section{Impact of Contextual Factors and Initial Conditions}

The literature on decentralized water resource management indicates that the outcome of decentralization is partly a function of the initial conditions that prevail at the time a decentralization initiative is attempted (path dependency). These initial conditions are elements of the economic, 
political and social context of the decentralization effort. Several variables that could capture such conditions are listed below.

Level of economic development in the nation measures the ability of the government to financially support the initial stages of the decentralization process. Although a decentralization initiative may be undertaken with the expectation to reduce the central government's financial outlays for river basin management, the early stages of decentralization may require some additional outlays in order to make the transition. Central government assistance to basin stakeholders in establishing some of the basin-level organizations and practices could be essential. Furthermore, successful decentralization does not mean terminating all central government functions in the area of water resource management. Aspects of water resource management that have the characteristics of "public goods" may be provided by a central government, even while additional aspects of water management are devolved.

Therefore, the level of economic development of the nation is an important contextual variable, to the extent that it affects the financial capacity of the central government to bear both the transition costs of the decentralization initiative and the ongoing costs of the central functions that support and facilitate basin-scale water resource management. All other things being equal, we would expect decentralization initiatives to be more likely to achieve sustainable success where the economic well-being of the nation allows the central government to bear those costs.

Level of economic development of the river basin region measures the ability of the basin stakeholders to commit financial and other resources necessary to the decentralization process in addition to central government provision of support for the decentralization effort. The literature on decentralized water resource management indicates that successful decentralization must include some degree of financial autonomy (Cerniglia, 2003; Musgrave, 1997). Sustaining this financial autonomy often depends upon the establishment of some form of water pricing or tariffs, having the users obeying such payments, and having the proceeds remain within or return to the basin.

Thus, decentralizing management to the basin level, developing and maintaining the institutional arrangements for basin-level management, and implementing any form of financial autonomy imply that some financial resources at the basin level will have to be committed to the decentralization effort. This in turn implies that basins that have a level of economic development which can sustain those resource commitments are (all other things being equal) more likely to achieve sustainable success in decentralization. 
Initial distribution of resources among basin stakeholders is an important contextual factor in the development and successful implementation of a decentralization initiative. This variable has interesting and complex properties, however. On the one hand and more obviously, extreme disparities in resource endowments among basin stakeholders can imperil decentralization success. If some privileged stakeholders may anticipate being worse off, they are unlikely to support the decentralization process and may even try to derail it. And if other stakeholders are so destitute as to be unable to bring any resources of their own to the decentralization initiative, they may rationally elect not to participate even though more effective resource management would promise to improve their situation in the long run. On the other hand and less obviously, some inequality of initial resource endowments may facilitate action by enabling some stakeholders to bear the costs of taking a leadership role (Blomquist, 1988; Ostrom, 1990).

Thus, some inequality of resource endowments is not necessarily lethal to a decentralization initiative, and may even facilitate it if better-situated users are willing to lead. Extreme inequality, however, may be detrimental or even derail the decentralization effort. The distribution of resource endowments among the basin stakeholders is therefore an important contextual variable affecting the prospects for successful decentralization. We hypothesize that the relationship between level of inequality of resource endowments and successful decentralization is quadratic, with greatest positive impact at a certain level of inequality and lower or negative impacts at both lower and higher levels of inequality of resource endowment distribution.

\section{Characteristics of the decentralization process}

Certain conditions or characteristics of the decentralization process itself may affect the prospects for successful implementation. Two necessary conditions of a decentralization initiative are (a) a devolution of authority and responsibility from the center, and (b) an acceptance of that authority and responsibility by the local or regional units. Whether (a) and (b) both occur will depend in part upon why and how the decentralization takes place. Below is a list of variables and their expected impact.

Top-down, bottom-up, or mutually desired devolution are ways of characterizing the decentralization initiative. In some cases, central government officials may have undertaken resource management decentralization initiatives in order to solve their own problems-e.g., to reduce or eliminate the central government's political accountability for past or current resource policy failures, resolve a budgetary crisis by cutting their financial responsibility for selected domestic 
policy areas (Simon 2002), respond to pressure from external support agencies to formulate a decentralization initiative as a condition of continued receipt of financial support, etc. In other cases it is "bottom up" pressure from the stakeholders that leads to the decentralization (Samad, 2005). In still other cases, the decision to decentralize resource management to a lower and more appropriate level may have been the outcome of a process of mutual discussion and agreement between central officials hoping to improve policy outcomes and local stakeholders desiring greater autonomy and/or flexibility.

Using the data we collect, we therefore attempt to identify the motivation and process by which the decentralization initiative came to pass. And, all other things being equal, we can anticipate that because decentralization initiatives require active basin-level stakeholder involvement, they are more likely to be implemented successfully if undertaken under the latter circumstances than under the former.

Existing local-level governance arrangements contribute to continuation. The literature suggests that decentralization initiatives are more likely to be accompanied by active involvement of basin stakeholders if existing community (village, tribe) governance institutions and practices are recognized and incorporated in the decentralization process. This observation has a transactions costs explanation, too: the costs (primarily in terms of time and effort) to basin stakeholders of relating on familiar organizational forms are expected to be smaller than the costs of relating to an additional set of organizational arrangements. In contrast, decentralization initiatives that feature central government construction of new sets of basin-level organizations that are largely separate from existing and traditional community governance institutions may face higher costs in achieving basin stakeholders' participation, resource commitments, and acceptance of decisions as legitimate. This does not mean that no new institutions will have to be created in order to achieve basin-scale management-in fact, new institutions will often be needed to promote communication and integrate decision making across communities within a river basin. Rather, all other things being equal, decentralization initiatives are more likely to succeed in gaining stakeholder acceptance if they are based upon, and constructed from, traditional community governance institutions and practices, i.e. take account of existing social capital.

\section{Characteristics of central government/ basin-level relationships and capacities}

Because successful decentralization requires complementary actions at the central government and local levels, other aspects of the central-local relationship can be expected to affect that success. Accordingly, our study includes a set of political and institutional variables having to do with the 
respective capacities of the central government and the basin-level stakeholders, and with the relationship between them, as can be seen below.

The extent of devolution of responsibilities and decision making. A decentralization policy initiative announced by a central government may be only symbolic, while the central government retains in practice control over all significant resource management decisions. Worse still, a decentralization policy can represent an abandonment of central government responsibility for resource management without a concomitant establishment of local level authority. In better situations, the central government transfers degrees of both authority and responsibility for resource management to the stakeholders.

These differences in the extent of actual devolution can be expected to affect the prospects for successful implementation of the decentralization policy. Symbolic or abandonment policies are at best unlikely to improve resource management, and at worst will undermine stakeholder willingness to commit to and sustain the extent of active involvement necessary for successful decentralization. All other things being equal, we would expect to see greater prospects for success increasing with level of devolution.

Financial autonomy and financial resources at the basin level reflect ability to implement decentralization. Decentralization of water resource management to the lowest appropriate level means at least some financial responsibilities are undertaken by basin-level organizations. If basinlevel stakeholders lack any autonomy to determine how funds shall be spent on resource management activities, the question is begged whether any meaningful decentralization has occurred. And certainly the "active involvement of stakeholders" implies to some degree that they commit some of their own financial resources to their resource management functions. On the other hand, decentralization does not have to mean that basin-level organizations and their members become solely responsible for all resource management funding. As already noted, one of the indicators of central government support for a decentralization policy can be the central government's willingness to provide financial assistance to basin-level organizations without maintaining intrusive control over basin-level decisions about the priorities on which those funds shall be spent.

Therefore, while logic and experience suggest that basin-level organizations must have some degree of financial autonomy and some extent of financial resources in order for decentralization initiatives to be implemented successfully, the impact may not be linear. Rather, all other things being 
equal, we would expect to see the prospects for a success bill shaped with complete central government funding and control at one pole and complete basin-level funding and control at the opposite pole.

Local autonomy in institutional reform is the extent to which local communities can design and implement their own institutional arrangements. It is a key element to the success of decentralization. Successful implementation of decentralization is likely to be a function of that local autonomy, because implementation costs are closely associated with information that is better obtained at local level, and also because stakeholder involvement is expected to be greater in crafting their own institutions. However, as stakeholders create more institutional arrangements (particularly organizations and agencies), they incur greater transaction costs of maintaining all of them and coordinating their activities.

Plainly, the effects of local autonomy are complex, but it is a critical institutional variable in relation to the prospects for successful implementation of water resource management decentralization. All other things being equal, we expect to find successful and sustainable implementation of decentralization initiatives more often in settings where local-level stakeholders are empowered to craft institutional arrangements for resource management at the basin and sub-basin levels (including cross-jurisdictional arrangements), and modify them as needed.

Local-level experience with self-governance and service provision. In any country, the decentralization of water resource management does not occur in a vacuum. The ability of central government officials to strike a balance between supportiveness and intrusiveness, and the capacity of basin-level stakeholders to organize and sustain institutional arrangements, will in part be a function of their experiences with respect to other public services or responsibilities. The ability of central and local participants to perform successfully will depend on the skills and experiences they have developed.

We would expect that water resource management decentralization initiatives are more likely to be implemented successfully in settings where local participants have experience in governing and managing other resources and/or public services—e.g., land uses, schooling, transportation, etc.

Economic, political and social differences among basin users. In many countries, the distribution of political influence will be a function of economic, religious, or other social and cultural distinctions. But even if it were not for the connection between these characteristics and political influence, the characteristics themselves can affect successful implementation of decentralization initiatives, 
through their independent effects on stakeholder communication, trust, and extent of experience in interdependent endeavors.

Economic, political, and social distinctions among basin-level stakeholders are likely to affect the implementation of decentralized resource management efforts. The greater and more contentious these distinctions, all other things being equal, the more difficult it will be to develop and sustain basin-scale institutional arrangements for governing and managing water resources.

It is important to add that these are empirical, not prescriptive, observations. Central government officials cannot make distinctions among basin-level stakeholders disappear. Nor should central government officials selectively apply decentralization policies only in relatively homogeneous settings.

Adequate time for implementation and adaptation. While it is obvious that longevity of water resource management arrangements may reflect their success, it may be less obvious that their success may depend on their longevity. Time is needed to develop basin-scale institutional arrangements, to experiment with alternatives and engage in some trial-and-error learning. Time is needed for trust building, so water users begin to accept new arrangements and gradually commit to sustaining them. Time is needed also to translate resource management plans into observable and sustained effects on resource conditions.

The relationship between time and success in water resource management is complicated. On the one hand, we have already said that adaptability is important—water users need to be able to modify institutional arrangements in response to changed conditions. On the other hand, patience is important, too-changing institutions quickly because a new approach has not succeeded can simply erode stakeholders' willingness to commit their time and effort to the next reform. We may observe a curvilinear relationship, in which successful implementation is less likely to be observed among decentralization initiatives that are very young, but is more likely at longer periods, but could taper off if central government and basin-level arrangements have proved insufficiently adaptable over long periods.

\section{The internal configuration of basin-level institutional arrangements}

Successful implementation of decentralized water resource management may also depend on features of the basin-level arrangements created by stakeholders and/or by the central government, as is captured by the variables below. 
Presence of basin-level governance institutions may be a prerequisite for successful water resource management. Sustained and effective participation of stakeholders presupposes the existence of arrangements by which stakeholders articulate their interests, share information, communicate and bargain, and take collective decisions. Basin-level governance is essential to the ability of water users to operate at multiple levels of action, which is a key to sustained successful resource preservation and efficient use (Ostrom, 1990).

Basin-level water resource management (in other words, a decentralized system) is neither achievable nor sustainable without the establishment and maintenance of basin-level governance arrangements. Because the existence of governance arrangements is a necessary, not sufficient, condition of successful resource management, we should not expect to find success everywhere we find basin-level governance institutions, but we should expect to find failure everywhere they are absent.

Recognition of sub-basin communities of interest. The water management issues in the basin are viewed differently by the stakeholders that share the resource in various parts of the basin, based mainly on the physical conditions and spatial situation of each group. For example, downstream users' perspectives on water quality differ from upstreamers. Users with access to groundwater have different views of drought exposure than surface water users. Municipal and industrial water users do not perceive the value of assured water supply reliability in the same fashion that agricultural water users do (Blomquist and Schlager, 1999). Thus, while basin-level governance and management arrangements are essential to decentralized water resource management, the ability of sub-basin stakeholders to address sub-basin issues may be as important.

Level of participation of various groups in basin-level decision making arrangements explains the direction and extent of the decentralization process. Of course, transaction costs of the decentralization process increase as such assurances are institutionalized, since a larger number of stakeholder organizations within the basin will bring greater coordination costs. All other things being equal, we would expect that successful implementation of basin decentralization has a positive relationship with level of participation of stakeholders in the process. However, with diverse and large number of stakeholders high transaction costs may become a constraint. Here too, then, a bill-shaped relation of this variable to successful decentralization may be expected, with the absence of sub-basin organizations and large numbers of sub-basin organizations negatively associated with lower success and greater prospects for success in between.

Information sharing and communication. The importance of information-more particularly, information symmetry - and opportunities for communication to the emergence and maintenance 
of cooperative decision making is relatively well understood. In water resource management especially, where there can be so many indicators of water resource conditions and the performance of management efforts, forums for information sharing are vital to reducing information asymmetries and promoting cooperation.

Since information will not automatically be perceived the same way by all stakeholders, and the implications of information about resource conditions will differ among these groups, it is arguably as important that there also be institutionalized or other regular forums in which basin stakeholders can communicate. All other things being equal, we expect to find successful decentralized water resource management more likely where information sharing and communication among stakeholders are more apparent.

Mechanisms for conflict resolution are needed to prevent disagreements from arising. Resource users can and will disagree about how well their interests are being represented and protected, about how well the resource management program is working and whether it is time for a change, about the distribution of benefits and costs, and manifold other issues.

The success and sustainability of decentralized resource management efforts therefore also depend on the presence of forums for addressing conflicts. All other things being equal, we would expect successful implementation of decentralized water resource management more likely in settings where forums for conflict resolution exist.

\section{The data collection and quality assurance process}

The above analytical framework was applied, using a comprehensive dataset of 83 river basin organizations. A survey instrument was developed and applied to river basins of the International Network of Basin Organizations (INBO) as well as to other river basin organizations that have been identified The instrument (Annex 4) provides the necessary data to be used in the empirical analysis.

\subsection{River basin organization data collection process}

The survey instrument was developed and was pre-tested on 25 RBOs prior to being modified and finalized. The survey questions correspond to the list of the variables that were presented in the Methodology section. The survey was administered by INBO (Annex 1), although several questionnaires were administered directly by the team data processors. Questionnaires in English, 
Spanish, French and Portuguese were sent to 197 RBOs around the world. In addition to hand mail and email, a website was created for the study, on which the survey was posted, ${ }^{4}$ with the capability of accommodating an online response. The data collection was completed after an iterative process of data acquisition and quality assurance reviews. The process involved the compilation of qualitative and quantitative data from a questionnaire, which INBO and data processors distributed.

Responses from 103 (52\% response rate) were obtained. After reviewing all responses for relevance (non transboundary rivers) ${ }^{5}$ and completeness and accuracy of data, 83 responses were included in the final dataset. To our knowledge this is the largest dataset of information about river basin organizations worldwide that is currently in existence. A tally of the survey responses is provided in Table 1.

Coordination between the data processors and INBO was very crucial for obtaining the final dataset (See Annex 1 for INBO's report). All responses were checked both by INBO and the data processors, for errors, which were critical to the study, such as missing answers to questions, which respondents for one reason or another did not or could not answer. In such cases, an attempt was made to identify parties who could respond comprehensively to the question(s). In addition to such a check, a further rudimentary statistical test was made on most variables, to identify outliers within the given responses. These were brought to the attention of the respondents and in the case of errors and/or mistakes efforts were made towards correction. Figure 1 is a flow chart summarizing the data collection and quality assurance processes.

\footnotetext{
${ }^{4}$ www.worldbank.org/riverbasinmanagement

${ }_{5}$ Transboundary riverbasin processes are significantly different from institutional processes in national basins. For this reason, the decision was taken to not include transboundary basins in the analysis. Three basins that could be considered transboundary were included, however, because they were either mostly contained in one country or featured a river basin organization that had been developed only in one country.
} 
Figure 1: Data Collection and Quality Assurance

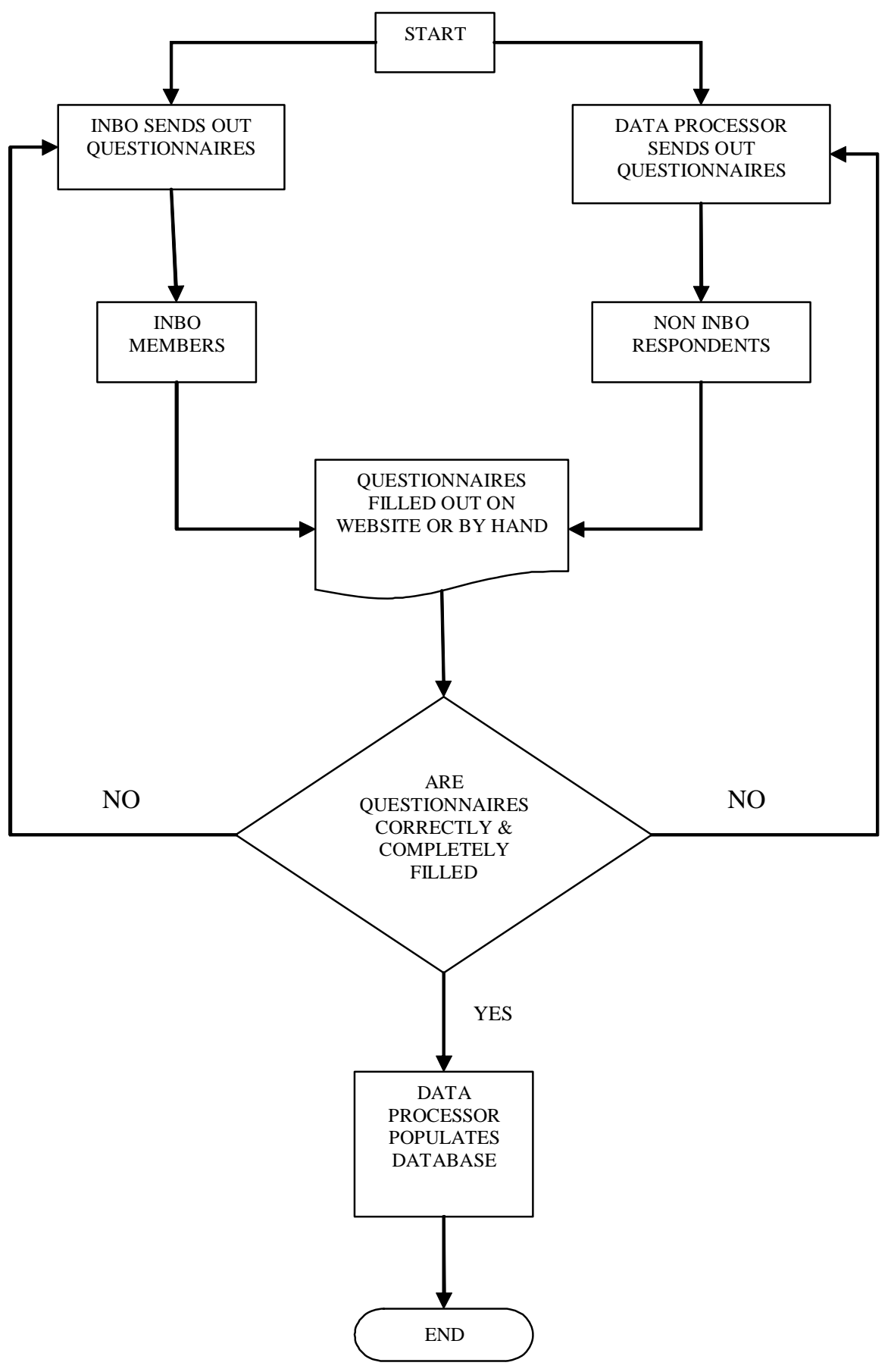


Table 1: The distribution of responses and data collection efforts by continents

\begin{tabular}{lrccc}
\hline Continent & $\begin{array}{c}\text { Questionnaires } \\
\text { sent }\end{array}$ & Responses & Eliminated & $\begin{array}{c}\text { Retained in the data } \\
\text { set }\end{array}$ \\
\hline Africa \& Middle East & 18 & 14 & 2 & $12(66)^{\text {a }}$ \\
\hline Latin America & 118 & 37 & 2 & $35(30)$ \\
\hline North America & 5 & 5 & 0 & $5(100)$ \\
\hline East Asia-Pacific & 7 & 7 & 3 & $4(57)$ \\
\hline Europe & 49 & 40 & 13 & $83(42)$ \\
\hline Total & 197 & 103 & 20 & \\
\hline
\end{tabular}

${ }^{a}$ In parentheses are percent of retained questionnaires from the number that were sent.

Distributional Facts of the Sample RBOs

The 83 retained questionnaires do reflect a representative distribution of river basin organizations (Table 2) both across continents and with regard to several basic characteristics. Latin America and Europe, which are the leading regions in reforms of river basin management, capture $75 \%$ of the sample RBOs. ${ }^{6}$

Table 2: Regional distribution of the sample RBOs

\begin{tabular}{lcccccc}
\hline Continent & $\begin{array}{c}\text { East Asia - } \\
\text { Pacific }\end{array}$ & $\begin{array}{c}\text { Africa and } \\
\text { Middle East }\end{array}$ & Europe & $\begin{array}{c}\text { Latin } \\
\text { America }\end{array}$ & $\begin{array}{c}\text { North } \\
\text { America }\end{array}$ & Total \\
\hline Number of Basins & 4 & 12 & 27 & 35 & 5 & 83 \\
\hline Share (rounded) & 4.8 & 14.5 & 32.5 & 42.2 & 6.0 & 100.0 \\
\hline
\end{tabular}

Looking at the year when sample RBOs were established suggests that 47 (57\%) of the sample RBOs were established in the last 15 years, ten of which (12\%) were established in the last 4 years. Table 3 provides the detailed distribution by decade.

Table 3: Distribution of RBOs by decade of their creation

\begin{tabular}{ccccccccccc}
\hline Y of creation & $1920-$ & $1931-$ & $1941-$ & $1951-$ & $1961-$ & $1971-$ & $1981-$ & $1991-$ & $>2001$ & Total \\
& 1930 & 1940 & 1950 & 1960 & 1970 & 1980 & 1990 & 2000 & & \\
\hline $\begin{array}{c}\text { Number of } \\
\text { RBOs }\end{array}$ & 2 & 1 & 0 & 1 & 17 & 2 & 7 & 37 & 10 & $77 \mathrm{a}$ \\
\hline$\%$ & 2.6 & 1.3 & 0.0 & 1.3 & 22.1 & 2.6 & 9.1 & 48.0 & 13.0 & 100.0 \\
\hline
\end{tabular}

${ }^{a}$ Several RBOs could not identify exactly the year of their creation.

${ }^{6}$ We are aware of the fact that our sample might be biased towards the 'French model' of basin management, as many of the basins that have been surveyed are basins that adopted the French system of river basin management. 
Of the 83 basins, 32 are located in developed countries and 51 are located in developing countries. These basins were within the borders of 27 countries. The basin area distribution indicates that $24(28.9 \%)$ basins comprise an area of less than 10,000 km², $56(67.5 \%)$ basins comprise an area of between 10,000-1,000,000 $\mathrm{km}^{2}$, and $3(3.6 \%)$ basins cover an area greater than 1 million $\mathrm{km}^{2}$. The population distribution indicates that more than $54(65.1 \%)$ of the river basins in the dataset have populations ranging from 1 to 10 million. About $10(12.0 \%)$ of the basins have populations of more than 10 million inhabitants, and 19 (22.9\%) having less than 1 million inhabitants.

Mean year of creation of basins in developed countries was 1979, with many basins created as early as 1961. Mean year of creation for basins in developing countries was ten years later, in 1989, with one basin created as early as 1927. It does not appear that the governing body of the river basin organization is related to whether the basin is in a developing or a developed country.

We conducted a preliminary analysis of basic correlations among key variables to find whether there are some a-priori relationships that we should pay attention to. For example, we were interested in seeing whether developing countries are different than developed ones. Do developing countries have longer processes of decentralization? Do they end up with a different governing body of the basin organization? Do they have inferior performance of the decentralization process compared to the developed countries? We could not find a significant difference between developed and developing countries with regard to these questions. We concluded, consistent with our analytical framework, that what actually affects the process and performances are the contextual and initial conditions on the one hand and the characteristics of central government/basin-level relationships and capacities on the other. Therefore, we did not include in our empirical analysis any dummy to distinguish between developed and developing countries.

\subsection{Data manipulation}

The questionnaire consists of 47 questions and the number of variables based on these questions is 226. They are divided into four groups, namely (a) general data variables that provide information on the RBO's contact information, (b) institutional setup variables that describe various aspects of the institutional arrangements in the basin before and after the decentralization process, (c) finance variables addressing aspects of the RBO's budget, and (d) performance indicators that measure various performances of the RBO. A detailed explanation and description of each variable is provided in Annex 2. 
As can be seen from the list of questions (Annex 4) and the list of variables that were extracted from the questionnaire (Annex 2), some of the questions provided a vector of variables that could be correlated as well as having a joint effect as explanatory variables in a regression equation. In such cases a Principal Component (PC) Analysis was performed and the set of variables in question were converted into one PC variable.

Another type of manipulation of the variables is the creation of indices to reflect values that are better expressed on a per unit basis rather than an absolute scale. It also should be mentioned that several questions were not answered by all RBOs and thus, several variables have a significant number of missing values and cannot be used. The original and newly created variables that were selected for inclusion in the analysis are presented in Annex 3, along with the hypotheses regarding their impact on the decentralization process.

In the next section we embark on the empirical analyses, which include several procedures and sets of equations to understand the process and the performance of decentralization and the interaction between them.

\section{Empirical Analysis}

This section provides the general framework for the econometric analysis of the data that was collected from river basins around the world. The framework is based on the theory and hypotheses described earlier, and on the hypotheses set, with empirical specifications adjusted to the variables that were prepared.

\subsection{The empirical models}

We are interested in two types of relationships. The first is a relationship that explains a certain phenomenon in the basin, such as specifics of the decentralization process, measured by the levels of $\underline{\boldsymbol{P}}$. The second is a relationship that explains level of success/progress of the decentralization process, measured by $S$.

The set of equations used in the estimation of the first relationship takes the following shape:

$[1] \underline{\boldsymbol{P}}=g(\underline{\boldsymbol{C}}, \underline{\boldsymbol{R}}, \underline{\boldsymbol{I}} \mid \underline{\boldsymbol{X}})$

where

$\underline{\boldsymbol{P}}$ is a vector of characteristics of the decentralization process; 
$\underline{\boldsymbol{C}}$ is a vector of contextual factors and initial conditions;

$\underline{\boldsymbol{R}}$ is a vector of characteristics of central government/basin-level relationships and capacities;

$\underline{I}$ is a vector of internal configuration of basin-level institutional arrangements;

$\underline{\boldsymbol{X}}$ is a vector of 'other' variables, identified as necessary,

A general relationship for decentralization success/progress, using the theory developed above is as follows:

[2] $S=f(\underline{\boldsymbol{C}}, \underline{\boldsymbol{P}}, \underline{\boldsymbol{R}}, \underline{\boldsymbol{I}} \mid \underline{\boldsymbol{X}})$, where

$S$ is a measure of success/progress of the performance of the decentralization of management in the river basin. We have several measures of success and several measures for levels of progress of the decentralization, as was discussed in detail in previous sections.

Note that equations [1] and [2] could be estimated as a system, relying on the fact that $\underline{\boldsymbol{P}}$, which is a dependent variable in [1], serves as an independent variable in [2], thus creating the necessary link between the equation that describes the nature of the decentralization process ([1]), and the equation that describes the performance of the decentralization reform ([2]). The equation system to be estimated consists of:

[3] $\left\{\begin{array}{l}\underline{\boldsymbol{P}}=e(\underline{\boldsymbol{C}}, \underline{\boldsymbol{R}}, \underline{\boldsymbol{I}} \mid \underline{\boldsymbol{X}}) \\ \underline{\boldsymbol{S}}=h(\underline{\boldsymbol{C}}, \underline{\boldsymbol{P}}, \underline{\boldsymbol{R}}, \underline{\boldsymbol{I}} \mid \underline{\boldsymbol{X}})\end{array}\right.$,

with all parameters having the same meaning as in equations [1] and [2].

We propose several types of specification of the functional form depending on the nature of the variable $S$. Based on our discussion in previous sections, one possible way to measure success is by using a dichotomous variable that takes the value 1 when decentralization was initiated and 0 when no decentralization took place in spite of government intent.

A second way of describing success is to measure normatively the extent of achieving several important original goals of the decentralization process. In this case the various RBOs have been ranked on a scale ranging from $\underline{s}$ to $\bar{s}$ in terms of the decentralization success, which allows $S$ to get more than 2 values.

A third way of measuring progress of decentralization is by comparing performance between present and the pre-decentralization period. Performance variables may include: level of 
participation, local responsibility, financial performance, economic activity etc. Using this definition, $S$ becomes a continuous variable.

\subsection{Empirical specifications of the decentralization process and its performance}

We start our investigation with specification of relationships explaining the characteristics of the decentralization process (equation [1]). Several variables could help shed light on the decentralization process. Few are probably of special interest as they contrast observations across river basin decentralization processes under a variety of situations. The length of the decentralization process, YrsDecentralization, the transaction costs of the process, measured by several variables such as InstDismntld, InstCreatn, PltclCost, and the level of involvement of the stakeholders,

WuasInvlv, are a few that caught our attention. Estimation procedure explaining YrsDecentralization uses a TOBIT procedure as values are continuous between 0-100. Estimation procedures explaining InstDismntld, InstCreatn, and PltclCost use a GLM procedure as these are string variables. And estimation procedures explaining YrsDecentralization use an OLS procedure as values of that variable are continuous (excluding zeroes). Table 4 summarizes the functional forms of the various equations we specified for estimating relationship [1] and the expected impact on the dependent variable.

We identified several variables that serve to measure decentralization success or progress. The estimates of relationships using the first two approaches (that have been mentioned earlier) to measuring success/progress imply having possibly zeros in the dependent variable and thus, a Logit, Tobit and GLM estimation procedures are necessary (Madalla, 1989). To be more specific, we use the dichotomous variable InstCng to measure whether or not an institutional change has occurred, and applied a Logit procedure to estimate that relationship. We use the two variables SuccObj1 and SuccObj2 to reflect achievement of various goals the decentralization process was aimed to achieve. We applied both a TOBIT and GLM procedures to estimate these relationships. Both these procedures are applied when a dependent variable is truncated varying between 0 and an upper value. However, because we are not sure that these values are distributed normally, we cannot use GLM as it may provide a biased estimate. Thus we also use the TOBIT procedure that assumes a Poisson distribution. Finally, we constructed several additional variables, Prblms Aftr, IncrmntTasks, IncrmntImprv, and ImprvRespons that are not truncated and thus an OLS estimation procedure is used for the estimations of their relationship. Table 5 summarizes the estimation procedures of the 
various equations we specified for estimating relationship [2], and the hypothesized directions of impact, based on the theory developed earlier.

Table 4: The estimated equations of the decentralization process ${ }^{7}$

\begin{tabular}{|l|c|c|c|c|c|}
\hline & InstCreatd & WuasInvlv & PltclCost & YrsDecent & InstDismntld \\
\hline$\%$ BgtBsn & NI & NI & NI & NI & + \\
\hline$\%$ BgtExtr & - & NI & NI & NI & NI \\
\hline$\%$ BgtSpnt & NI & - & NI & NI & - \\
\hline$\%$ BgtSrcs & NI & - & NI & NI & NI \\
\hline$\%$ UrPay & NI & NI & - & - & - \\
\hline Facilities & NI & NI & + & NI & NI \\
\hline FormsDisput & NI & + & NI & NI & NI \\
\hline FormsDisput 2 & + & NI & NI & NI & NI \\
\hline GovrBdy & - & - & NI & - & NI \\
\hline MainObj & NI & NI & NI & + & NI \\
\hline MinrObj & + & NI & - & NI & NI \\
\hline PrblmsBfr & - & NI & - & NI & NI \\
\hline Scarcity1 & NI & NI & NI & - & NI \\
\hline SectrComposit & + & + & NI & NI & + \\
\hline ShareSw & + & + & + & NI & NI \\
\hline TypesDisput & NI & NI & NI & NI & - \\
\hline WuasInvlv & + & & + & & POISSON \\
\hline Functional form & GLM & OLS & GLM & GLM \\
\hline
\end{tabular}

Note: NI=Not Included

\section{Results}

Due to the large number of variables in the dataset, and the high level of association among many of them (leading to high auto-correlation), we administered principal component (PC) analyses that helped us group these correlated variables and reduce the number of variables with inter-correlation on the right hand side of the estimated equation. We constructed a working dataset that includes the PC variables and some other variables that were incorporated in our regression analyses. The PC variables are described in Annex 3, but the results of the PC analysis are presented below. Following the PC results, we present the descriptive statistics of the variables in the working dataset. Finally, the Results section is concluded with the various regression outcomes and their interpretation.

${ }^{7}$ Some of the variables presented here are explained in the section "Principal Component Results". 


\subsection{Principal Component results}

We constructed a total of $15 \mathrm{PC}$ variables that were described in the data manipulation section. For each PC analysis we obtained the following procedure: Let $\varepsilon_{i, k}^{j}$ be the value of estimated $i$-th component of the $j$-th eigenvector of PC variable $k$. We then calculate the value of variable $k$ as

$P C_{k}^{j}=\sum_{i=1}^{I_{k}} V_{i} \cdot \varepsilon_{i, k}^{j} \quad j=1, \ldots, \quad I ; \quad \forall k$

Table 6 below presents the estimated PC coefficients that were used to create the PC variables, using the first eigenvector from the PC analysis. The eigenvectors of the first principal components, which were used in the creation of the principal component variables, are presented in the table. These eigenvectors explain between 25 and 99 percent of the standardized variance among the variables.

\subsection{Descriptive statistics}

The descriptive statistics presented in Table 7 refers to the variables in the working dataset.

\section{Econometric findings}

The presentation of the econometric results will be split into three sub-sections: the equations describing the decentralization process, the equations describing the decentralization performance, and the equation systems describing the interaction between the decentralization process and the level of performance.

\section{The decentralization process}

We identified several relationships that could shed light on the characteristics of the decentralization process in terms of its length, complexity and participation of stakeholders. The hypothesized relationships between the variables in the empirical analysis are presented in Table 4. We were able to estimate five equations representing various aspects of the decentralization process. We explained institutions that were created, the institutions that were dismantled, the involvement of water user groups, the political cost of the decentralization process and the length of the decentralization process. The explanatory variables used in the analysis are generally in line with the hypothesized signs. Certain variables, such as \%UsrPay, ShareSW and GovrBdy that were included in 
more than two equations are significant and their signs are as expected. ${ }^{8}$ We also will mention results pertaining to variables that were included in one equation only. Scarcity 1 has a significant negative impact on the length of the decentralization process with basins facing higher scarcity ${ }^{9}$ perform the decentralization faster than basins with more abundant water. FormDisput1 stimulates involvement of user groups in the process, and existence of Facilities creates higher political cost to the decentralization process.

\section{The decentralization performance}

We present the estimated decentralization performance equations in three tables, using different estimation procedures and explanatory and dependent variables (Tabes 9, 10, 11). Generally speaking, the various estimated model equations display a robust set of results that support the hypotheses. All estimated coefficients are significant at the 10 percent and better. Most variables are significant at the 1 percent and better. Only one coefficient $(\% B g t B s n)$ in one equation displays the opposite sign to what has been expected. Fit and significant tests of the models suggest that all are significant at 5 percent and less and all except one are significant at 1 percent and less in explaining the variation in the level of performance of the decentralization.

The main results in Table 9 suggest that the higher the share of the budget that is spent in the basin, and the higher the share of the budget that is provided from sources external to the basin the higher is the level of the decentralization success; also, the higher the share of users that pay their tariffs the higher is the level of the decentralization success. Two decentralization objectives variables also suggest that the more comprehensive the set of objectives that decentralization reforms were supposed to address, the higher the success. In addition, top-down initiation of decentralization reform was found to be detrimental for success of the decentralization process. Finally, water scarcity level in the basin positively ${ }^{10}$ affected the measured success of the decentralization.

\footnotetext{
${ }^{8}$ Given the nature of the 5 dependent variables we expect to have different signs of the same explanatory variable, depending on the equation.

${ }_{9}$ Notice that the lower the ratio of rainfall to evaporation, the higher the scarcity, so a negative sign of the scarcity coefficient in the equation reads as a higher level of scarcity.

${ }^{10}$ Notice that the lower the ratio of rainfall to evaporation, the higher the scarcity, so a negative sign of the scarcity coefficient in the equation reads as a higher level of scarcity.
} 
Table 5: The estimated equations of the decentralization performance

\begin{tabular}{|c|c|c|c|c|c|c|c|}
\hline $\begin{array}{l}\text { Estimation } \\
\text { procedure }\end{array}$ & $\begin{array}{c}\text { TOBIT or } \\
\text { GLM }\end{array}$ & $\begin{array}{c}\text { TOBIT or } \\
\text { GLM }\end{array}$ & OLS & OLS & OLS & OLS & LOGIT \\
\hline Independent Var. & $\begin{array}{l}\overrightarrow{\bar{a}} \\
\overline{0} \\
\stackrel{u}{0} \\
\vec{n}\end{array}$ & 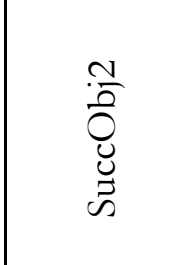 & 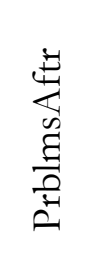 & 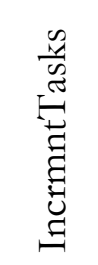 & 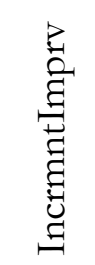 & 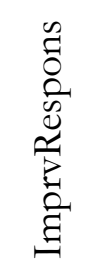 & 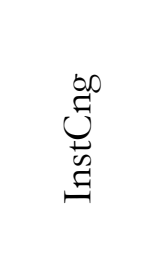 \\
\hline$\%$ BgtBsn & \multicolumn{2}{|r|}{+} & \multicolumn{4}{|c|}{$\mathrm{NI}$} & $\mathrm{NI}$ \\
\hline$\%$ BgtExtr & \multicolumn{2}{|r|}{+} & \multicolumn{4}{|c|}{+} & $\mathrm{NI}$ \\
\hline$\%$ BgtSpnt & \multicolumn{2}{|c|}{+} & \multicolumn{4}{|c|}{+} & + \\
\hline$\%$ BgtSrcs & \multicolumn{2}{|r|}{-} & \multicolumn{4}{|c|}{-} & $\mathrm{NI}$ \\
\hline$\%$ UsrPay & \multicolumn{2}{|r|}{+} & \multicolumn{4}{|c|}{$\mathrm{NI}$} & $\mathrm{NI}$ \\
\hline BgtPrCpta & \multicolumn{2}{|c|}{+} & \multicolumn{4}{|c|}{$\mathrm{NI}$} & $\mathrm{NI}$ \\
\hline ExistUsrGrp & & + & \multicolumn{4}{|c|}{+} & $\mathrm{NI}$ \\
\hline Facilities & \multicolumn{2}{|r|}{+} & \multicolumn{4}{|c|}{$\mathrm{NI}$} & $\mathrm{NI}$ \\
\hline FormsDisput1 & \multicolumn{2}{|c|}{+} & \multicolumn{4}{|c|}{$\mathrm{NI}$} & $\mathrm{NI}$ \\
\hline FormsDisput2 & \multicolumn{2}{|c|}{ Undecided } & \multicolumn{4}{|c|}{$\mathrm{NI}$} & $\mathrm{NI}$ \\
\hline GovrBdy & \multicolumn{2}{|c|}{$\mathrm{NI}$} & \multicolumn{4}{|c|}{-} & $\mathrm{NI}$ \\
\hline InstDismntld & \multicolumn{2}{|c|}{-} & \multicolumn{4}{|c|}{+} & + \\
\hline MainObj & \multicolumn{2}{|r|}{+} & \multicolumn{4}{|c|}{+} & $\mathrm{NI}$ \\
\hline MinrObj & \multicolumn{2}{|c|}{+} & \multicolumn{4}{|c|}{ NI } & $\mathrm{NI}$ \\
\hline MtdCreatn & \multicolumn{2}{|c|}{-} & \multicolumn{4}{|c|}{$\mathrm{NI}$} & $\mathrm{NI}$ \\
\hline PltclCost & \multicolumn{2}{|c|}{-} & \multicolumn{4}{|c|}{-} & - \\
\hline PrblmsBfr & \multicolumn{2}{|c|}{$\mathrm{NI}$} & & & & & + \\
\hline Scarcity1 & & - & & & & & - \\
\hline SectrComposit & & $\mathrm{NI}$ & & & & & $\mathrm{NI}$ \\
\hline SectrUseShars & & - & & & & & $\mathrm{NI}$ \\
\hline ShareSW & Unde & ecided & & & ded & & $\mathrm{NI}$ \\
\hline TypesDisput & & - & & & & & $\mathrm{NI}$ \\
\hline YrCreation & & - & & & & & $\mathrm{NI}$ \\
\hline YrsDecentralization & & - & & & & & $\mathrm{NI}$ \\
\hline
\end{tabular}

Note: NI=Not Included 
Table 6: Principal Component Analyses Results

\begin{tabular}{|c|c|c|c|c|c|c|c|c|c|c|c|c|c|c|c|}
\hline EC Variables & 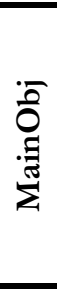 & 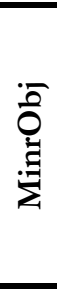 & 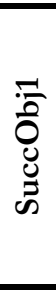 & 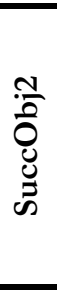 & : & 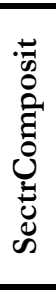 & 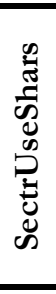 & 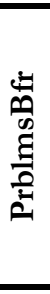 & 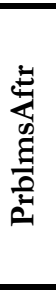 & 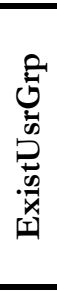 & 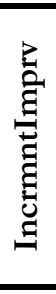 & 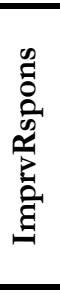 & 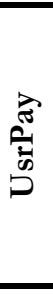 & 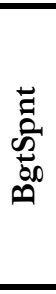 & 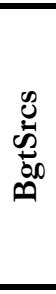 \\
\hline $\operatorname{Var} 1^{\mathrm{a}}$ & 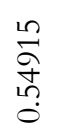 & 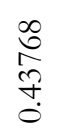 & 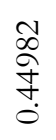 & 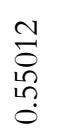 & $\begin{array}{l}\hat{\imath} \\
\stackrel{n}{n} \\
\\
0\end{array}$ & $\begin{array}{l}\stackrel{+}{\Omega} \\
\text { aे } \\
\sigma\end{array}$ & 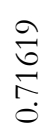 & 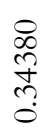 & 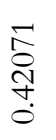 & $\begin{array}{l}\text { గ్ర } \\
\text { in } \\
\text { In }\end{array}$ & 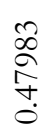 & $\begin{array}{c}\text { ले } \\
\stackrel{+}{0}\end{array}$ & 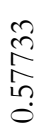 & 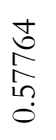 & $\begin{array}{l}n \\
\stackrel{0}{0} \\
\hat{0}\end{array}$ \\
\hline Var 2 & $\begin{array}{l}\hat{0} \\
\infty \\
\infty \\
0 \\
0\end{array}$ & $\begin{array}{l}\text { Ln } \\
\text { त̂̀ } \\
\text { ర్ } \\
0\end{array}$ & 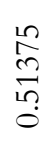 & \begin{tabular}{l} 
P \\
\multirow{2}{0}{} \\
$\stackrel{0}{10}$ \\
0
\end{tabular} & $\begin{array}{l}\text { Jे } \\
\text { స̦ } \\
\text { ô }\end{array}$ & $\begin{array}{l}\infty \\
\stackrel{\infty}{N} \\
\\
\stackrel{0}{0}\end{array}$ & 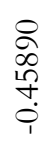 & 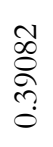 & 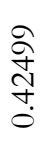 & $\begin{array}{l}\stackrel{0}{\circ} \\
\stackrel{0}{0} \\
0\end{array}$ & $\begin{array}{l}\stackrel{2}{3} \\
\stackrel{\tilde{\Omega}}{0} \\
\stackrel{0}{0}\end{array}$ & $\begin{array}{c}\text { + } \\
\substack{\infty \\
+\infty \\
+\infty}\end{array}$ & 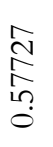 & $\begin{array}{l}\infty \\
\infty \\
0 \\
0 \\
10 \\
0\end{array}$ & $\begin{array}{l}\infty \\
\stackrel{0}{0} \\
\stackrel{1}{0} \\
\dot{1}\end{array}$ \\
\hline $\operatorname{Var} 3$ & $\begin{array}{l}\hat{0} \\
8 \\
0 \\
0 \\
0\end{array}$ & \begin{tabular}{l}
$\stackrel{\infty}{N}$ \\
\multirow{f}{f}{} \\
0 \\
0
\end{tabular} & 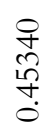 & $\begin{array}{l}\text { fo } \\
\text { o } \\
0 \\
0\end{array}$ & 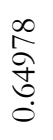 & $\begin{array}{l}+ \\
\infty \\
0 \\
0 \\
0 \\
0\end{array}$ & 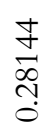 & 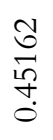 & \begin{tabular}{l}
$\vec{\sigma}$ \\
ळे \\
\multirow{0}{*}{}
\end{tabular} & $\begin{array}{l}\stackrel{+}{N} \\
\text { Nn } \\
\\
0\end{array}$ & 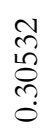 & $\begin{array}{l}\stackrel{q}{\sigma} \\
\text { qे. } \\
\text { o. }\end{array}$ & $\begin{array}{l}\underset{f}{\stackrel{2}{f}} \\
\text { in } \\
0\end{array}$ & 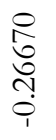 & 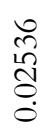 \\
\hline $\operatorname{Var} 4$ & & & 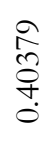 & & $\begin{array}{l}\frac{\hat{n}}{f} \\
\stackrel{f}{f} \\
\stackrel{0}{0}\end{array}$ & 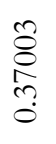 & \begin{tabular}{l}
\multirow{J}{0}{} \\
\multirow{J}{*}{} \\
$\stackrel{0}{0}$
\end{tabular} & 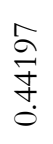 & 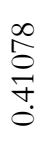 & & $\begin{array}{l}\stackrel{N}{\hat{N}} \\
\stackrel{0}{0} \\
\stackrel{0}{0}\end{array}$ & 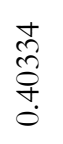 & & $\begin{array}{l}\text { in } \\
\infty \\
o n \\
\\
0\end{array}$ & \\
\hline $\operatorname{Var} 5$ & & & 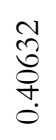 & & & 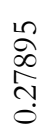 & 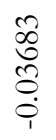 & $\begin{array}{l}\infty \\
\infty \\
\infty \\
\stackrel{\sim}{0} \\
\stackrel{0}{0}\end{array}$ & 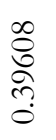 & & $\begin{array}{l}\stackrel{R}{f} \\
\stackrel{5}{ \pm} \\
\stackrel{0}{0}\end{array}$ & 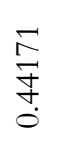 & & & \\
\hline $\operatorname{Var} 6$ & & & & & & & & 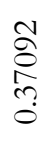 & \begin{tabular}{l}
$\hat{\sigma}$ \\
ֶ̊ \\
\multirow{+}{0}{} \\
0
\end{tabular} & & 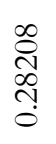 & & & & \\
\hline $\operatorname{Var} 7$ & & & & & & & & & & & 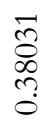 & & & & \\
\hline $\operatorname{Var} 8$ & & & & & & & & & & & $\frac{\infty}{\stackrel{\infty}{\Xi}}$ & & & & \\
\hline $\begin{array}{l}\text { \% of } \\
\text { Explained } \\
\text { standardized } \\
\text { variance by } \\
\text { the first eigen } \\
\text { vector } \\
\end{array}$ & 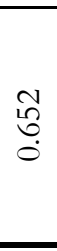 & $\begin{array}{l}\stackrel{0}{\sigma} \\
\stackrel{0}{0}\end{array}$ & 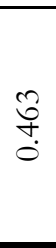 & 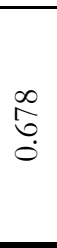 & 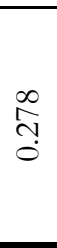 & $\begin{array}{l}\text { तु } \\
\stackrel{0}{0}\end{array}$ & 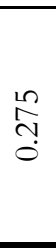 & กิ? & $\begin{array}{l}\tilde{\delta} \\
\stackrel{0}{0} \\
0\end{array}$ & $\begin{array}{l}m \\
\stackrel{\infty}{\infty} \\
0 \\
0\end{array}$ & 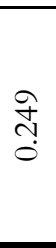 & $\stackrel{f}{f}$ & & $\begin{array}{l}\vec{n} \\
\stackrel{n}{0} \\
0\end{array}$ & 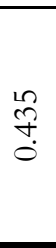 \\
\hline
\end{tabular}

${ }^{a}$ Note: Var 1-8 constitute different variables, depending on each Principal Component Analysis. For the specific variables in each analysis see Annex 3. 
Table 7: Descriptive statistics of the variables included in the working dataset

\begin{tabular}{|c|c|c|c|c|}
\hline Variable & Mean & Standard Deviation & Minimum $^{\mathrm{a}}$ & Maximum \\
\hline Scarcity1 & 5.056 & 27.965 & 0.000 & 246.679 \\
\hline Scarcity2 & 177.383 & 1142.484 & 0.000 & 10438.417 \\
\hline YrsDecentralization & 2.711 & 7.547 & 0.000 & 36.000 \\
\hline YrCreation & 1985.229 & 18.486 & 1926.000 & 2002.000 \\
\hline MainObj & 1.008 & 0.692 & 0.000 & 1.731 \\
\hline MinrObj & 6.208 & 8.791 & 0.000 & 33.972 \\
\hline SuccObj1 & 3.540 & 7.814 & 0.000 & 63.510 \\
\hline SuccObj2 & 2.907 & 2.551 & 0.000 & 7.555 \\
\hline GovrBdy & 3.566 & 1.768 & 0.000 & 5.000 \\
\hline MtdCreatn & 1.193 & 0.903 & 0.000 & 2.000 \\
\hline InstDismntld & 0.627 & 0.837 & 0.000 & 3.000 \\
\hline InstCreatd & 1.542 & 1.262 & 0.000 & 3.000 \\
\hline PltclCost & 0.494 & 0.942 & 0.000 & 5.000 \\
\hline FormsDisput1 & 2.241 & 1.265 & 0.000 & 4.000 \\
\hline FormsDisput2 & 0.940 & 0.502 & 0.000 & 2.000 \\
\hline TypesDisput & 4.207 & 2.934 & 0.000 & 9.000 \\
\hline Facilities & 21.762 & 263.256 & -1410.219 & 1348.949 \\
\hline SectrComposit & 1.257 & 0.793 & 0.000 & 2.183 \\
\hline SectrUseShars & 0.299 & 0.768 & -0.425 & 6.609 \\
\hline ShareSW & 0.434 & 0.381 & 0.000 & 1.000 \\
\hline PrblmsBfr & 6.871 & 1.823 & 0.000 & 9.750 \\
\hline PrblmsAftr & 5.837 & 1.524 & 2.334 & 8.967 \\
\hline IncrmntTasks & 0.128 & 0.371 & -2.671 & 0.762 \\
\hline IncrmntImprv & 0.104 & 0.518 & -4.162 & 0.728 \\
\hline ImprvRespons & 1.466 & 3.639 & -8.294 & 9.217 \\
\hline ExistUsrGrp & 0.871 & 0.783 & 0.000 & 1.731 \\
\hline$\%$ UsrPay & 2.084 & 13.990 & 0.000 & 127.886 \\
\hline BgtPrCpta & 0.292 & 2.658 & 0.000 & 24.213 \\
\hline$\%$ BgtExtr & 0.190 & 0.328 & 0.000 & 1.000 \\
\hline$\%$ BgtBsn & 0.356 & 0.391 & 0.000 & 1.000 \\
\hline$\%$ BgtSrcs & -0.115 & 0.413 & -0.713 & 0.710 \\
\hline$\%$ Bgtspnt & 0.287 & 0.474 & -0.267 & 1.370 \\
\hline InstCng & 0.627 & 0.487 & 0.000 & 1.000 \\
\hline
\end{tabular}

${ }^{a}$ PC variables may have negative minimum values due to the process of their estimation. 
Table 8: The equations describing some features of the decentralization process

\begin{tabular}{|c|c|c|c|c|c|}
\hline Estimation Procedure & GLM & OLS & GLM & POISSON & GLM \\
\hline $\begin{array}{l}\text { Dependent Var. } \\
\text { Independent } \\
\text { Var. }\end{array}$ & InstCreatd & WuasInvlv & PltclCost & YrsDecent & InstDismntld \\
\hline Intercept & $\begin{array}{l}0.461 \\
(0.76)\end{array}$ & $\begin{array}{l}0.045 \\
(0.41)\end{array}$ & $\begin{array}{c}1.183^{* *} \\
(1.97)\end{array}$ & $\begin{array}{c}1.745^{* *} \\
(1.96)\end{array}$ & $\begin{array}{c}0.321^{* *} \\
(1.99)\end{array}$ \\
\hline$\%$ BgtBsn & & & & & $\begin{array}{c}1.456^{* * * *} \\
(7.08) \\
\end{array}$ \\
\hline$\%$ BgtExtr & $\begin{array}{c}-1.001 * * * \\
(-3.45)\end{array}$ & & & & \\
\hline$\%$ BgtSpnt & & $\begin{array}{l}-0.093 \\
(-1.31)\end{array}$ & & & $\begin{array}{c}-0.497 * * * \\
(4.45)\end{array}$ \\
\hline$\%$ BgtSrcs & & $\begin{array}{c}-0.212 * * * \\
(-2.66) \\
\end{array}$ & & & \\
\hline$\%$ UsrPay & & & $\begin{array}{c}.007 * * * \\
(-3.35) \\
\end{array}$ & $\begin{array}{c}0.017^{* * *} \\
(4.58)\end{array}$ & $\begin{array}{c}-0.012 * * * \\
(-8.91) \\
\end{array}$ \\
\hline Facilities & & & $\begin{array}{c}0.001 * * * \\
(2.57)\end{array}$ & & \\
\hline FormsDisput1 & & $\begin{array}{c}0.068^{* * *} \\
(2.53)\end{array}$ & & & \\
\hline FormsDisput2 & $\begin{array}{l}0.319^{*} \\
(1.53)\end{array}$ & & & & \\
\hline GovrBdy & $\begin{array}{l}-0.052 \\
(-0.81) \\
\end{array}$ & $\begin{array}{c}-0.028^{* *} \\
(-1.62) \\
\end{array}$ & & $\begin{array}{c}-0.498^{* * *} \\
(-3.48) \\
\end{array}$ & \\
\hline MainObj & & & & $\begin{array}{l}0.510 \\
(1.05) \\
\end{array}$ & \\
\hline MinrObj & $\begin{array}{l}0.016 \\
(1.44)\end{array}$ & & $\begin{array}{l}-0.011 \\
(1.31)\end{array}$ & & \\
\hline PrblmsBfr & $\begin{array}{l}-0.056 \\
(-0.79) \\
\end{array}$ & & $\begin{array}{l}-0.131^{*} \\
(-1.63)\end{array}$ & & \\
\hline Scarcity1 & & & & $\begin{array}{c}-0.009 * * * \\
(-3.79) \\
\end{array}$ & \\
\hline SectrComposit & $\begin{array}{c}0.519^{* * *} \\
(3.66)\end{array}$ & $\begin{array}{l}-0.006 \\
(-0.16)\end{array}$ & & & $\begin{array}{c}0.179 * * * \\
(2.04) \\
\end{array}$ \\
\hline ShareSw & $\begin{array}{c}1.864 * * * \\
(6.41) \\
\end{array}$ & $\begin{array}{c}0.395^{* * * *} \\
(4.61) \\
\end{array}$ & $\begin{array}{c}0.482^{* *} \\
(1.88) \\
\end{array}$ & & \\
\hline TypesDisput & & & & & $\begin{array}{c}-0.063^{* * *} \\
(-2.76) \\
\end{array}$ \\
\hline WuasInvlv & $\begin{array}{l}-0.126 \\
(-0.36) \\
\end{array}$ & & $\begin{array}{l}0.259 \\
(0.80)\end{array}$ & & \\
\hline Log Pseudolikelihood & -115.59 & & -105.84 & -354.38 & -73.37 \\
\hline F-test & & $11.01 * * *$ & & & \\
\hline Adjusted-R ${ }^{2}$ & & 0.423 & & & \\
\hline Wald Chi-square & & & & $28.42 * * *$ & \\
\hline Pseudo-R $^{2}$ & & & & 0.241 & \\
\hline
\end{tabular}

Note: ${ }^{* * *} \mathrm{p}<0.01 ;{ }^{* *} \mathrm{p}<0.05 ;{ }^{*} \mathrm{p}<0.10$. 
Table 9: The GLM and TOBIT equations of the Decentralization Performance

\begin{tabular}{|c|c|c|c|c|}
\hline $\begin{array}{l}\text { Estimation } \\
\text { procedure }\end{array}$ & GLM & TOBIT & GLM & TOBIT \\
\hline $\begin{array}{l}\text { Dependent Var. } \\
\text { Independent } \\
\text { Var. }\end{array}$ & SuccObj1 & SuccObj1 & SuccObj2 & SuccObj2 \\
\hline Intercept & $\begin{array}{l}-0.305 \\
(-0.12)\end{array}$ & $\begin{array}{c}13.183^{*} \\
(1.52)\end{array}$ & $\begin{array}{c}-0.802^{* *} \\
(-2.00)\end{array}$ & $\begin{array}{c}-0.900 * * * \\
(-3.34)\end{array}$ \\
\hline$\%$ BgtBsn & & $\begin{array}{c}-13.335^{* *} \\
(-1.96)\end{array}$ & $\begin{array}{c}1.077^{* * *} \\
(2.46) \\
\end{array}$ & $\begin{array}{c}0.398^{* *} \\
(2.21) \\
\end{array}$ \\
\hline$\%$ BgtExtr & $\begin{array}{c}8.744 * * * \\
(3.50)\end{array}$ & $\begin{array}{c}15.063^{* * *} \\
(2.28)\end{array}$ & $\begin{array}{l}0.726^{*} \\
(1.35)\end{array}$ & \\
\hline$\%$ BgtSrcs & & $\begin{array}{c}-19.373^{* *} \\
(-2.04) \\
\end{array}$ & & \\
\hline$\%$ UsrPay & & & $\begin{array}{c}0.019 * * \\
(1.67)\end{array}$ & $\begin{array}{c}0.015^{* * *} \\
(2.84)\end{array}$ \\
\hline BgtPrCpta & & & $\begin{array}{c}-0.155^{* * *} \\
(-2.56)\end{array}$ & \\
\hline Facilities & & $\begin{array}{c}0.0004 \\
(1.35)\end{array}$ & & \\
\hline FormsDisput1 & $\begin{array}{c}1.446^{* *} \\
(2.10)\end{array}$ & $\begin{array}{c}0.272^{* * *} \\
(4.24)\end{array}$ & & \\
\hline FormsDisput2 & & $\begin{array}{c}0.323^{* *} \\
(2.24)\end{array}$ & & \\
\hline InstDismntld & & $\begin{array}{c}-0.460 * * * \\
(-3.87)\end{array}$ & & \\
\hline MainObj & $\begin{array}{c}2.809 * * * \\
(2.28)\end{array}$ & $\begin{array}{c}1.099 * * * \\
(6.67)\end{array}$ & $\begin{array}{c}3.085^{* * *} \\
(12.55)\end{array}$ & $\begin{array}{c}1.451 * * * \\
(9.36)\end{array}$ \\
\hline MinrObj & $\begin{array}{c}0.147^{* *} \\
(1.59)\end{array}$ & $\begin{array}{c}0.042^{* * *} \\
(6.08)\end{array}$ & $\begin{array}{c}0.027^{*} \\
(1.51)\end{array}$ & $\begin{array}{c}0.015^{* *} \\
(2.12)\end{array}$ \\
\hline MtdCreatn & & $\begin{array}{c}-0.335^{* * *} \\
(-3.54)\end{array}$ & & $\begin{array}{c}-0.189 * * * \\
(-2.36)\end{array}$ \\
\hline PltclCost & & & & $\begin{array}{c}0.116^{*} \\
(1.50) \\
\end{array}$ \\
\hline Scarcity1 & $\begin{array}{c}-0.019^{* *} \\
(-1.80)\end{array}$ & $\begin{array}{c}-0.009^{*} \\
(-1.46)\end{array}$ & $\begin{array}{c}-0.020 * * * \\
(-3.63)\end{array}$ & $\begin{array}{c}-0.014^{* *} \\
(-1.72)\end{array}$ \\
\hline SectrComposit & $\begin{array}{c}-2.426^{* * *} \\
(-2.34)\end{array}$ & $\begin{array}{c}-0.297 * * * \\
(-3.22)\end{array}$ & & \\
\hline SectrUseShars & & $\begin{array}{c}0.199^{* *} \\
(2.15)\end{array}$ & & \\
\hline ShareSW & $\begin{array}{c}-4.055^{* *} \\
(-1.82)\end{array}$ & $\begin{array}{c}-0.424 * * * \\
(-2.35)\end{array}$ & & \\
\hline TypesDisput & & $\begin{array}{c}-0.129 * * * \\
(-4.43)\end{array}$ & & \\
\hline YrCreation & & $\begin{array}{c}-0.006^{*} \\
(-1.55)\end{array}$ & & \\
\hline YrsDecentralization & & $\begin{array}{c}-0.022^{* *} \\
(-2.12)\end{array}$ & & \\
\hline LR Chi-square & & $392.76^{* * *}$ & & $159.47 * * *$ \\
\hline $\mathrm{R}^{2}$ or pseudo $\mathrm{R}^{2}$ & & 0.593 & & 0.385 \\
\hline Log Likelihood & -271.69 & -167.95 & -139.70 & -127.27 \\
\hline
\end{tabular}

Note: ${ }^{* * *} \mathrm{p}<0.01 ; * * \mathrm{p}<0.05 ;{ }^{*} \mathrm{p}<0.10$. 
Table 10: The OLS equations of the Decentralization Performance

\begin{tabular}{|c|c|c|c|c|c|c|c|c|}
\hline Estimation & \multicolumn{8}{|c|}{ OLS } \\
\hline Independent Var & 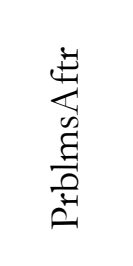 & 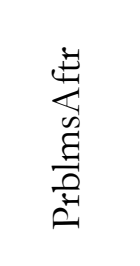 & 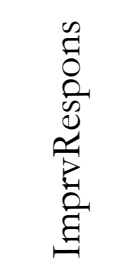 & 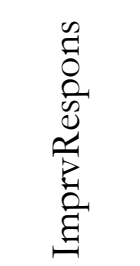 & 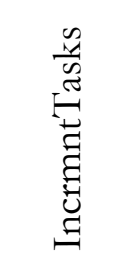 & 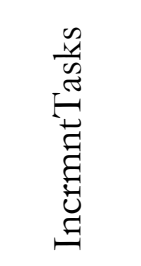 & 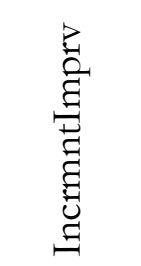 & 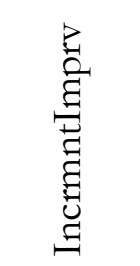 \\
\hline Intercept & $\begin{array}{c}1.942^{* * * *} \\
(2.94)\end{array}$ & $\begin{array}{c}1.950^{* * * *} \\
(2.95)\end{array}$ & $\begin{array}{l}0.001 \\
(0.00) \\
\end{array}$ & $\begin{array}{l}.056 \\
(0.06) \\
\end{array}$ & $\begin{array}{l}0.062 \\
(0.86) \\
\end{array}$ & $\begin{array}{l}0.066 \\
(1.28) \\
\end{array}$ & $\begin{array}{c}0.198^{* *} \\
(1.81) \\
\end{array}$ & $\begin{array}{c}0.191^{* *} \\
(1.86) \\
\end{array}$ \\
\hline$\%$ BgtExtr & & & & & & & $\begin{array}{c}0.255^{* *} \\
(1.56) \\
\end{array}$ & $\begin{array}{l}0.255 \\
(1.11) \\
\end{array}$ \\
\hline$\%$ Bgtspnt & $\begin{array}{c}0.536^{* *} \\
(1.80)\end{array}$ & $\begin{array}{c}0.471 * * \\
(1.67)\end{array}$ & $\begin{array}{c}2.134 * * * \\
(2.64)\end{array}$ & $\begin{array}{c}2.100^{* * *} \\
(2.78)\end{array}$ & & & & \\
\hline$\%$ BgtSrcs & $\begin{array}{l}-0.483 \\
-1.53)\end{array}$ & $\begin{array}{l}-0.496 \\
-1.25)\end{array}$ & & & & & & \\
\hline ExistUsrGrp & $\begin{array}{c}0.432^{* * * *} \\
(2.44)\end{array}$ & $\begin{array}{c}0.388^{* *} \\
(2.04)\end{array}$ & & & & & & \\
\hline GovrBdy & $\begin{array}{c}-0.091^{*} \\
(-1.14) \\
\end{array}$ & $\begin{array}{l}-0.085 \\
(-1.00) \\
\end{array}$ & & & & & & \\
\hline InstDismntld & & & & & $\begin{array}{c}0.116^{* * *} \\
(2.66)\end{array}$ & $\begin{array}{c}0.119 * * * \\
(3.29)\end{array}$ & $\begin{array}{c}0.161^{* * *} \\
(2.47)\end{array}$ & $\begin{array}{c}0.165^{* *} \\
(1.94)\end{array}$ \\
\hline MainObj & $\begin{array}{c}0.300^{* *} \\
(1.60)\end{array}$ & $\begin{array}{l}0.312^{* *} \\
(1.66)\end{array}$ & $\begin{array}{c}1.357 * * * \\
(2.47)\end{array}$ & $\begin{array}{c}1.376^{* * *} \\
(2.47)\end{array}$ & & & & \\
\hline PltclCost & & & $\begin{array}{c}-0.789 * * * \\
(-1.94)\end{array}$ & $\begin{array}{c}-0.817^{* *} \\
(-1.84)\end{array}$ & $\begin{array}{c}0.170^{* * *} \\
(-4.37)\end{array}$ & $\begin{array}{c}-0.172^{* *} \\
(-1.93)\end{array}$ & $\begin{array}{c}0.240 * * * \\
(-4.23)\end{array}$ & $\begin{array}{c}-0.240^{*} \\
(1.55)\end{array}$ \\
\hline PrblmsBfr & $\begin{array}{c}0.470^{* * *} \\
(6.73)\end{array}$ & $\begin{array}{c}0.477 * * * \\
(5.82)\end{array}$ & & & & & & \\
\hline Scarcity1 & & $\begin{array}{l}-0.001 \\
(-0.68) \\
\end{array}$ & & $\begin{array}{c}-0.104 * * * \\
(-2.43)\end{array}$ & & $\begin{array}{c}-0.001 * * * \\
(-2.50) \\
\end{array}$ & & $\begin{array}{c}-0.001 * * * \\
(-3.01) \\
\end{array}$ \\
\hline SectrComposit & & & & & & & $\begin{array}{l}-0.098^{*} \\
(-1.40) \\
\end{array}$ & $\begin{array}{l}-0.093 \\
(-0.77) \\
\end{array}$ \\
\hline ShareSW & & & $\begin{array}{c}1.640^{* *} \\
(1.60) \\
\end{array}$ & $\begin{array}{l}1.721^{*} \\
(1.59)\end{array}$ & & & & \\
\hline TypesDisput & & & $\begin{array}{l}-0.197 * \\
(-1.54)\end{array}$ & $\begin{array}{l}-0.204^{*} \\
(-1.46)\end{array}$ & $\begin{array}{c}0.018^{*} \\
(1.48)\end{array}$ & $\begin{array}{c}0.018^{* *} \\
(1.88)\end{array}$ & & \\
\hline YrsDecentralization & $\begin{array}{c}0.028^{* *} \\
(1.56)\end{array}$ & $\begin{array}{c}0.026^{* * *} \\
(2.39)\end{array}$ & & & & & & \\
\hline F-test & $10.43^{* * * *}$ & $12.35^{* * *}$ & $4.13^{* * *}$ & $4.46^{* * *}$ & $8.93^{* * *}$ & $3.10^{* *}$ & $5.83^{* * *}$ & $2.69^{* *}$ \\
\hline Adjusted $\mathrm{R}^{2}$ & 0.449 & 0.485 & 0.162 & 0.220 & 0.227 & 0.258 & 0.192 & 0.232 \\
\hline
\end{tabular}

Note: ${ }^{* * *} \mathrm{p}<0.01 ; * * \mathrm{p}<0.05 ;{ }^{*} \mathrm{p}<0.10$. 
Table 11: The LOGIT equations of the Decentralization Performance

\begin{tabular}{|l|r|r|}
\hline Estimation procedure & LOGIT & LOGIT \\
\hline Dependent Var. & & \\
& & InstCng \\
& InstCng & \\
\hline Independent Var & & $-1.370^{*}$ \\
& & $(-1.27)$ \\
\hline Intercept & $-1.375^{* * *}$ & $1.462^{* *}$ \\
& $(-2.99)$ & $(2.22)$ \\
\hline \%Bgtspnt & $1.400^{* *}$ & $1.266^{* * *}$ \\
& $(1.91)$ & $(4.10)$ \\
\hline InstDismntld & $1.198^{* * *}$ & $-0.762^{* * *}$ \\
& $(2.99)$ & $(-2.35)$ \\
\hline PltclCost & $-0.753^{* * *}$ & $0.191^{*}$ \\
& $(-2.52)$ & $(1.30)$ \\
\hline PrblmsBfr & $0.198^{*}$ & -0.005 \\
& $(1.32)$ & $(-0.86)$ \\
\hline Scarcity1 & & $22.71^{* * *}$ \\
\hline LR/Wald Chi-square & $23.94^{* * *}$ & 0.225 \\
\hline Pseudo R & 0.222 & \\
\hline Note: & & \\
\hline
\end{tabular}

Note: ${ }^{* * *} \mathrm{p}<0.01 ;{ }^{* *} \mathrm{p}<0.05 ;{ }^{*} \mathrm{p}<0.10$.

The interaction between the decentralization process and its level of performance

In order to assess the impact of the decentralization process on the level of success, we estimated several equation systems consisting of two equations. The first equation depicts the decentralization process, as was described in the previous section, and then the dependent process variable was included as an instrumental variable in a relationship that describes the performance of the decentralization process.

Table 12 presents the results of the estimation of system equations that include non OLS (GLM and Poisson) estimated decentralization process variables as instrumental variables in the decentralization performance equations (that are also GLM and Poisson estimates) in two stages. Because there is no procedure to run 2-stage models for GLM and poisson, it was performed manually by first estimating models (a), (b) and (c) and then using the predicted values to estimate $\mathrm{Aa}, \mathrm{Ab}$ and Ac. This does produce the same coefficients but the standard errors are not the same as if we were to run a simultaneous 2 stage process. 
Table 12: Results of a manually estimated GLM-Poisson equation system of decentralization process-performance

\begin{tabular}{|c|c|c|c|c|c|c|c|}
\hline \multicolumn{4}{|c|}{ Decentralization Process Equation } & \multicolumn{4}{|c|}{ Decentralization Performance Equation } \\
\hline & 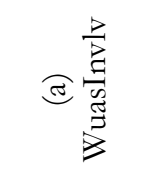 & 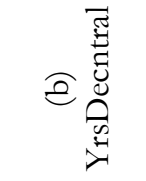 & 仓 & & 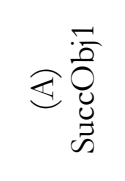 & ヘิ & 仓 \\
\hline Constant & $\begin{array}{l}0.045 \\
(0.41) \\
\end{array}$ & $\begin{array}{c}1.745^{* *} \\
(1.96)\end{array}$ & $\begin{array}{c}0.321 * * \\
(1.99)\end{array}$ & Constant & $\begin{array}{l}7.707 \\
(0.10) \\
\end{array}$ & $\begin{array}{l}18.99 \\
(0.29)\end{array}$ & $\begin{array}{c}20.854 \\
(0.35) \\
\end{array}$ \\
\hline$\%$ BgtExtr & & & & $\%$ BgtExtr & $\begin{array}{l}92.165 \\
(1.33)\end{array}$ & $\begin{array}{l}93.97 \\
(1.32)\end{array}$ & $\begin{array}{l}101.08 \\
(1.37)\end{array}$ \\
\hline$\%$ Bgtspnt & $\begin{array}{c}-0.093^{* *} \\
(-1.70)\end{array}$ & & $\begin{array}{c}-0.497 * * * \\
(-4.45) \\
\end{array}$ & $\%$ BgtSrcs & $\begin{array}{l}-116.56 \\
(-1.25)\end{array}$ & $\begin{array}{c}-120.19 \\
(-1.26)\end{array}$ & $\begin{array}{c}-130.82 \\
(-1.31)\end{array}$ \\
\hline$\%$ BgtBsn & & $\begin{array}{c}1.456^{* * *} \\
(7.08)\end{array}$ & & $\%$ BgtBsn & $\begin{array}{c}-79.490 \\
(-1.22)\end{array}$ & $\begin{array}{l}-82.04 \\
(-1.23)\end{array}$ & $\begin{array}{c}-89.531 \\
(-1.28)\end{array}$ \\
\hline$\% \mathrm{BgtSrcs}$ & $\begin{array}{c}-0.212^{* * *} \\
(-2.58)\end{array}$ & & & InstDismntld & $\begin{array}{l}-1.928 \\
(-1.26)\end{array}$ & $\begin{array}{l}-1.842 \\
(-1.38)\end{array}$ & $\begin{array}{l}-1.995 \\
(-1.12)\end{array}$ \\
\hline$\%$ UsrPay & & $\begin{array}{c}0.017 * * * \\
(4.58) \\
\end{array}$ & $\begin{array}{c}-0.012^{* * *} \\
(-8.91) \\
\end{array}$ & MainObj & $\begin{array}{c}3.116^{* *} \\
(2.16) \\
\end{array}$ & $\begin{array}{c}3.121 * * \\
(2.23) \\
\end{array}$ & $\begin{array}{c}2.958^{* *} \\
(2.16) \\
\end{array}$ \\
\hline FormsDisput1 & $\begin{array}{c}0.068^{* * *} \\
(2.60) \\
\end{array}$ & & & Scarcity1 & $\begin{array}{l}-0.020^{*} \\
(-1.77)\end{array}$ & $\begin{array}{c}-0.020^{* * *} \\
(-2.44) \\
\end{array}$ & $\begin{array}{c}-0.021 * * * \\
(-2.45)\end{array}$ \\
\hline GovrBdy & $\begin{array}{c}-0.028^{*} \\
(-1.56) \\
\end{array}$ & $\begin{array}{c}-0.498^{* * * *} \\
(-3.48)\end{array}$ & & SectrComposit & $\begin{array}{l}-1.932^{*} \\
(-1.67)\end{array}$ & $\begin{array}{c}-1.963^{*} \\
(1.66)\end{array}$ & $\begin{array}{l}-1.927 \\
(-1.38)\end{array}$ \\
\hline MainObj & & $\begin{array}{l}0.510 \\
(1.05)\end{array}$ & & ShareSW & $\begin{array}{l}-4.985 \\
(-0.66)\end{array}$ & $\begin{array}{l}-4.328 \\
(-1.11)\end{array}$ & $\begin{array}{l}-4.246 \\
(-1.03)\end{array}$ \\
\hline Scarcity1 & & $\begin{array}{c}-0.009 * * * \\
(-3.79) \\
\end{array}$ & & TypesDisput & $\begin{array}{c}-0.533^{*} \\
(-1.58) \\
\end{array}$ & $\begin{array}{c}-0.497 * \\
(1.59)\end{array}$ & $\begin{array}{c}-0.526^{*} \\
(-1.72) \\
\end{array}$ \\
\hline SectrComposit & $\begin{array}{l}-0.006 \\
(-0.15)\end{array}$ & & $\begin{array}{c}0.178^{* *} \\
(2.04)\end{array}$ & $\begin{array}{l}\text { Yrs- } \\
\text { Decentralization }\end{array}$ & $\begin{array}{l}-0.097 \\
(-1.28)\end{array}$ & $\begin{array}{l}-0.136 \\
(-0.73)\end{array}$ & $\begin{array}{l}-0.078 \\
(-1.32)\end{array}$ \\
\hline ShareSW & $\begin{array}{c}0.395^{* * *} \\
(4.21) \\
\end{array}$ & & & WuasInvolv & $\begin{array}{l}1.578 \\
(0.15) \\
\end{array}$ & & \\
\hline TypesDisput & & & $\begin{array}{c}-0.063^{* * *} \\
(-2.76)\end{array}$ & MinrObj & $\begin{array}{l}0.193^{*} \\
(1.83)\end{array}$ & $\begin{array}{c}0.194^{* *} \\
(1.87)\end{array}$ & $\begin{array}{c}0.193^{* *} \\
(1.80)\end{array}$ \\
\hline $\begin{array}{l}\text { Yrs- } \\
\text { Decentralization }\end{array}$ & & & & MtdCreatn & $\begin{array}{l}-1.276^{*} \\
(-1.56) \\
\end{array}$ & $\begin{array}{l}-1.320 \\
(-1.53)\end{array}$ & $\begin{array}{c}-1.25)^{*} \\
(-1.58)\end{array}$ \\
\hline & & & & FormsDisput1 & $\begin{array}{l}1.851^{*} \\
(1.55)\end{array}$ & $\begin{array}{l}2.018 \\
(1.41) \\
\end{array}$ & $\begin{array}{l}1.744 \\
(1.44) \\
\end{array}$ \\
\hline & & & & SctrUseShars & $\begin{array}{l}0.448 \\
(1.09) \\
\end{array}$ & $\begin{array}{l}0.304 \\
(0.74) \\
\end{array}$ & $\begin{array}{l}0.232 \\
(0.59) \\
\end{array}$ \\
\hline & & & & FormsDisput2 & $\begin{array}{l}1.331 \\
(0.82)\end{array}$ & $\begin{array}{l}1.126 \\
(0.74)\end{array}$ & $\begin{array}{l}0.870 \\
(0.62) \\
\end{array}$ \\
\hline & & & & YrsCreatn & $\begin{array}{l}-0.003 \\
(-0.10) \\
\end{array}$ & $\begin{array}{l}-0.009 \\
(-0.29)\end{array}$ & $\begin{array}{l}-0.009 \\
(-0.33)\end{array}$ \\
\hline & & & & Facilities & $\begin{array}{l}0.001 \\
(0.42) \\
\end{array}$ & $\begin{array}{l}0.001 \\
(0.54) \\
\end{array}$ & $\begin{array}{l}0.001 \\
(0.59) \\
\end{array}$ \\
\hline $\begin{array}{l}\text { Esimation } \\
\text { Procedure }\end{array}$ & GLM & Poisson & GLM & $\begin{array}{l}\text { Estimation } \\
\text { Procedure }\end{array}$ & GLM & GLM & GLM \\
\hline $\begin{array}{l}\text { Log } \\
\text { Pseudolikelihood }\end{array}$ & -6.916 & & -73.373 & & -267.49 & -267.81 & -268.49 \\
\hline Pseudo $\mathrm{R}^{2}$ & & 0.241 & & & & & \\
\hline Wald $\mathrm{Chi}^{2}$ & & $28.42 * * *$ & & & & & \\
\hline
\end{tabular}

Note: (1) ${ }^{* * *} \mathrm{p}<0.01 ;{ }^{* *} \mathrm{p}<0.05$; $^{*} \mathrm{p}<0.10$.

(2)The equation systems that were estimated consist of equations $\mathrm{aA}, \mathrm{bB}$, and $\mathrm{cC}$. 
The statistical results follow more or less the lines that were reported in the case of the single equation models. That is, similar signs and sizes of the coefficients of the various equations in the system. However, several of the important coefficients were not significant in the system equation compared with the single equation estimates. These findings hold also for the simultaneously estimated equation system reported in Table 13. We will discuss the meaning of the results in the following section.

Table 13: Results of a simultaneously-estimated OLS equation system of decentralization process-performance

\begin{tabular}{|c|c|c|c|c|}
\hline & \multicolumn{2}{|c|}{ Equation 1} & \multicolumn{2}{|c|}{ Equation 2} \\
\hline & Wuasinvlv & PrblmsAfter & Wuasinvlv & ImprvRespons \\
\hline Constant & $\begin{array}{l}-0.033 \\
(-0.19) \\
\end{array}$ & $\begin{array}{c}1.945^{* * *} \\
(2.89) \\
\end{array}$ & $\begin{array}{l}0.019 \\
(0.15) \\
\end{array}$ & $\begin{array}{l}-0.913 \\
(-1.06) \\
\end{array}$ \\
\hline$\%$ BgtSpnt & $\begin{array}{c}-0.09 \\
(-1.20)\end{array}$ & $\begin{array}{l}0.404 \\
(1.24) \\
\end{array}$ & $\begin{array}{l}-0.100 \\
(-1.42)\end{array}$ & $\begin{array}{c}2.293^{* * *} \\
(2.71)\end{array}$ \\
\hline$\%$ BgtSrcs & $\begin{array}{c}-0.219 * * * \\
(-2.70)\end{array}$ & $\begin{array}{c}-0.616^{*} \\
(-1.58)\end{array}$ & $\begin{array}{c}-0.234^{* * *} \\
(-2.94)\end{array}$ & \\
\hline ExistUsrGrp & $\begin{array}{l}-0.001 \\
(-0.02)\end{array}$ & $\begin{array}{c}0.415^{* *} \\
(2.14)\end{array}$ & & \\
\hline FormsDisput1 & $\begin{array}{c}0.076^{* * *} \\
(2.64)\end{array}$ & & $\begin{array}{c}0.081 * * * \\
(2.91)\end{array}$ & \\
\hline GovrBdy & $\begin{array}{l}-0.024 \\
(-1.27)\end{array}$ & $\begin{array}{l}-0.087 \\
(-1.06)\end{array}$ & $\begin{array}{l}-0.025 \\
(-1.34)\end{array}$ & \\
\hline MainObj & $\begin{array}{l}-0.046 \\
(-0.95)\end{array}$ & $\begin{array}{l}0.316^{*} \\
(1.65)\end{array}$ & $\begin{array}{l}-0.038 \\
(-0.81)\end{array}$ & $\begin{array}{c}1.286^{* *} \\
(2.34)\end{array}$ \\
\hline PltclCst & & & $\begin{array}{c}0.058^{*} \\
(1.75)\end{array}$ & $\begin{array}{c}-0.895^{* *} \\
(-2.20)\end{array}$ \\
\hline PrblmsBfr & $\begin{array}{l}0.014 \\
(0.84)\end{array}$ & $\begin{array}{c}0.489 * * * \\
(6.61)\end{array}$ & & \\
\hline SectrComposi & $\begin{array}{l}-0.018 \\
(-0.44)\end{array}$ & & $\begin{array}{c}-0.01 \\
(-0.27)\end{array}$ & \\
\hline ShareSw & $\begin{array}{c}0.383^{* * *} * \\
(4.16)\end{array}$ & & $\begin{array}{c}0.360^{* * *} \\
(4.15)\end{array}$ & $\begin{array}{l}1.304 \\
(0.90)\end{array}$ \\
\hline Wuasinvlv & & $\begin{array}{l}-0.427 \\
(-0.58)\end{array}$ & & $\begin{array}{l}0.902 \\
(0.39)\end{array}$ \\
\hline YrsDecentralization & $\begin{array}{c}0.04 \\
(0.99)\end{array}$ & $\begin{array}{l}0.029 \\
(1.53)\end{array}$ & $\begin{array}{l}0.005 \\
(1.26)\end{array}$ & $\begin{array}{l}0.024 \\
(0.49)\end{array}$ \\
\hline System F-test & \multicolumn{2}{|c|}{$8.75^{* * *}$} & \multicolumn{2}{|c|}{$2.81 * * *$} \\
\hline System Adjusted-R ${ }^{2}$ & \multicolumn{2}{|c|}{0.429} & \multicolumn{2}{|c|}{0.167} \\
\hline
\end{tabular}

Note: $\quad * * * \mathrm{p}<0.01 ; * * \mathrm{p}<0.05 ; * \mathrm{p}<0.10$. 
Table 13 presents the results of a 2-SLS estimation procedure for OLS equations. As was reported for the results of the manually estimated equation system, although the size and direction of mainly all coefficients are as expected, several coefficients that were significant in the single equation estimates, are not significant in the system equation model. We will discuss the overall fit of the results and their meaning in the following section.

\section{Interpretation of the Results}

In working our way through the results, we follow the set of variables that was the basis for our theory and hypotheses. We report the most robust and relevant results in the analysis. We group the results by the (1) impact of contextual factors and initial conditions, by the (2) characteristics of the decentralization process, by the (3) government-basin relationships, and by the (4) internal configuration of basin-level institutional arrangements. The results have to be interpreted in the context of a comparative static framework, that is, the impact of a change in the value of one variable while holding all other variables constant. We address additional aspects of handling the results in the conclusion section, below.

\subsection{Impact of contextual factors and initial conditions}

Variables in this group significantly affect the nature of the decentralization process and its performance. Several examples suggest that:

- The greater the extent of initial decentralization in the basin, the less time the decentralization process took

- The greater the reliance on surface water in the basin, the higher the degree of water user involvement and participation

- The larger the number of institutions that were created during the decentralization process, the greater the political transaction costs associated with the process

- The greater the number of major problems in the basin prior to decentralization, the greater the extent of reported improvement between "before" and "after" decentralization

- The larger the number of institutions that were created during the decentralization process, the greater the extent of reported improvement between "before" and "after" decentralization. 
We pay special attention to the water scarcity variable, because it is reflected in many river basins around the world and also it fits nicely with the notion of 'Scarperation' (Dinar and Dinar, 2005), which suggests that scarcity is an incentive for cooperation among the parties involved. And indeed the basin water scarcity variable was the most robust variable in the various analyses we conducted. Several of these findings suggest that:

- The greater the water scarcity problem in the basin, the less time the decentralization process took

- The greater the water scarcity in the basin, the greater the extent of reported improvement between "before" and "after" decentralization

- The greater the water scarcity in the basin, the greater the extent of reported success with respect to the major objectives of basin management.

The starting point and level of the natural resource endowments in the basin matter a great deal and thus, where one stands dictates how one should implement the reform and thus, how one may end up. Our take from this set of findings is that rich and well endowed basins do not necessarily have an advantage over less endowed basins. Stressed resource conditions and the presence of multiple major problems can be stimulants to effective action and not only obstacles. Approaches for decentralization would address such differences and may lead to similar performances.

\subsection{Characteristics of the decentralization process}

Variables in this group, such as the political economy of the process, participation, compliance, and governance level suggest an array of supporting results as follows:

- The greater the extent of tariff compliance the lower the political transaction costs of the decentralization process; and the smaller the number of institutions that were dismantled during the decentralization process

- The larger the number of water use sectors present in the basin, the larger the number of institutions that were created during the decentralization process

- The greater the availability of forums for dispute resolution, the greater the extent of water user involvement and participation 
- The larger the number of types of disputes in the basin, the greater the extent of reported improvement between "before" and "after" decentralization

- The larger the number of water use sectors present in the basin, the larger the number of institutions that were created during the decentralization process

- The greater the political transaction costs associated with the decentralization process, the smaller the reported improvement between "before" and "after" decentralization; and the less likely that some form of institutional change was associated with the decentralization process

- The greater the number of institutions dismantled during the decentralization process, the greater the reported improvement between "before" and "after" decentralization.

- The longer the decentralization process took, the greater the extent of reported improvement between "before" and "after" decentralization.

- The more comprehensive the basin management objectives were, the greater the extent of reported success with respect to the major objectives of basin management; the greater the reported improvement between "before" and "after" decentralization.

The results associated with this set of variables suggest that indeed political economy plays a role in the decentralization process and affects its performance level, by a need for a compromise and increased transaction costs. But a relevant and coherent decentralization agenda proved to be effective and successful. Our take from this set of finding is that diverse and 'crowded' basins do not necessarily have to face higher political cost and lower levels of performance of the reform, if an appropriate set of mechanisms and objectives, such as forums for dispute resolution, and a coherent reform agenda, are put in place at the appropriate time. Another important result is that decentralization takes time, and depending on the length of the process, some dividends can become evident.

\subsection{Government-basin relationships}

Variables included in this set, such as budget and funding by the government agencies, and the initiation of the reform process are also consistent with our expectations. The common findings include:

- The larger the share of the RBO budget received from external governmental agencies, the smaller the number of institutions that were created during the decentralization process 
- The greater the share of the RBO budget coming from external governmental agencies, the greater the reported improvement between "before" and "after" decentralization

- The more "top-down" the decentralization process was, the smaller the extent of reported success with respect to the major objectives of basin management

The results of this group of variables suggest that government support is an important factor that has to be included at the right dose. On the other hand, the experience in the basins we analyzed suggest that initiation of the decentralization process by governments is counter productive and ends in lower levels of reform performance. Our take for this group of variables is that Government is good as long as it allows the stakeholders to initiate and lead the reform process, with a certain budget support.

\subsection{Internal configuration of basin-level institutional arrangements}

Under this set of variables we include local configurations such as: presence of user groups, budget sources and usage. Common findings across the regression models suggest that:

- The greater the share of the RBO budget contributed by other sources, the smaller the extent of water user involvement and participation

- The larger the share of the RBO budget collected from basin stakeholders, the greater the number of institutions that were dismantled during the decentralization process; and the longer the decentralization process took

- The greater the presence of existing user groups in the basin, the greater the reported improvement between "before" and "after" decentralization

- The greater the share of the RBO budget spent within/returned to the basin, the greater the extent of reported improvement between "before" and "after" decentralization; the more likely that some form of institutional change was associated with the decentralization process; and the greater the extent of reported success with respect to the major objectives of basin management

- The greater the RBO budget per capita, the lower the extent of reported success with respect to the major objectives of basin management.

The overall results of this group of variables indicate the importance of the presence of water user organizations in making the difference between pre and past decentralization reforms. 
Involvement of such groups, as other participatory processes, may make the process longer, but as we already indicated, longer doesn't necessarily mean worse. The results also provide additional support to the old 'mantra' that budget that goes back to the source has a greater impact on stakeholder involvement and system performance-in this case the decentralization reform. One interesting result is that richer basins - this time measured in budget per capita-are not necessarily more successful. As with our earlier findings about natural resource endowments, success in river basin management is not necessarily confined to well-endowed basins. Our take from these results is that the RBO budget is an important tool for management, enhancement of participation and if well designed and managed, could promote the decentralization process.

With this summary and lessons, we can move now to discuss the overall conclusions and policy implications that one can draw from the analysis.

\section{Conclusion, Policy Implications and Extension of the Analysis}

The results of our econometric estimates suggest that both the decentralization process and the performance level of the decentralization are well explained by a set of explanatory variables. Several independent variables provide a robust explanation regardless of the equation selected and the estimation procedure used. We would like to especially address several of these variables, which worked well throughout the various sets of estimates.

Water scarcity is an important variable that affects the process as well as the performance of decentralization. When water in the basin is less abundant, incentives for a simpler decentralization process and a more successful outcome are more likely. Scarcity was positively associated with several aspects of the decentralization process and with the decentralization performance (remember that the more negative the scarcity coefficient the more scarce water is). The presence of scarcity may therefore be a stimulus to reform, uniting the stakeholders in the basin.

In addition to water scarcity, the number and severity of other water resource problems present in a basin prior to decentralization was (perhaps surprisingly) a positive factor with respect to both the initiation of decentralization reforms and their perceived success. The more ambitious and nearly comprehensive the decentralization effort was, and the greater the problems users faced, the more likely they were to see the effort as worthwhile and effective.

Existence and number of existing organized user groups was positively associated with the initiation of decentralization reforms, but also with the costs and difficulty of achieving 
decentralization. Existence of dispute resolution mechanisms was positively associated with water user involvement and with perceived decentralization performance. Length of the decentralization process was positively associated with perceptions of decentralization success and with tariff compliance and share of the RBO budget contributed by stakeholders. A decentralization process that was characterized by protracted political struggle leaves a negative impact on the decentralization performance.

Dismantling of institutions during the decentralization process contributes to the performance of the decentralization process. Combined with the two preceding findings, it appears that complexity and conflict are two distinct characteristics and work in opposite ways. The mere presence of a larger number of organizations within a river basin, and the sheer length of time a decentralization reform takes do not appear to be substantial negative factors. On the other hand, highly conflictive decentralization processes are associated with poorer performance, and some elimination of previously existing institutional arrangements may be a positive factor. Thus what matters is not so much how complicated or lengthy the process is, but the degree of conflict and the ability to make organizational changes along the way.

River basins with higher percentages of their budgets from external governmental sources (such as the local and federal governments) benefit from better stability and support and it shows in the performance of the decentralization process, although the same relationship does not hold for the budget share contributed by other outside sources.

In basins where stakeholders accepted greater financial responsibility, complying with tariffs and contributing to the budget for basin management, decentralization process and performance measures increased. ${ }^{11}$ Combined with the preceding finding, it appears that the financial dimensions of decentralized river basin management are both important and complex: success is associated with central government support as well as water user financial responsibility and with revenues generated within the basin remaining in the basin. Thus it is the combination of financial responsibility (on the part of water users), financial autonomy (basin revenues remaining in the basin), and central government support that is associated with success, and not necessarily one element alone. This is consistent with our analytical framework, which hypothesized that a configuration of factors that

\footnotetext{
${ }^{11}$ A reviewer correctly indicated that compliance is good also in cases where centralized management is in place. It was suggested that compliance with tariff payment is a critical measure of the reform success that deserves to be treated as a dependent variable also. Our future work will address this proposed analysis.
} 
included a supportive but not controlling role for the central government, and responsibility but not complete independence for the water users in the basin, would be associated with successful implementation of decentralization reforms.

Although we addressed a comprehensive list of relationships in the quest to understand the process and level of success of river basin decentralization, we still feel that many questions can be answered using the data we collected. We mainly are interested in answering questions about the interactions among variables and the shape of the estimated relationship function. In this report we use only linear relationships and do not consider interaction terms; we would need to extend the work to address such issues as well.

The results reported in this working paper are preliminary in that they assume simplistic relationships between the process and performance variables and the explanatory variables. For example, the transmission links between the four sets of variables and the process and performance variables are unidirectional, but indeed, they are linked as a system and should be analyzed using a more complicated analytical framework such that the single equation or at most the dual equation system we used.

Another aspect that might be of great importance is the possibility of estimating various reform packaging and sequencing options and their impact on the process and performance of the decentralization. Given initial conditions in the basins, this analysis may yield some recommendations of tailor made packaging and sequencing, with special attention to be given to the mix of certain issues such as balanced functional specialization between local to federal agencies, user participation policy, and property rights format, or others that have been identified in the analysis. 


\section{References}

Alaerts, G.J. 1999. "Institutions for River Basin Management. The Role of External Support Agencies (International Donors) in Developing Cooperative Arrangements", International Workshop on River Basin Management - Best Management Practices, Delft University of Technology/River Basin Administration (RBA), The Hague, October 27-29, 1999.

Allee, David J. 1988. River Basin Management", Proceedings of an Engineering Foundation Conference: the Role of Social and Behavioral Sciences in Water Resources Planning and Management", New York: NY.

Azevedo, G. and M. Asad. 2000. "The Political Process behind the Implementation of Bulk Water Pricing in Brazil", p 317. Dinar, A. (ed.) The Political Economy of Water Pricing Reforms. New York: Oxford University Press.

Bennett (Lewis), L., 2000, “The Integration of Water Quality into Transboundary Allocation Agreements: Lessons from the Southwestern United States," Agricultural Economics, 24, 113125.

Bennett (Lewis), L., Ragland, S. and P. Yolles. 1998. "Facilitating International Agreements Through and Interconnected Game Approach: The Case of River Basins," in Conflict and Cooperation on Trans-Boundary Water Resources (Just and Netanyahu, Eds.), Kluwer Academic Publishers, Boston, 61-85.

Blomquist, W. 1988. "Getting Out of the Commons Trap: Variables, Process, and Results in Four Groundwater Basins,” Social Science Perspectives Journal. Vol. 2, Number 4, pp. 16-44.

Blomquist, W. 1992. Dividing the Waters: Governing Groundwater in Southern California. San Francisco, CA: ICS Press

Blomquist, W. 1994. "Changing Rules, Changing Games: Evidence from Groundwater Systems in Southern California," In Rules, Games, and Common-Pool Resources. Elinor Ostrom, Roy Gardner, and James Walker, eds. Ann Arbor, MI: University of Michigan Press, pp. 283-300

Blomquist, W. and E. Schlager. 1999. Watershed Management from the Ground Up: Political Science and the Explanation of Regional Governance Arrangements. Paper presented at the annual meeting of the American Political Science Association, Atlanta, Georgia, September 2-5, 1999. 54 pp.

Borge, L., 1996, "The Behavior of Bureaucrats and the Choice between Single-Purpose and Multipurpose Authorities,” Public Finance Quarterly. Vol. 24 (2). p 173-91. April.

Bromley, D.W. 1989. Economic Interests and Institutions. New York: Basil Blackwell.

Casella, A. and B. Frey. 1992. "Federalism and Clubs: Towards an Economic Theory of Overlapping Political Jurisdictions," European Economic Review, Vol. 36 (2-3). p 639-46. April.

Cerniglia, Floriana. 2003. "Decentralization in the Public Sector: Quantitative Aspects in Federal and Unitary Countries. Journal of Policy Modeling, 25: 749-776.

Dinar, Shlomi and Ariel Dinar. 2005. "SCARPERATION: The Role of Scarcity in Cooperation among Basin Riparians", Paper presented at the 2005 International Study Association Convention, Honolulu, Hawaii, March 1-5.

El-Awad, O.M. and Ahmed, S.E. 1999. "Economic Reforms of Sudan Irrigation Sub-sector and Impact on Water Use," Comprehensive water resources development of the Nile Basin: the vision for the 
next century. Proceedings of the Seventh Nile 2002 Conference, Cairo, Egypt, 15-19 March, 1999.

Folmer, H., P. van Mouche and S. Ragland, "Interconnected Games and International Environmental Problems," Resource and Environmental Economics, 3: 313-335.

Gustafsson, J.E. 1989. Vattenfoervaltning i Frankrike. Rapport R21:1989. Stockholm: Byggforskningsraadet.

Global Water Partnership (GWP), 2000. “Integrated Water Resources Management” Background Paper No. 4, Stockholm: GWP.

Global Water Partnership (GWP), 2004. "Informal Stakeholder Baseline Survey: Current Status of National Efforts to Move Towards Sustainable Water Management Using an IWRM Approach" Status Report No. 1, April. Stockholm: GWP.

Hinchcliffe, Fiona, John Thompson, and Jules Pretty, eds. 1998. Fertile Ground: The Impacts of Participatory Watershed Management. Stylus Publishers.

Holling, C.S. 1978. Adaptive Environmental Assessment and Management. New York, NY: John Wiley \& Sons

ICWE 1992. The Dublin Statement and Report of the Conference. International Conference on Water and the Environment, 26-31 January 1992.

Kemper, K. E. and D. Olson 2000. "Water Pricing: The Dynamics of Institutional Change in Mexico and Ceará, Brazil," p. 335, Dinar, A. (ed.) Water Pricing: The dynamics of institutional change in Mexico and Ceara, Brazil, New York: Oxford University Press.

Kemper, K.E. 1996. The Cost of Free Water. Water Resources Allocation and Use in the Curu Valley, Ceará, Northeast Brazil. Ph.D. Dissertation, Linkoping University, Department of Water and Environmental Studies: Linkoping, Sweden.

Libecap, G.D. 1994. "The Conditions for Successful Collective Action," Journal of Theoretical Politics. Volume 6, Number 4, pp. 563-592

Maddala, G.S. 1989. Limited-Dependent and Qualitative Variables in Econometrics. Econometric Society Monographs No.3. Cambridge University Press.

McGinnis, Michael D., ed. 1999. Polycentric Governance and Development. Ann Arbor: University of Michigan Press

McGinnis, Michael D., ed. 1999. Polycentric Governance and Local Public Economies. Ann Arbor: University of Michigan Press

McGinnis, Michael D., ed. 2000. Polycentric Games and Institutions. Ann Arbor: University of Michigan Press

Meinzen-Dick, R. and A. Subramanian 1996. Incentives for Water Users' Associations: Evidence from Experience. International Commission on Irrigation and Drainage (ICID): New Delhi, India.

Mody, J. 2001. Literature Review: Management of River Basin Systems Through Decentralization. Unpublished. Report prepared for the World Bank, Washington, D.C.

Musgrave, Warren, 1997. Decentralized Mechanisms and Institutions for Managing Water Resources: Reflections on Experience from Australia. In: Parker Douglas and Yacov Tsur, 
(Eds.) Decentralization and Coordination of Water Resource Management. KLuwer Academic Publishers pp. 429-447.

Naiman, Robert I., ed. 1994. Watershed Management: Balancing Sustainability and Environmental Change. Berlin: Springer Verlag

Newson, Malcolm D. 1997. Land, Water and Development: Sustainable Management of River Basin Systems. Second Edition. London, UK: Routledge

Niranjan, P. 1999. "Impact of irrigation management transfer in Maharashtra. An assessment," Economic and Political Weekly, vol. 34 (13): p.A-17-A-26.

Oechssler, J. 1997. "Decentralization and the Coordination Problem," Journal of Economic Behavior and Organization, 32, 119-135.

Olson, M. 1965. The Logic of Collective Action. Cambridge: Harvard University Press.

Ostrom, E. 1990. Governing the Commons: The Evolution of Institutions for Collective Action. New York, NY: Cambridge University Press

Ostrom, E. 1992. Crafting Institutions for Self-Governing Irrigation Systems. San Francisco, CA: ICS Press

Pradhan, P. and D.J. Bandaragoda 1997. Legal and Institutional Environment of W ater Users' Association for Sustainable Irrigation Management. Asian Productivity Organization: Tokyo, Japan.

Ragin, Charles. 1987. The Comparative Method: Moving Beyond Qualitative and Quantitative Strategies. Berkeley, CA: University of California Press

Ragland, S.E. 1995. International Environmental Externalities and Interconnected Games. Ph.D. dissertation, University of Colorado, Boulder.

Salman, S.M.A. 1997. The Legal Framework for Water Users' Associations: A Comparative Study. World Bank Technical Paper No. 360. World Bank: Washington, D.C.

Samad, Madar, 2005. Water institutional reforms in Sri Lanka. Water Policy, xxxxxxxxxx

Shubik, M. 1984. A Game-Theoretic Approach to Political Economy, Vol. 2 of Game Theory in the Social Sciences, MIT Press, Cambridge.

Simon, Benjamin, 2002. Devolution of Bureau of Reclamation Constructed Facilities. Journal of the American Water Resources Association, 38(5):1187-1194.

Straffin, P.D. 1993. Game Theory and Strategy. The Mathematical Association of America.

Vermillion, D.L. and C. Garces-Restrepo, C. 1998. Impacts of Colombia's Current Irrigation Management Transfer Program. Research Report - International Irrigation Management Institute. Colombo, Sri Lanka.

Walther, P. 1987. "Against Idealistic Beliefs in the Problem-Solving Capacities of Integrated Resource Management.” Environmental Management. Volume 11, Number 4 (July/Aug.), pp. 439-446

World Bank 1993. Water Resources Management: A World Bank Policy Paper. Washington, DC.

World Bank 1999. Mexico - Policy Options for Aquifer Stabilization. Volume I. Policy Report. Mexico Country Management Unit (unpublished). 


\section{Annex 1: Administering the River Basin Survey (Report prepared by INBO) ${ }^{12}$}

About 200 questionnaires were sent by e-mail, fax or surface mail to RBOs, national administrations in charge of water, and international commissions. ${ }^{13}$

Some answers were clear:

- positive in some cases, as some administrations forwarded the questionnaire to the relevant bodies,

- or negative from the international commissions, those usually being a small coordination unit not able to answer the questions that were actually relevant to the different countries concerned, as members of the International Commission. In the case of the Danube River for instance, 13 countries are involved and compiling data from all these countries is a difficult task.

The only positive answers from International Commissions came from the Zambezi River Basin Authority and the Niger Basin Authority. ${ }^{14}$

As far as the national administrations are concerned, if we except some countries like Burkina Faso, the Czech Republic and Romania for instance, the answers were mainly negative (Ivory Coast, South Africa, Bulgaria, etc.) as the creation of RBOs was planned but not effective at that time.

\section{Difficulties encountered}

The first difficulty is that people usually are not keen about answering any kind of questionnaire or do not give it first priority. Therefore several reminders (three) were necessary to have any kind of reply.

Another difficulty encountered is that there are several kinds of RBOs with different responsibilities, therefore one single questionnaire could not cover them all, or some questions were outside RBOs responsibilities.

There are:

RBOs that have existed for a long time

\footnotetext{
${ }^{12}$ RBOs with no entries in the table were either not approached nor been followed.

${ }^{13}$ INBO Members have commented about this questionnaire and found it non adapted to practical RBOs in the field and, therefore, faced numerous difficulties in answering it.

${ }^{14}$ Questionnaires from RBOs of transboundary rivers were eliminated from the sample.
} 
This is the case of the French Water Agencies, created by the 1964 law, and the Spanish Hydrological Confederations that have been created since 1926 (year of the creation of the Confederación Hidrográfica del Ebro, the first one to be created). Therefore the differentiation between what happened before and after the creation of the RBO was not relevant, one can hope that some progress has been achieved but quantifying it is a cumbersome, if not impossible exercise.

\section{RBOs newly created}

This is specially the case in the Eastern European countries (Poland, Romania), in some LatinAmerican (Colombia, Costa Rica, Ecuador, Peru, etc.) and North African countries (Algeria, Morocco), for which answering to all questions were sometimes difficult, although they made tremendous efforts to do so.

Regional Water, Environmental or land planning Authorities. They are of two kinds:

either they have existed for some time and have also some RBOs responsibilities, this is the case of the Czech Republic (1966), Italy (1989-1990) and the Philippines (LLDA - 1966),

or are being planned to become RBOs in the long term (Mexico).

It is also the case in Poland and Romania where the regional water authorities are also RBOs, in their case answering all the questions may be easier if all data are available.

\section{Basin Committees}

These committees may be an advisory body complementary to the RBO itself (France) or a body gathering volunteers from water professionals, the civil society and users, whose task is advising in any matter related to the river basin, this is the case in Quebec and for most of the Brazilian Basin Committees, some of those are almost RBOs or will become one in the future.

Another difficulty is that very few RBOs cover all aspects of water management:

Water supply and sanitation are usually under the responsibility of other administrations, municipalities, local governments or private companies and, therefore, the RBOs may not have the data regarding these aspects, the same occurs for electricity,

water infrastructures may be managed directly by the RBOs (dams, dikes, etc.), this is the case of the Spanish Confederations and Polish RZGWs for instance, or by other administrations or large private or state-governed developing companies (France). 
Clearly, the main difficulty encountered are the data themselves (available or not). This lead to several kinds of situation:

The data do exist but are dispersed or too plentiful: this is typically the case of the large river basins, international or national ones. As regards the large transboundary basins (for example the Danube, the Rhine, etc.), the data exist at the level of the countries.

RBOs may also cover very large national river basins, or several river basins, and in that case the data may be available in a database, or several databases: this means making choices between data widely different in each point of the basin or basins.

An example can be given: it concerns the water quality parameters. The same parameters may be used in the whole basin, with perhaps some additional ones in very specific sampling points, but the results may be very different from a measurement station to another. This will depend of the station location. In the case of the Rhone basin for instance, a station located in Lyons (a very large town with an industrial complex on the main watercourse) will provide results very different (as pollution is high) from a station located on a tributary in the mountains (although some nitrates may be found in agricultural areas). Therefore, giving some exact figures characterizing the whole basin is impossible, even if all these data do exist.

The river basin is small but the data do not exist or are not gathered in a database. Giving figures (exact or estimated), if at all, may be difficult in that case. This might be better in the future, as river basin databases are now created when the RBOs are being set up (although this is not true everywhere).

\section{Outcome}

In spite of these difficulties, many countries have responded. The following is a tally of the responses by regions:

\section{Africa}

The RBOs are not yet widely developed in Africa. If we except some international commissions (Chad, Niger, Senegal, the Nile, Zambezi, etc.), there are few RBOs at the national level, so the answers were limited: Algeria, Burkina Faso, Kenya and Morocco. 
Asia- Pacific

There are few RBOs in Asia, or even Basin Development Authorities (Philippines). The existing or newly created RBOs did respond: Indonesia, Philippines, Vietnam and Uzbekistan.

Latin America

The RBOs are widely developing in the Latin American Countries. Some already do exist in different forms, such as (a) RBO as such, (b) a regional authority with RBO responsibilities, (c) a consortium, or (d) a Basin Committee.

However, the answers were few if compared with the total number of organizations (116), 69 from Brazil alone (Basin Committees and consortiums). The answers came from Brazil (9), Colombia (5), Ecuador (2), Guatemala (1), Mexico (13), Peru (1) and Venezuela (1).

\section{North America}

If there are some kinds of RBO in the United States: Basin Committees or Basin Development Authorities, the Basin Committees are new in Canada, in the Quebec Province. So there were few answers, 2 from each country, the USA being directly contacted by the World Bank.

\section{Europe}

Some RBOs have existed for a long time (Spain, France) or are relatively new (Poland, Romania).

In the Eastern European Countries, candidates to accession to the European Union, management of water resources at the level of basin districts will become compulsory to comply with the European Water Framework Directive of 2000, therefore the creation of RBOs is either under way or planned in some countries (Bulgaria, Slovenia, etc.).

The Czech Republic, Poland and Romania fully responded, France, Italy and Spain less so. There were 29 replies in total.

Signed by Joël MANCEL

INBO Deputy Technical Secretary

Prepared by Gisèle SINE

INBO Permanent Technical Secretariat 


\section{Tally of the Basins that were approached by INBO}

\begin{tabular}{|c|c|c|c|c|}
\hline Basin Name & $\begin{array}{c}\text { Reply to } 1^{\text {st }} \\
\text { request }\end{array}$ & $\begin{array}{l}\text { Reply to } 2^{\text {nd }} \\
\text { request }\end{array}$ & $\begin{array}{c}\text { Reply to } 3^{\text {rd }} \\
\text { request }\end{array}$ & $\begin{array}{c}\text { Had to be } \\
\text { revisited }\end{array}$ \\
\hline $\begin{array}{l}\text { ALGEROIS - HODNA - SOUMMAN (AHS) } \\
\text { Algeria }\end{array}$ & 1 & & & 1 \\
\hline CHELIFF ZAHREZ (ABH-CZ) - Algeria & & 1 & & 1 \\
\hline CONSTANTINOIS - SEYBOUSSE - MELLEGUE - Algeria & & 1 & & \\
\hline \multicolumn{5}{|l|}{ ORANIE-CHOTT CHERGUI - Algeria } \\
\hline \multicolumn{5}{|l|}{ EWASO NGIRO NORTH DEVELOPMENT AUTHORITY - Kenya } \\
\hline \multicolumn{5}{|l|}{ EWASO NGIRO SOUTH DEVELOPMENT AUTHORITY - Kenya } \\
\hline TANA AND ATHI RIVERS (TARDA) - Kenya & & 1 & & \\
\hline \multicolumn{5}{|l|}{ COAST DEVELOPMENT AUTHORITY - Kenya } \\
\hline \multicolumn{5}{|l|}{ COMOE - Burkina Faso } \\
\hline VOLTA (Nakanbé) - Burkina Faso & 1 & & & \\
\hline \multicolumn{5}{|l|}{ KAGERA - Rwanda } \\
\hline OUM ER RBIA - Morocco & & & 1 & \\
\hline SEBOU - Morocco & & & 1 & \\
\hline LOUKKOS - Morocco & & & 1 & 1 \\
\hline NIGER & & 1 & & 1 \\
\hline \multicolumn{5}{|l|}{ ORANGE RIVER - South Africa } \\
\hline ZAMBEZI RIVER - Zambia & 1 & & & \\
\hline \multicolumn{5}{|l|}{ MATANZA-RIACHUELO 6 Argentina } \\
\hline \multicolumn{5}{|l|}{ RIO BERMEJO - Argentina } \\
\hline \multicolumn{5}{|l|}{ SALTO GRANDE - Argentina } \\
\hline SOROCABA E MEDIO TIETE (CBH-SMT) - Brazil & 1 & & & 1 \\
\hline PIRACICABA E CAPIVARI - Brazil & 1 & & & \\
\hline CBH-MOSQUITO - Brazil & 1 & & & 1 \\
\hline \multicolumn{5}{|l|}{ RIO ITAJAI - Brazil } \\
\hline \multicolumn{5}{|l|}{ ALTO TIETE (CBH-AT) - Brazil } \\
\hline \multicolumn{5}{|l|}{ PEIXE PARANAPANEMA (CHB-PP) - Brazil } \\
\hline \multicolumn{5}{|l|}{ AGUAPEI/PEIXE (CBH-AP) - Brazil } \\
\hline \multicolumn{5}{|l|}{ BAIXO TIETE (CBH-BT) - Brazil } \\
\hline SAO JOSE DOS DOURADOS (CBH-SJD) - Brazil & & & & \\
\hline TURVO/GRANDE (CBH-TG) - Brazil & & & & \\
\hline ALTO PARANAPANEMA (CBH-ALPA) - Brazil & & & & \\
\hline LITORAL NORTE (CBH-LN) - Brazil & & & & \\
\hline BAIXADA SANTISTA (CBH-BS) - Brazil & & & & \\
\hline IGUAPE E LITORAL SUL (CBH-RB) - Brazil & & & & \\
\hline PARDO (CBH-PARDO) - Brazil & 1 & & & 1 \\
\hline SAPUCAI-MIRIM/GRANDE (CBH-SMG) - Brazil & & & & \\
\hline TIETE/JACARE (CBH-TJ) - Brazil & & & & \\
\hline BAIXO PARDO/GRANDE (CBH-BPG) - Brazil & & & 1 & 1 \\
\hline RIO PARA (CBH-PARA) - Brazil & & & & \\
\hline VALE DO JIQUIRICA - Brazil & & & & \\
\hline RIO TAQUARI (COINTA) - Brazil & & & & \\
\hline RIOS APA E MIRANDA (CIDEMA) - Brazil & & & & \\
\hline RIO SAO FRANCISCO (CEIVASF) - Brazil & & & & \\
\hline RIO GRANDE DO SUL (CHR-RS) - Brazil & & & & \\
\hline PARAIBA DO SUL E MANTIQUEIRA (CBH-PSM) - Brazil & & & & \\
\hline RIO PARANAIBA (EM FERMACAO) - Brazil & & & & \\
\hline RIO MOGI GUACU (CBH-MOGI) - Brazil & & & & \\
\hline Rios Cachoeira e Almada - Brazil & & & & \\
\hline RIO MURIAE E POMBA - Brazil & & & & \\
\hline PARAIBA DO SUL (CEIVAP) - Brazil & & & & \\
\hline RIO PIRAPAMA - Brazil & & & & \\
\hline RIO IPOJUCA - Brazil & & & & \\
\hline RIO PARACATU - Brazil & & & & \\
\hline RIO PARAOPEBA (CIBAPAR) - Brazil & & & 1 & 1 \\
\hline RIO ARAGUARI - Brazil & & & & \\
\hline RIO ARAGUARI - Brazil & & & & \\
\hline RIO VERDE - Brazil & & & & \\
\hline RIO CARATINGA - Brazil & & & & \\
\hline RIO JACARAIPE - Brazil & & & & \\
\hline RIO SERGIPE - Brazil & & & & \\
\hline RIO GUANDU - Brazil & & & & \\
\hline PONTAL DO PARANAPANEMA - Brazil & & & & \\
\hline
\end{tabular}




\begin{tabular}{|c|c|c|c|}
\hline SERRA DA MANTIQUEIRA - Brazil & & & \\
\hline LITORAL NORTE - Brazil & & & \\
\hline ALTO IGUACU/RIBEIRA - Brazil & & & \\
\hline RIO JORDAO - Brazil & & & \\
\hline RIO DO PEIXE - Brazil & & & \\
\hline RIO CAMBORIU - Brazil & & & \\
\hline RIO DO TIJUCAS - Brazil & & & \\
\hline RIO CUBATAO - Brazil & & & \\
\hline RIO ITAPOCU - Brazil & & & \\
\hline RIO TUBARAO E COMPLEXO LAGUNAR - Brazil & & 1 & 1 \\
\hline RIOS TURVO - SANTA ROSA - SANTO CRISTO - Brazil & & & \\
\hline RIO APUAE-INHANDAVA - Brazil & & & \\
\hline Rio Ibicuí - Brazil & & & \\
\hline SANTA MARIA - Brazil & & 1 & 1 \\
\hline RIOS TAQUARI E ANTAS - Brazil & & & \\
\hline RIO ALTO JACUI - Brazil & & 1 & \\
\hline RIOS VACACAI E VACACAI MIRIM - Brazil & & & \\
\hline RIO BAIXO JACUI - Brazil & & & \\
\hline RIO CAI - Brazil & & & \\
\hline RIO GRAVATAI - Brazil & & & \\
\hline LAGO GUAIBA - Brazil & & & \\
\hline RIO TRAMANDAI - Brazil & & & \\
\hline RIO CAMAMAQUA - Brazil & & & \\
\hline RIO IJUI - Brazil & & & \\
\hline BIO BIO - Chile & & & \\
\hline CUNDINAMARCA (CAR) - Colombia -5 basins & $1(5)$ & & 1 \\
\hline CAUCA - Colombia & & & \\
\hline RIONEGRO-NARE (CORNARE) - Colombia & & & \\
\hline RIOS NIMA Y AMAINE - Colombia & & & \\
\hline RIOS BOGOTA, UBATE Y SUAREZ - Colombia & & & \\
\hline CORANTOQUIA - Colombia & & & \\
\hline ASOCARS - Colombia & & & \\
\hline Norte y Oriente Amazónico (CDA) - Colombia & & & \\
\hline ALTO MAGDALENA (CAM) - Colombia & & & \\
\hline CHOCO (CODECHOCO) - Colombia & & & \\
\hline Meseta de Bucaramanga (CDMB) - Colombia & & & \\
\hline MACARENA - Colombia & & & \\
\hline MAGDALENA (CORPAMAG) - Colombia & & & \\
\hline CALDAS (CORPOCALDAS) - Colombia & & & \\
\hline FRONTERA NORORIENTE (CORPONOR) - Colombia & & & \\
\hline URABÁ (CORPOURABA) - Colombia & & & \\
\hline QUINDÍO (CRQ) - Colombia & & & \\
\hline Guavio (CORPOGUAVIO) - Colombia & & & \\
\hline ORINOQUIA (CORPORINOQUIA) - Colombia & & & \\
\hline RISARALDA (CARDER) - Colombia & & & \\
\hline SAN JUAN - Costa Rica & & & \\
\hline RIO GRANDE DE TARCOLES (CRGT) - Costa Rica & & & \\
\hline RIO TEMPISQUE (ASOTEM) - Costa Rica & & & \\
\hline RIO MACHANGARA - Ecuador & 1 & & \\
\hline Rio Cutuchi - Ecuador & 1 & & \\
\hline RIO PAUTE - Ecuador & & & \\
\hline LAGO DE AMATITLAN (AMSA) - Guatemala & 1 & & 1 \\
\hline BAJA CALIFORNIA - Mexico & & 1 & \\
\hline RIO BALSAS - Mexico & & 1 & \\
\hline RIO BRAVO - Mexico & & 1 & \\
\hline CUENCAS CENTRALES - Mexico & & 1 & \\
\hline FRONTERA SUR - Mexico & & 1 & \\
\hline GOLFO CENTRO - Mexico & & 1 & \\
\hline GOLFO NORTE - Mexico & & 1 & \\
\hline LERMA SANTIAGO - Mexico & & 1 & \\
\hline NOROESTE - Mexico & & 1 & \\
\hline PACIFICO NORTE - Mexico & & 1 & \\
\hline PACIFICO SUR - Mexico & & 1 & \\
\hline PENINSULA YUCATAN - Mexico & & 1 & \\
\hline VALE DE MEXICO - Mexico & & 1 & \\
\hline RIO PILCOMAYO - Paraguay & & & \\
\hline CHIRA-PIURA - Peru & 1 & & \\
\hline JEQUETEPEQUE - Peru & & & \\
\hline
\end{tabular}




\begin{tabular}{|c|c|c|c|c|}
\hline \multicolumn{5}{|l|}{ LAGO DE MARACAIBO (ICLAM) - Venezuela } \\
\hline \multicolumn{5}{|l|}{ RÍO TUY - Venezuela } \\
\hline \multicolumn{5}{|l|}{ Lago de Valencia - Venezuela } \\
\hline ESCOUMINS - Quebec - Canada & & & 1 & \\
\hline YAMASKA - Quebec - Canada & & & 1 & \\
\hline Fraser bRITISH cOLUMBIA cANADA & 1 & & & \\
\hline JASA TIRTA - Indonesia & 1 & & & \\
\hline LAGUNA LAKE (LLDA) - Philippines & & & 1 & 1 \\
\hline RED RIVER - Vietnam & & & 1 & 1 \\
\hline CENTRAL ASIA (SIC ICWC)- Uzbekistan & 1 & & & 1 \\
\hline \multicolumn{5}{|l|}{ MURRAY-DARLING - Australia } \\
\hline POVODI LABE - Czech Republic & & 1 & & \\
\hline POVODI ODRY-Czech Republic & & & 1 & \\
\hline POVODI OHRE - Czech Republic & & & 1 & \\
\hline \multicolumn{5}{|l|}{ POVODI VITAVY - Czech Republic } \\
\hline POVODI MORAVY - Czech Republic & & & 1 & \\
\hline Ile de la Réunion - France & 1 & & & 1 \\
\hline RHIN-MEUSE - France & 1 & & & 1 \\
\hline \multicolumn{5}{|l|}{ GUADELOUPE - France } \\
\hline \multicolumn{5}{|l|}{ GUYANE - France } \\
\hline \multicolumn{5}{|l|}{ ARTOIS-PICARDIE - France } \\
\hline \multicolumn{5}{|l|}{ MARTINIQUE - France } \\
\hline \multicolumn{5}{|l|}{ LOIRE-BRETAGNE - France } \\
\hline RHONE-MEDITERRANEE-CORSE - France & 1 & & & \\
\hline ADOUR-GARONNE - France & & & 1 & \\
\hline \multicolumn{5}{|l|}{ SEINE-NORMANDIE - France } \\
\hline \multicolumn{5}{|l|}{ ADIGE - Italy } \\
\hline \multicolumn{5}{|l|}{ ARNO - Italy } \\
\hline \multicolumn{5}{|l|}{ Basilicata - Italy } \\
\hline \multicolumn{5}{|l|}{ Liri, Garigliano e Volturno - Italy } \\
\hline \multicolumn{5}{|l|}{ Tevere - Italy } \\
\hline \multicolumn{5}{|l|}{ RENO - Italy } \\
\hline Sarno - Italy & & & 1 & \\
\hline PO - Italy & & 1 & & \\
\hline SERCHIO - Italy & & & & \\
\hline MAGRA - Italy & & & & \\
\hline Alto Adriatico - Italy & & & 1 & \\
\hline GLIWICE - Poland & & & & \\
\hline WROCLAW - Poland & & & & \\
\hline POZNAN - Poland & 1 & & & \\
\hline WARSZAWA - Poland & 1 & & & 1 \\
\hline GDANSK - Poland & 1 & & & 1 \\
\hline KRAKOW - Poland & & 1 & & \\
\hline SZCZECIN - Poland & & 1 & & 1 \\
\hline Ialomita-Buzau - Romania & 1 & & & \\
\hline Somes Tisza - Romania & & 1 & & 1 \\
\hline Mures River - Romania & & & 1 & \\
\hline Olt River - Romania & & & 1 & \\
\hline Siret - Romania & 1 & & & 1 \\
\hline Danube \& Seashore - Romania & & & 1 & \\
\hline Banat - Romania & & & 1 & \\
\hline GUADALQUIVIR - Spain & 1 & & & 1 \\
\hline JUCAR - Spain & 1 & & & 1 \\
\hline GUADIANA - Spain & & & 1 & 1 \\
\hline TAJO - Spain & & & & \\
\hline SUR - Spain & & & 1 & 1 \\
\hline SEGURA - Spain & & & & \\
\hline EBRO - Spain & & 1 & & 1 \\
\hline NORTE - Spain & & & & \\
\hline DUERO - Spain & & & & \\
\hline
\end{tabular}




\section{Annex 2: Structure of variables in Dataset}

\section{Legend:}

string data exists as a string (abcde) in database

int data exists as an integer in database

float data exists in double precision float $(0.00)$ format in database

scale $\quad$ response is expected to fit into a predetermined scale $(0-6=x, 6-12=y$, etc $)$

percentage response is expected in percentages (i.e. $0.79=79 \%$ )

number to be interpreted as a number $(1,2,3,4$, etc $)$ indicating quantity

$\mathrm{m}^{3} \quad$ response to be interpreted in cubic meters of volume

$\mathrm{km}^{2} \quad$ response to be interpreted in square kilometers of area

variables are arranged chronologically by question number. (e.g Variable \#1 = Question \#1, Variable \#11 = Question \#2,.... Variable \#223 = Question \#47 )

\section{General Data}

Variable \#1 | Question \#1| basinname | name of basin | string

Variable \#2| Question \#1 | country | name of country | string

Variable \#3| Question \#1| rboname | name of river basin organization | string

Variable \#4 | Question \#1| address | river basin organizations' address | string

Variable \#5 | Question \#1 | contactperson | contact person | string

Variable \#6 | Question \#1 | position | organizational position of contact person | string

Variable \#7| Question \#1| telephone | contact telephone information | int

Variable \#8 | Question \#1 | fax | contact fax information | int

Variable \#9| Question \#1| email | contact email information \& website for river basin organization | string 


\section{Institutional Setup}

Variable \#10 | Question \#1 | basinarea | area of river basin in square km | float

Variable \#11 | Question \#2 | populationtotal | total population in river basin | int

Variable \#12 | Question \#2 | populationrural | rural population as percentage of total | float

Variable \#13 | Question \#3 | precipitation | river basin precipitation in millimeters | float

Variable \#14 | Question \#4 | evapotransp | river basin evapotranspiration in millimeters | float

Variable \#15 | Question \#5 | waterresources | river basin water resources in million cubic meters per year | float

Variable \#16 | Question \#6 | countriesshare | number of countries sharing river basin | int

Variable \#17 | Question \#7 | iyeadecentr | period over which decentralization occurred in years | float

Variable \#18 | Question \#8 | iyearrbo | year of creation of river basin | int

Variable \#19 | Question \#9 | iobjectwaterconflict | water conflict as RBO objective | int

Variable \#20 | Question \#9 | iobjectflood | flood control as RBO objective | int

Variable \#21 | Question \#9 | iobjectwaterscarcity | water scarcity as RBO objective | int

Variable \#22,23,24 | Question \#9 | iobjectothers | iobjectothers2 | iobjectothers3 | other RBO objectives $\mid 0=\mathrm{n} / \mathrm{a}, 1=$ pollution, $2=$ water resources management, $3=$ water quality, $4=$ hydropower, $5=$ planning, $6=$ stabilization of aquifer, $7=$ conservation, $8=$ iwrm, $9=$ development schemes, $10=$ public awareness, $11=$ resource evaluation, $12=$ maintenance, $13=$ water management education,14 = hydrological work,15 = sanitation,16 = watershed conservation,17 = improve efficiency,18 = navigation,19 = flood control,20 = water scarcity,21 = water conflicts, $22=$ water utilization, $23=$ recreation, $24=$ dam safety, $25=$ river administration $\mid$ int

Variable \#25,26,27,28,29,30 | Question \#10 | ifloodscale | iwaterscarcscale | iwaterconflictscale | iothers1scale | iothers2scale | measurement of success against objectives | scale | int 
Variable \#31 | Question \#11 | ibody | governing body of the river basin $\mid 0=$ "N/A",1 = "Federal", 2 = "State Authority"”3 = "State owned company",4 = "Regional Authority",5 = "Regional Board/Council/Committe" | int

Variable \#32 | Question \#13 | ilaws | laws and decrees governing RBO | string

Variable \#33,34 | Question \#14 | icreationrbo | icreationrboupdown | method of RBO creation (bottom/up or Top/Bottom), $0=$ "N/A",1 = "Bottom-up",2 = "Top-Down"| any explanations offered | int | string

Variable \#35 | Question \#15 | iinstdismantled | institutions dismantled in decentralization process | string

Variable \#36 | Question \#16 | inewinstitution | new institutions that had to be created in decentralization process $\mid$ string

Variable \#37 | Question \#17 | icostdecentinstitutions | cost of the decentralization process via the creation of new institutions $\mid 0=$ none, $1=$ Low, $2=2,3=3,4=4,5=$ high $\mid$ int Variable \#38, 39, 40 | Question \#17 | icostdecent17othername1 | icostdecent17othername2 | icostdecent17othername 3 cost of the decentralization process via other processes $\mid 0=n / a, 1=$ resource allocation, $2=$ profit sharing, $3=$ Operating costs, $4=$ new laws, $5=$ activities coordination | string

Variable \#41, 42, 43 | Question \#17 | icostdecent17other1 | icostdecent17other2 | icostdecent17other3 | scale of decentralization process cost $\mid$ scale $\mid 0$ = none, 1=Low, 5=high | int

Variable \#44 | Question \#18 | iforums | forums available to hear disputes | string Variable \#45 | Question \#18 | iforumsyesno | Do forums exist for hearing disputes | $0=$ $\mathrm{n} / \mathrm{a}, 1=$ yes, $2=$ no $\mid$ int

Variable \#46 | Question \#19 | iissuesresolved | main types of disputes/issues that usually need resolving | string

Variable \#47 | Question \#20 | iwaterassociations | degree of involvement of water user associations | percentage | float 
Variable \#48 | Question \#20 | iwaterassociationsyesno | have water user associations been established $\mid 0=\mathrm{n} / \mathrm{a}, 1=$ yes, $2=$ no $\mid$ int

Variable \#49 | Question \#20 | iwaterassociationshowmany | how many water user associations have been established | int

Variable \#50 | Question \#21| itypesinfrustcanal | quantity of canals in the basin (number if $<=20)$ | number and $\mathrm{km} \mid$ int

Variable \#51 | Question \#21| itypesinfrustreservoir | quantity of reservoirs in the basin (number if $<=300) \quad$ number and $\mathrm{m}^{3} \mid$ int

Variable \#52 | Question \#21 | itypesinfrustdam | quantity of dams in the basin | number | int Variable \#53 | Question \#21| itypesinfrustwatertreat | quantity of water treatment facilities in the basin | number | int

Variable \#54,55| Question \#21| itypesinfrust21othername1 | itypesinfrust21othername2 | other types of infrastructure in the basin $\mid 0=\mathrm{n} / \mathrm{a}, 1=$ dewatering stations, $2=$ protection of banks, $3=$ pump stations, $4=$ waste water treatment, $5=$ sluices, $6=$ tunnels, $7=$ piped schemes, $8=$ hydropower, $9=$ wells,10 $=$ navigation, $11=$ control structures, $12=$ water tanks, $13=$ drainage network | (number if $<=300$ except for 11 \& 4) | number and $\mathrm{km} \mid$ int

Variable \#56,57 | Question \#21| itypesinfrust21other1 | itypesinfrust21other2 | quantity of other types of infrastructures in the basin | number | int

Variable \#58 | Question \#22 | iwateruse1 | irrigation users in the basin $\mid 0=$ no,1 = yes $\mid$ int Variable \#59 | Question \#22 | iwateruse2 | industrial users in the basin |

Variable \#60 | Question \#22 | iwateruse3 | domestic users in the basin $0=$ no,1 = yes $\mid$ int Variable \#61 | Question \#22 | iwateruse4 | hydropower usage in the basin $\mid 0=$ no,1 = yes $\mid$ int Variable \#62 | Question \#22 | iwateruse5 | environmental uses/applications in the basin | $0=$ no, $1=$ yes $\mid$ int

Variable \#63, 64, 65, | Question \#22 | iwateruse22other1 | iwateruse22other2 | iwateruse22other3 | other user types in the basin $\mid \mathrm{O}=\mathrm{n} / \mathrm{a}, 1=$ wetlands, $2=$ animal husbandry,3 $=$ navigation, $4=$ livestock, $5=$ fisheries, $6=$ pisciculture, $7=$ transportation, $8=$ thermal power plants, $9=$ minning, $10=$ recreation, $11=$ zootechny $\mid$ int 
Variable \#66 | Question \#22 | ishare1 | share of irrigation use in the basin | percentage | float Variable \#67 | Question \#2 | ishare2 | share of industrial use in the basin | percentage | float Variable \#68 | Question \#22 | ishare3 | share of domestic use in the basin | percentage | float Variable \#69 | Question \#22 | ishare4 | share of hydropower use in the basin | percentage | float Variable \#70 | Question \#22 | ishare5 | share of environmental use in the basin | percentage | float

Variable \#71, 72, 73 | Question \#22 | ishare22other1 | ishare22other2 | ishare22other3 | share of other uses in the basin | percentage | float

Variable \#74 | Question \#24 | waterusegw | share of ground water (only) in the basin | percentage | float

Variable \#75 | Question \#24 | waterusesw | share of surface water (only) in the basin | percentage | float

Variable \#76 | Question \#24 | wateruseboth | share of both ground water and surface water in the basin | percentage | float

Variable \#77,78,79 | Question \#24 | wateruse24othername1 | wateruse24othername2 | wateruse24othername3 | other types of water $\mid 0=\mathrm{n} / \mathrm{a}, 1=$ rainwater harvesting,2= mine water | int

Variable \#80,81,82 | Question \#24 | wateruse24other1 | wateruse24other2 | wateruse24other3 | share of other water types in the basin | percentage | float

Variable \#83 | Question \#25 | indprobbfloods | level of flooding problems before establishment of $\mathrm{RBO} \mid 1$ = no response, $2=$ no problem, $3=$ some problem, $4=$ severe problem $\mid$ int

Variable \#84 | Question \#25 | indprobbwaterscarcity | level of water scarcity problems before establishment of RBO $\mid 1=$ no response, $2=$ no problem, $3=$ some problem, $4=$ severe problem | int

Variable \#85 | Question \#25 | indprobbenvquality | level of environmental quality problems before establishment of RBO $\mid 1=$ no response, $2=$ no problem, $3=$ some problem, $4=$ severe problem | int 
Variable \#86 | Question \#25 | indprobbwaterconflicts | level of water conflict problems before establishment of RBO | 1 = no response, $2=$ no problem, $3=$ some problem, $4=$ severe problem | int

Variable \#87 | Question \#25 | indprobblanddegrad | level of land degradation problems before establishment of RBO $\mid 1$ = no response, $2=$ no problem, $3=$ some problem, $4=$ severe problem | int

Variable \#88 | Question \#25 | indprobbdevelpissues | level of problems with development issues before establishment of $\mathrm{RBO} \mid 1=$ no response, $2=$ no problem, $3=$ some problem, $4=$ severe problem | int

Variable \#89 | Question \#25 | othername | Other problems (before and after) the establishment of RBO $\mid 0=\mathrm{n} / \mathrm{a}, 1=$ water mgt issues and authority crises, $2=$ Env. Awareness, $3=$ Organization, 4 = Hydropower,5 = Water Supply,6 = Drought $\mid$ int

Variable \#90 | Question \#25 | indprobbother25 | level of other problems before establishment of RBO $\mid 1=$ no response, $2=$ no problem, $3=$ some problem, $4=$ severe problem $\mid$ int

Variable \#91 | Question \#25 | indprobafloods | level of flooding problems after establishment of $\mathrm{RBO} \mid 1=$ no response, $2=$ situation same, $3=$ situation improved, $4=$ situation worsened $\mid$ int Variable \#92 | Question \#25 | indprobawaterscarcity | | level of water scarcity problems after establishment of RBO | 1 = no response, 2 = situation same,3 = situation improved,4 = situation worsened | int

Variable \#93 | Question \#25 | indprobaenvquality | | level of environmental quality problems after establishment of RBO | 1 = no response, 2 = situation same, 3 = situation improved,4 = situation worsened | int

Variable \#94 | Question \#25 | indprobawaterconflicts | level of water conflict problems after establishment of RBO | 1 = no response,2 = situation same,3 = situation improved,4 = situation worsened | int

Variable \#95 | Question \#25 | indprobalanddegrad | level of land degradation problems after establishment of RBO | 1 = no response, 2 = situation same, 3 = situation improved,4 = situation worsened | int 
Variable \#96 | Question \#25 | indprobadevelpissues | | level of problems with development issues after establishment of RBO | 1 = no response, 2 = situation same, 3 = situation improved,4 = situation worsened $\mid$ int

Variable \#97 | Question \#25 | indprobaother25 | level of other problems after establishment of RBO $\mid 1=$ no response, $2=$ situation same, $3=$ situation improved, $4=$ situation worsened $\mid$ int Variable \#98 | Question \#26 | iadmblocal | percentage of water administration decision making at the local level before the creation of $\mathrm{RBO} \mid$ percentage $\mid$ float Variable \#99 | Question \#26 | iadmbbasin | percentage of water administration decision making at the basin level before the creation of RBO | percentage | float

Variable \#100 | Question \#26 | iadmbstate | percentage of water administration decision making at the statel level before the creation of RBO | percentage | float

Variable \#101 | Question \#26 | iadmbgov | percentage of water administration decision making at the government level before the creation of RBO | percentage | float

Variable \#102 | Question \#26 | ifinblocal | percentage of infrastructure financing decision making at the local level before the creation of RBO | percentage | float

Variable \#103 | Question \#26 | ifinbbasin | percentage of infrastructure financing decision making at the basin level before the creation of RBO | percentage | float

Variable \#104 | Question \#26 | ifinbstate | percentage of infrastructure financing decision making at the state level before the creation of RBO | percentage | float

Variable \#105 | Question \#26 | ifinbgov | percentage of infrastructure financing decision making at the government level before the creation of RBO | percentage | float

Variable \#106 | Question \#26 | ienfblocal | percentage of water quality enforcement decision making at the local level before the creation of RBO | percentage | float

Variable \#107 | Question \#26 | ienfbbasin | percentage of water quality enforcement decision making at the basin level before the creation of $\mathrm{RBO} \mid$ percentage | float

Variable \#108 | Question \#26 | ienfbstate | percentage of water quality enforcement decision making at the state level before the creation of RBO | percentage | float 
Variable \#109 | Question \#26 | ienfbgov | percentage of water quality enforcement decision making at the government level before the creation of RBO | percentage | float

Variable \#110 | Question \#26 | istdsblocal | percentage of the setting of water quality standards decision making at the local level before the creation of RBO | percentage| float

Variable \#111 | Question \#26 | istdsbbasin | percentage of the setting of water quality standards decision making at the basin level before the creation of RBO | percentage | float

Variable \#112 | Question \#26 | istdsbstate | percentage of the setting of water quality standards decision making at the state level before the creation of RBO | percentage | float

Variable \#113 | Question \#26 | istdsbgov | percentage of the setting of water quality standards decision making at the government level before the creation of RBO | percentage float

Variable \#114 | Question \#26 | iotherblocal26 | percentage of decision making for other responsibilities at the local level before the creation of RBO | percentage | float

Variable \#115 | Question \#26 | iotherbbasin26 | percentage of decision making for other responsibilities at the basin level before the creation of RBO | percentage | float

Variable \#116 | Question \#26 | iotherbstate26 | percentage of decision making for other responsibilities at the state level before the creation of RBO | percentage float

Variable \#117 | Question \#26 | iotherbgov26 | percentage of decision making for other responsibilities at the government level before the creation of RBO | percentage | float

Variable \#118 | Question \#26 | iadmalocal | percentage of water administration decision making at the local level after the creation of RBO | percentage | float

Variable \#119 | Question \#26 | iadmabasin | percentage of water administration decision making at the basin level after the creation of RBO | percentage | float

Variable \#120 | Question \#26 | iadmastate | percentage of water administration decision making at the state level after the creation of RBO | percentage | float

Variable \#121 | Question \#26 | iadmagov | percentage of water administration decision making at the government level after the creation of RBO | percentage | float

Variable \#122 | Question \#26 | ifinalocal | percentage of water administration decision making at the local level after the creation of RBO | percentage | float 
Variable \#123 | Question \#26 | ifinabasin | percentage of infrastructure financing decision making at the basin level after the creation of RBO | percentage | float

Variable \#124 | Question \#26 | ifinastate | percentage of infrastructure financing decision making at the state level after the creation of $\mathrm{RBO} \mid$ percentage| float

Variable \#125 | Question \#26 | ifinagov | percentage of infrastructure financing decision making at the government level after the creation of RBO | percentage | float

Variable \#126 | Question \#26 | ienfalocal | percentage of water quality enforcement decision making at the local level after the creation of RBO | percentage | float

Variable \#127 | Question \#26 | ienfabasin | percentage of water quality enforcement decision making at the basin level after the creation of RBO | percentage | float

Variable \#128 | Question \#26 | ienfastate | percentage of water quality enforcement decision making at the state level after the creation of RBO | percentage | float

Variable \#129 | Question \#26 | ienfagov | percentage of water quality enforcement decision making at the government level after the creation of RBO | percentage | float

Variable \#130 | Question \#26 | istdsalocal | percentage of the setting of water quality standards decision making at the local level after the creation of RBO | percentage | float

Variable \#131 | Question \#26 | istdsabasin | percentage of the setting of water quality standards decision making at the basin level after the creation of RBO | percentage | float

Variable \#132 | Question \#26 | istdsastate | percentage of the setting of water quality standards decision making at the state level after the creation of RBO | percentage | float

Variable \#133 | Question \#26 | istdsagov | percentage of the setting of water quality standards decision making at the government level after the creation of RBO | percentage | float

Variable \#134 | Question \#26 | i_26_othername | other responsibilities |1 = Quality objectives,2 $=\mathrm{O} \& \mathrm{M}, 3=$ Management,4 $=$ Planning, $5=$ Water Supply $\mid$ int

Variable \#135 | Question \#26 | iotheralocal26 | percentage of the decision making for other responsibilities at the local level after the creation of RBO | percentage | float

Variable \#136 | Question \#26 | iotherabasin26 | percentage of the decision making for other responsibilities at the basin level after the creation of RBO | percentage | float 
Variable \#137 | Question \#26 | iotherastate26 | percentage of the decision making for other responsibilities at the state level after the creation of RBO | percentage | float

Variable \#138 | Question \#26 | iotheragov26 | percentage of the decision making for other responsibilities at the government level after the creation of $\mathrm{RBO} \mid$ percentage $\mid$ float

Variable \#139 | Question \#27 | wrmibwatertypes | Water rights before RBO existence |0= None,1 = Permanent Rights, 2 = Long-Term use concession $(>10$ yrs),3 = Short-Term use concession $(<10$ yrs $), 4=$ Permanent Transferable, $5=$ Permanent non-transferable $\mid$ int

Variable \#140| Question \#28 | wrmibresponsiblerigths | responsibility for awarding water rights before RBO existence $\mid 0=\mathrm{n} / \mathrm{a}, 1=$ Federal, $2=$ National Agency,3 $=$ State $/$ Provincial,4 $=$ Regional Organization, $5=, 6=$ River Basin Org. $\mid$ int

Variable \#141 | Question \#29 | wrmibresponsibleallocation | responsibility for water allocation before RBO existence $\mid 0=\mathrm{n} / \mathrm{a}, 1=$ Federal, $2=$ National Agency, $3=$ State $/$ Provincial, $4=$ Regional Organization,5 = Local Government,6 = River Basin Org. | int

Variable \#142 | Question \#30 | wrmibresponsiblemodfore | responsibility for modeling and forecasting water availability before RBO existence | $\mid 0=\mathrm{n} / \mathrm{a}, 1=$ Federal,2 $=$ National Agency,3 $=$ State $/$ Provincial, $4=$ Regional Organization, $5=$ Local Government, $6=$ River Basin Org. $\mid$ int

Variable \#143 | Question \#31 | wrmibresponsiblemonit | responsibility for monitoring and enforcement of water quality before RBO existence $\mid \quad 0=\mathrm{n} / \mathrm{a}, 1=$ Federal,2 $=$ National Agency,3 $=$ State $/$ Provincial, $4=$ Regional Organization, $5=$ Local Government, $6=$ River Basin Org. $\mid$ int

Variable \#144 | Question \#32 | wrmibresponsibletariff | responsibility for collecting tariffs before RBO existence $|\quad| \quad 0=\mathrm{n} / \mathrm{a}, 1=$ Federal,2 $=$ National Agency,3 $=$ State $/$ Provincial,4 $=$ Regional Organization,5 = Local Government, $6=$ River Basin Org. | int

Variable \#145 | Question \#27 | wrmiawatertypes | Water rights after RBO existence | $0=$ None,1 = Permanent Rights, $2=$ Long-Term use concession $(>10$ yrs),3 = Short-Term use concession $(<10$ yrs), $4=$ Permanent Transferable, $5=$ Permanent non-transferable $\mid$ int

Variable \#146 | Question \#28 | wrmiaresponsiblerigths | responsibility for awarding water rights after RBO existence $\mid 0=\mathrm{n} / \mathrm{a}, 1=$ Federal, $2=$ National Agency, $3=$ State $/$ Provincial, $4=$ Regional Organization,5 = Local Government, 6 = River Basin Org. | int 
Variable \#147 | Question \#29 | wrmiaresponsibleallocation | responsibility for water allocation before RBO existence $\mid 0=\mathrm{n} / \mathrm{a}, 1=$ Federal, $2=$ National Agency, $3=$ State $/$ Provincial, $4=$ Regional Organization,5 = Local Government,6 = River Basin Org. | int

Variable \#148 | Question \#30 | wrmiaresponsiblemodfore | responsibility for modeling and forecasting water availability after RBO existence $\mid 0=\mathrm{n} / \mathrm{a}, 1=$ Federal, $2=$ National Agency,3 $=$ State $/$ Provincial, $4=$ Regional Organization, $5=$ Local Government, $6=$ River Basin Org. $\mid$ int

Variable \#149 | Question \#31 | wrmiaresponsiblemonit | responsibility for monitoring and enforcement of water quality after RBO existence $\mid 0=\mathrm{n} / \mathrm{a}, 1=$ Federal, $2=$ National Agency,3 $=$ State $/$ Provincial, $4=$ Regional Organization, $5=$ Local Government, $6=$ River Basin Org. $\mid$ int

Variable \#150 | Question \#32 | wrmiaresponsibletariff | responsibility for collecting tariffs after RBO existence $\quad 0=\mathrm{n} / \mathrm{a}, 1=$ Federal, $2=$ National Agency,3 $=$ State $/$ Provincial, $4=$ Regional Organization, $5=$ Local Government,6 = River Basin Org. | int

Variable \#151 | Question \#33 | wrmiuser1 | existence of water tariff on irrigation | $0=\mathrm{n} / \mathrm{a}, 1=$ yes, $2=$ no $\mid$ int

Variable \#152 | Question \#33 | wrmiuser2 | existence of water tariff on industry $\mid 0=\mathrm{n} / \mathrm{a}, 1=$ yes, $2=$ no $\mid$ int

Variable \#153| Question \#33 | wrmiuser3 | existence of water tariff on domestic use | $0=\mathrm{n} / \mathrm{a}, 1$ $=$ yes, $2=$ no $\mid$ int

Variable \#154-156 | Question \#33 | wrmi33other1user | wrmi33other2user | wrmi33other3user $\mid$ other user groups paying water tax $\mid 0=\mathrm{n} / \mathrm{a}, 1=$ electricity, $2=$ tertiary sector, $3=$ tourism, $4=$ fisheries, $5=$ thermal energy, $6=$ sewerage charges, $7=$ animal breeding, $8=$ mining \& oil | int

Variable \#157| Question \#33 | wrmitariff1 | value of tariff (2002 USD) on irrigation | float Variable \#158 | Question \#33 | wrmitariff2 | value of tariff (2002 USD) on industry | float Variable \#159 | Question \#33 | wrmitariff3 | value of tariff (2002 USD) on domestic use | float Variable \#160-162 | Question \#33 | wrmi33other1tariff | wrmi33other2tariff wrmi33other3tariff | value of tariff (2002 USD) on other user groups | float 
Variable \#163 | Question \#34 | wrmiusersgroup1 | (existence of) irrigation user group |0= $\mathrm{n} / \mathrm{a}, 1=$ yes $\mid$ int

Variable \#164 | Question \#34 | wrmiusersgroup2 | (existence of) industry user group |0= $\mathrm{n} / \mathrm{a}, 1=$ yes $\mid$ int

Variable \#165 | Question \#34 | wrmiusersgroup3 | (existence of) domestic user group |0= $\mathrm{n} / \mathrm{a}, 1=$ yes $\mid$ int

Variable \#166-168 | Question \#34 | wrmi34other1usersgroup | wrmi34other2usersgroup | wrmi34other3usersgroup | other user groups identified $\mid 0=\mathrm{n} / \mathrm{a}, 1=$ electricity, $2=$ fishfarming, $3=$ thermal energy, $4=$ animal breeding $\mid$ int

Variable \#169 | Question \#34 | wrmigroup1 | percentage of irrigation users who pay tariff | percent $\mid$ float

Variable \#170 | Question \#34 | wrmigroup2 | percentage of industry users who pay tariff | percent $\mid$ float

Variable \#171 | Question \#34 | wrmigroup3 | percentage of domestic users who pay tariff | percent $\mid$ float

Variable \#172-174 | Question \#34 | wrmi34other1group | wrmi34other2group | wrmi34other3group | percentage of other user groups who pay tariff | percent | float

Variable \#175 | Question \#35 | wrmidestination | amount of tariff going to other destinations | percent $\mid$ float

Variable \#176 | Question \#36 | wrmiactivitiesprivate | extent of private sector activities | percent $\mid$ float

Variable \#177 | Question \#37 | wrmiinfostakeh | information sharing among stakeholders | string

Variable \#178 | Question \#38 | wrmicapacitystakeh | capacity building for stakeholders | string

\section{Financing}

Variable \#179 | Question \#39 | fannualbudget | annual budget (million dollars per year) | float 
Variable \#180| Question \#39 | fbudgetextagency | amount of budget allocated by external (government) agency | percent | float

Variable \#181 | Question \#39 | fbudgetwhichagency | name of external agency $\mid 0=\mathrm{n} / \mathrm{a}, 1=$ Government, $2=$ SRBC, $3=$ Provincial, $4=$ Central Gov't, $5=$ Hydrologic funds, $6=$ Env. Ministry, 7 $=$ Fundo Hydricos, 8 = Agric. Ministry,9 = BM,10 = BIRF $\mid$ int

Variable \#182 | Question \#39 | fbudgetstakeh | amount of budget derived from basin stakeholders | percent | float

Variable \#183 | Question \#39 | fbudgetothersources | amount of budget from other sources | percent $\mid$ float

Variable \#184 | Question \#40 | fbudgetinvestmentbasin | amount of budget used for investment in the basin | percent | float

Variable \#185 | Question \#41 | fbudgetotheractivities | amount of budget used for other development activities | percent | float

Variable \#186 | Question \#42 |fbudgetom | amount of budget used for O\&M | percent | float Variable \#187 | Question \#43 | fbudgetwaterquality | amount of budget used for water quality activities : percent | float

Variable \#188 | Question \#44 | fbudgetother | amount of budget used in other activities | percent $\mid$ float

Variable \#189 | Question \#44 | other44 | other activities | $1=$ hydraulics,2 = hydrology,3 = communication, $4=$ national budget, $5=$ institutional cost, $6=$ personnel cost, $7=\mathrm{R} \& \mathrm{D}, 8=$ education $\mid$ int

\section{Performance Indicators}

Variable \#190 | Question \#45 | pigdpyesno | Does the basin measure GDP | $0=$ no,1 = yes | int

Variable \#191-194 | Question \#45 | piyear1 | piyear2 | piyear3 | piyear4 | year of GDP measurement | int 
Variable \#195-198 | Question \#45 | pigdp1 | pigdp2 | pigdp3 | pigdp4 | GDP (millions per year) corresponding to given year | float

Variable \#199| Question \#46 | pisector1 | (existence of) agricultural sector | $0=$ no,1 = yes | int

Variable \#200 | Question \#46 | pisector2 | (existence of) forest sector | $0=$ no,1 = yes $\mid$ int

Variable \#201 | Question \#46 | pisector3 | (existence of) urban zones | $0=$ no,1 = yes $\mid$ int

Variable \#202 | Question \#46 | pisector4 | (existence of) Open Land | $0=$ no,1 = yes | int

Variable \#203-205 | Question \#46 | pi46other1 | pi46other2 | pi46other3 | other sectors utilizing basin land area $\mid 1=$ vegetation de paramo,2 $=$ non-vegetated, $3=$ irrigation, $4=$ arable land, $5=$ surface vegetation, $6=$ rural zones, $7=$ urban zones, $8=$ parks, $9=$ water plan, $10=$ pisciculture, $11=$ reservoirs, $12=$ permanent crops,13 $=$ non-permanent crops,14 = lakes, $15=$ grazing land $\mid$ int

Variable \#206 | Question \#46 | pibasinarea1 | basin land area utilized by agriculture sector $\mid \mathrm{km}^{2}$ | float

Variable \#207 | Question \#46 | pibasinarea2 | basin land area utilized by forestry sector | $\mathrm{km}^{2}$ | float

Variable \#208 | Question \#46 | pibasinarea3 | basin land area utilized by urban zones $\left|\mathrm{km}^{2}\right|$ float

Variable \#209 | Question \#46 | pibasinarea4 | basin land area utilized by Open Land | $\mathrm{km}^{2}$ | float

Variable \#210-212 | Question \#46 | pibasinarea46other1 | pibasinarea46other2 | pibasinarea46other3 |

Variable \#213 | Question \#47| piquality1 | Disolved Oxygen |0= no,1 = yes | int Variable \#214 | Question \#47 | piquality2 | PH | $0=$ no,1 = yes | int

Variable \#215 | Question \#47 | piquality3 | Temperature | $0=$ no,1 = yes $\mid$ int

Variable \#216 | Question \#47 | piquality4 | Conductivity | $0=$ no,1 = yes $\mid$ int

Variable \#217 | Question \#47 | piquality5 | Suspended Solids | $0=$ no,1 = yes $\mid$ int 
Variable \#218-219 | Question \#47 | pi47other1 | pi47other2 | other quality indicators |1 = odor $\&$ taste, $2=$ BOD5, COD,3 $=$ Nutrients $($ TSS), $4=$ Ammonium, $5=$ salinity, $6=$ Nitrate itrogen, $7=$ Boron, $8=$ Calcium,9 $=$ turbidity, $10=$ phosphorus, $11=$ oil,12 =Flourine, $13=$ chlorine, $14=$ TDS,15 = Residuals, $16=$ Zinc, $17=$ solids, $18=$ Iron $\mid$ int

Variable \#220 | Question \#47 | pivalue1 | Disolved Oxygen | mg/l | float

Variable \#221 | Question \#47 | pivalue2 | PH | float

Variable \#222 | Question \#47| pivalue3 | Temperature | degree centigrade | float

Variable \#223 | Question \#47 | pivalue4 | Conductivity | EC | float

Variable \#224 | Question \#47 | pivalue5 | Suspended Solids | mg/l | float

Variable \#225-226 | Question \#47| pi47other1value | pi47other2value | values for other quality indicators | float 


\section{Annex 3: Variables uded in the analysis}

\section{Variables taken directly from the questionnaire}

GovrBdy=V31. This variable distinguishes between level of governance of the RBO. With Values ranging from 1-5, with higher ones expressing more decentralization. It can be used as a dummy variable.

PltclCost $=\mathrm{V} 37$. This variable measures the political/transaction cost of the decentralization process. It is expressed on a scale from 1-5, with 5 being the highest. It can serve as an independent as well as a dependent variable. As an independent variable it may explain low success or longer period of decentralization. As a dependent variable it may be positively correlated with variables expressing the complexity of the basin.

$\boldsymbol{\%} \boldsymbol{B g} \boldsymbol{B} \boldsymbol{s} \boldsymbol{n}=\mathrm{V} 182$. This variable measures the share of the budget obtained from basin stakeholders. It is expected that the higher BgtBsn the more likely the decentralization success.

\%BgtExtr=V180. The share of the basin's budget allocated by external (government) agency. It is expected the higher the \%BgtExtr the more likely the decentralization process to succeed.

\%BgtSrcs=PC(V180, V182, V183). Share of budget from sources other than Government and Basin stakeholders. It is expected that the more diverse the budget sources the more difficult it will be to implement the decentralization.

FormsDispute1=V44. The forums that are available to hear/solve disputes.

FormsDisput2=V45. This variable might have a pivotal role in explaining success of decentralization. It measures, using a dichotomy variable $\mathrm{Y}=1 ; \mathrm{N}=0$ the existence of dispute resolution institutions. It is expected that existence of such institutions be positively correlated with higher level of success of decentralization.

GovrBdy=V31. This variable distinguishes between level of governance of the RBO, with values ranging from 1-5, with higher ones expressing more centralization $(5=$ "Federal", $4=$ "State Authority" $3=$ "State owned company",2 = "Regional Authority",1 = "Regional Board/Council/Committee").

MtdCreatn $=\mathrm{V} 33$. This variable indicates the way the $\mathrm{RBO}$ was created. $\mathrm{N} / \mathrm{A}=0$, Bottom $\mathrm{Up}=1$, and Top Down=2. We expect that a bottom up method of creation is associated with more successful decentralization. 
PltclCost $=$ V37. This variable measures the political/transaction cost of the decentralization process via the creation of new institutions $(0=$ none, $1=$ Low $, \ldots, 5=$ high). As an independent variable it may explain low success or longer period of decentralization. As a dependent variable it may be positively correlated with variables expressing the complexity of the basin.

$\boldsymbol{R e s p W t r A l o c A f t r}=\mathrm{V} 147$. This Variable measures administration of water allocation after the decentralization on a scale of 1-6 with 6 indicating a higher level of decentralization.

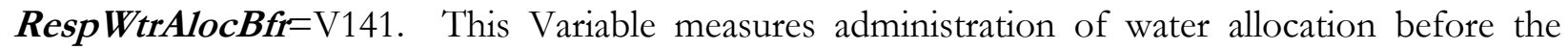
decentralization on a scale of 1-6 with 6 indicating a higher level of decentralization.

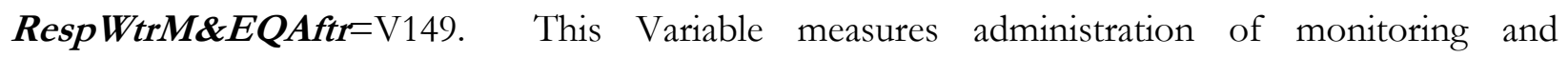
enforcement of water quality after the decentralization on a scale of 1-6 with 6 indicating a higher level of decentralization.

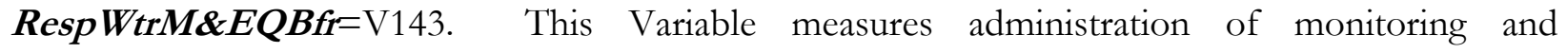
enforcement of water quality before the decentralization on a scale of 1-6 with 6 indicating a higher level of decentralization.

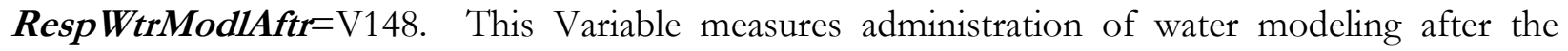
decentralization on a scale of 1-6 with 6 indicating a higher level of decentralization.

$\boldsymbol{R e s p W t r M o d l B f} \boldsymbol{f}=\mathrm{V} 142$. This Variable measures administration of water modeling before the decentralization on a scale of 1-6 with 6 indicating a higher level of decentralization.

$\boldsymbol{R e s p W t r R i g h t A f t r}=\mathrm{V} 146$. This Variable measures administration of water rights after the decentralization on a scale of 1-6 with 6 indicating a higher level of decentralization.

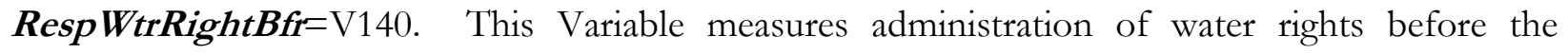
decentralization on a scale of 1-6 with 6 indicating a higher level of decentralization.

$\boldsymbol{R e s p W t r}$ TarifAftr $=\mathrm{V} 150$. This Variable measures administration of water tariff collection after the decentralization on a scale of 1-6 with 6 indicating a higher level of decentralization.

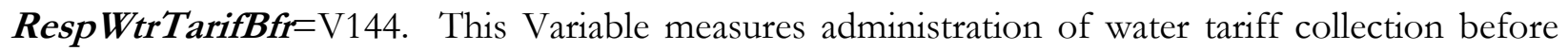
the decentralization on a scale of 1-6 with 6 indicating a higher level of decentralization.

Share $\boldsymbol{S W}=\mathrm{V} 75$. This variable measures the share of surface water in the available water resources in the basin. Lower values of ShareSW mean that other sources are the majority, and higher values of ShareSW mean that surface water is the majority. In both cases, namely that one source prevails, it is 
expected that it will be easier to manage the water in the basin compared to a situation where there are multiple sources. Therefore, having all other factors constant, the relationship between this variable and the successful management of the RBO or the success of the decentralization process are hill shaped.

WuasInvlv=V47. This variable assesses the degree of WUA involvement and participation, expressed as a continuous variable on a scale between 0-100. We expect that the higher the values of WuasInvlv, the higher the level of decentralization success.

WuasNum=V49. This variable indicates the total number of WUAs in the basin. We expect that the higher WuasNum the higher the level of success of the RBO and the decentralization process.

YrCreation $=\mathrm{V} 18$. This variable measures the year in which the RBO was created. The earlier the $\mathrm{RBO}$ creation, the stronger it is and thus the easier it is to achieve the decentralization process.

YrsDecentral $=V 17$. This variable measures the length of the decentralization process. It can be either an independent or a dependent variable. It is expected that the more complicated the process is the longer it takes to decentralize (independent), and the shorter the process the more successful the decentralization process (dependent).

Variables that underwent Principal Component (PC) Analysis and expectations regarding their impact

\%UsrPay $=\mathbf{P C}(V 169$, V170, V171). This PC variable measures the percentage of users in the irrigation, industrial, and urban sectors that pay their tariffs. It is expected that higher values of UsrPay indicate a more likely decentralization process.

ExistUsrGrp $=\mathbf{P C}(V 163, \mathrm{~V} 164, \mathrm{~V} 165)$. This PC variable is another way to measure participation in the basin. Detecting the existence of irrigation, industrial and domestic user groups via dichotomy variables allows to expect that existence is likely to lead to successful process of decentralization.

Facilities $=\mathbf{P C}(\mathrm{V} 50, \mathrm{~V} 51, \mathrm{~V} 52, \mathrm{~V} 53)$. This PC variable incorporates the values (length or quantity and capacity) of canals, reservoirs, dams and treatment facilities into one 'facilities' variable. Because the measurement units of each of the variables comprising Facilities are on a different scale we may face problems in the PC variable. However, we expect that an RBO with more infrastructure (higher level/number/capacity of Facilities) will face difficulties because of the claimed rights in the status quo, and may have lower level of success in decentralization. 
ImprvRespons $=\mathbf{P C}(\mathrm{V} 146-\mathrm{V} 140, \mathrm{~V} 147-\mathrm{V} 141, \mathrm{~V} 148-\mathrm{V} 142, \mathrm{V149-V143,} \mathrm{V150-V144).} \mathrm{This} \mathrm{is} \mathrm{a} \mathrm{PC}$ variable, taking into account the difference between 'after and before' decentralization regarding 5 responsibilities. The higher the value the more successful the decentralization. ImproRespons will serve as a dependent variable.

IncrmntImprv $=\mathbf{P C}((\mathrm{V} 91-\mathrm{V} 83, \mathrm{~V} 92-\mathrm{V} 84, \mathrm{~V} 93-\mathrm{V} 85, \mathrm{~V} 94-\mathrm{V} 86, \mathrm{~V} 95-\mathrm{V} 87, \mathrm{~V} 96-\mathrm{V} 88)$.$) . This \mathrm{PC}$ variable measures the incremental improvement in various problems in the basin between before and after' decentralization. ???????????????

IncrmntTasks $=\mathbf{P C}(\mathrm{V} 118-\mathrm{V} 98, \mathrm{V199-V99}, \mathrm{V122-V102,V123-V103，V126-V106,} \mathrm{V127-V107,}$ V130-V110, V131-V111). This PC variable measures the incremental change in 8 variables measuring tasks at local and basin-level management between 'before and after' decentralization. The higher the value the more successful the decentralization. IncrmntTasks will serve as a dependent variable.

MainObj=PC(V19, V20, V21). This is a Principal Component variable, comprising of three main objectives on the RBO-conflict resolution, flood control, and water scarcity improvement. The higher the value of this variable, the more comprehensive the objective is. We expect that holding other variables constant, the higher the value of MainObj the more complicated the process, leading to a lengthier decentralization and lower likelihood of success.

MinrObj= PC $(\mathrm{V} 22, \mathrm{~V} 23, \mathrm{~V} 24)$. This PC variable, comprises of three minor objectives of the RBOa combination of a set of 25 possible minor objectives (See variables 22-24 in Annex 23). We expect a similar relationship as for MainObj.

PrblmsAftr $=$ PC(V91, V92, V93, V94, V95, V96). This PC variable measures composite success of decentralization. No response=1, Situation improved=4, SameSame situation=3, Situation worsen $=2$. (Originally it was: Same situation $=2$, Situation improved $=3$; Situation worsen $=4$, but reordered.) Prblms Aftr will serve as a dependent variable.

PrblmsBfr $=\mathbf{P C}(\mathrm{V} 83, \mathrm{~V} 84, \mathrm{~V} 85, \mathrm{~V} 86, \mathrm{~V} 87, \mathrm{~V} 88)$. This PC variable measures composite level of problems in several domains related to management issues in the basin: flooding, water scarcity, environmental quality, water conflicts, land degradation, development issues. All values are measured on the same scale (1-4), with 4 measuring severe problems. The direction of impact of this variable is undecided. On the one hand increased level of problems may provide incentive for the decentralization process, but on the other hand problems that are too severe may hamper the 
decentralization process. So, we expect a quadratic relationship between level of problems and level of success.

SectrComposit $=\mathbf{P C}(\mathrm{V} 58, \mathrm{~V} 59, \mathrm{~V} 60, \mathrm{~V} 61, \mathrm{~V} 62)$. This PC variable measures the composition of the subsectors in the basin-irrigation, industry, domestic, hydropower, environment, which expressed as $\mathrm{Y}=1$ if the sector exist, and $\mathrm{N}=0$ if the sector doesn't exist in the basin. We expect that the more sub-sectors are involved in water utilization the more difficult is the decentralization process.

SectrUseShars $=\mathbf{P C}(\mathrm{V} 66, \mathrm{~V} 67, \mathrm{~V} 68, \mathrm{~V} 69, \mathrm{~V} 70)$. This PC variable takes into account the distribution of water use shares of the five main water using sectors-irrigation, industry, domestic, hydropower and environment. We expect that the more skewed the distribution the easier it will be to decentralize the RBO, because of power relations between the sectors.

SuccObj1 $=\mathbf{P C}(\mathrm{V} 25, \ldots, \mathrm{V} 30)$. This PC variables captures the integrated level of success of the three main objectives and the other 25 minor objectives, each measured on a scale of 1-5 with 5 indicating high level of success. SuccObj1 will serve as a dependent variable.

SuccObj2 $=\mathbf{P C}(\mathrm{V} 25, \ldots, \mathrm{V} 27)$. This PC variable, measuring the success of only the 3 main objectives, is constructed because we are afraid that there are not enough observations that distinguish among the minor objectives. It is measured on the same scale as SuccObj1. SuccObj2 will serve as a dependent variable.

\section{Indices created}

\%BgtSpnt $=\mathrm{V} 184+\mathrm{V} 185+\mathrm{V} 186+\mathrm{V} 187$. This variable measures the share of the budget that is spent in the basin and not returned to external governments. It is expected that higher values of BgtSpnt are likely to indicate a higher level of success.

AdminBasnImprv=V199-V99. This variable measures the increase in share of administrative responsibilities at basin level.

AdmnLocallmprv $=\mathrm{V} 118-\mathrm{V} 98$. This variable measures the increase in share of administrative responsibilities at local level.

BgtPrCpta=V179/V11. This variable expresses budget per capita in the basin. It is expected that higher values are associated with likely success of the decentralization process.

InfrBasnImprv=V123-V103. This variable measures the increase in share of infrastructure financing at basin level. 
InfrLocalImprv $=\mathrm{V} 122-\mathrm{V} 102$. This variable measures the increase in share of infrastructure financing at local level.

InstCng. This is a dichotomous variable measuring whether or not there was an institutional change associated with the decentralization process. If (V146-V140 $\geq 1$, OR V147-V141 $\geq 1$, OR

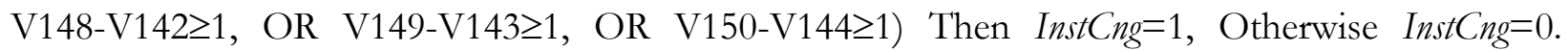
InstCng will be used as a dependent variable.

QenfBasnImprv $=\mathrm{V} 127-\mathrm{V} 107$. This variable measures the increase in share of water quality enforcement at basin level.

QenfLocalImprv=V126-V106. This variable measures the increase in share of water quality enforcement at local level.

QstdBasnImprv=V131-V111. This variable measures the increase in share of water quality standard setting at basin level.

QstdLocalImprv=V130-V110. This variable measures the increase in share of water quality standard setting at local level.

Scarcity1=V13/V14. This variable reflects one measure of scarcity, measured as the ratio between rainfall and evapotranspiration [millimeter/millimeter]. We expect that, holding other thing constant, higher levels of Scarcity1 will be positively correlated with success of reform, and negatively correlated with length of reform.

Scarcity2 $=$ V15/V12. This variable measures available water resources per person residing in the basin $\left[\mathrm{m}^{3} /\right.$ person]. We expect Scarcity 2 to behave in a similar way to Scarcity1. 


\section{Annex 4: River Basin Organization Survey}

\section{Dear Survey Respondent:}

This survey is part of a research project which tries to assess in which way the creation of Riverbasin Organizations leads to decentralization of water resources management to other - lower - levels of decision making. The research project also tries to assess in which way the creation of Riverbasin Organizations leads to improved water resources management results.

The specific information (in the box below) regarding each individual basin will be kept in confidentiality not to allow identification of the Riverbasin Organization.

The results of the research effort will be made publicly available and hopefully help in the worldwide effort to bring about sustainable integrated water resources management.

If you find you have not enough space to fill out the questionnaire, you can expand the sections in this Word document or provide annexing sheets.

Your collaboration in this effort is highly appreciated.

The survey can be found in: www.worldbank.org/riverbasinmanagement

or directly by clicking on:

http://wbln0018.worldbank.org/essd/rdvsurveys.nsf/home?OpenView 


\section{River Basin Organization Survey}

\section{General Data}

\begin{tabular}{|c|c|}
\hline Basin: & Country: \\
\hline RBO Name: & \\
\hline RBO Address: & \\
\hline $\begin{array}{l}\text { Contact } \\
\text { Person: }\end{array}$ & Position: \\
\hline Telephone: & Fax: \\
\hline Email: & \\
\hline Website: & \\
\hline
\end{tabular}

\section{Institutional Setup}

\begin{tabular}{|l|||l|l|}
\hline 1. Basin area (square $\mathrm{km}):$ & \\
\hline 2. Population Total: & & \\
\hline 3. Annual precipitation (mm):
\end{tabular}




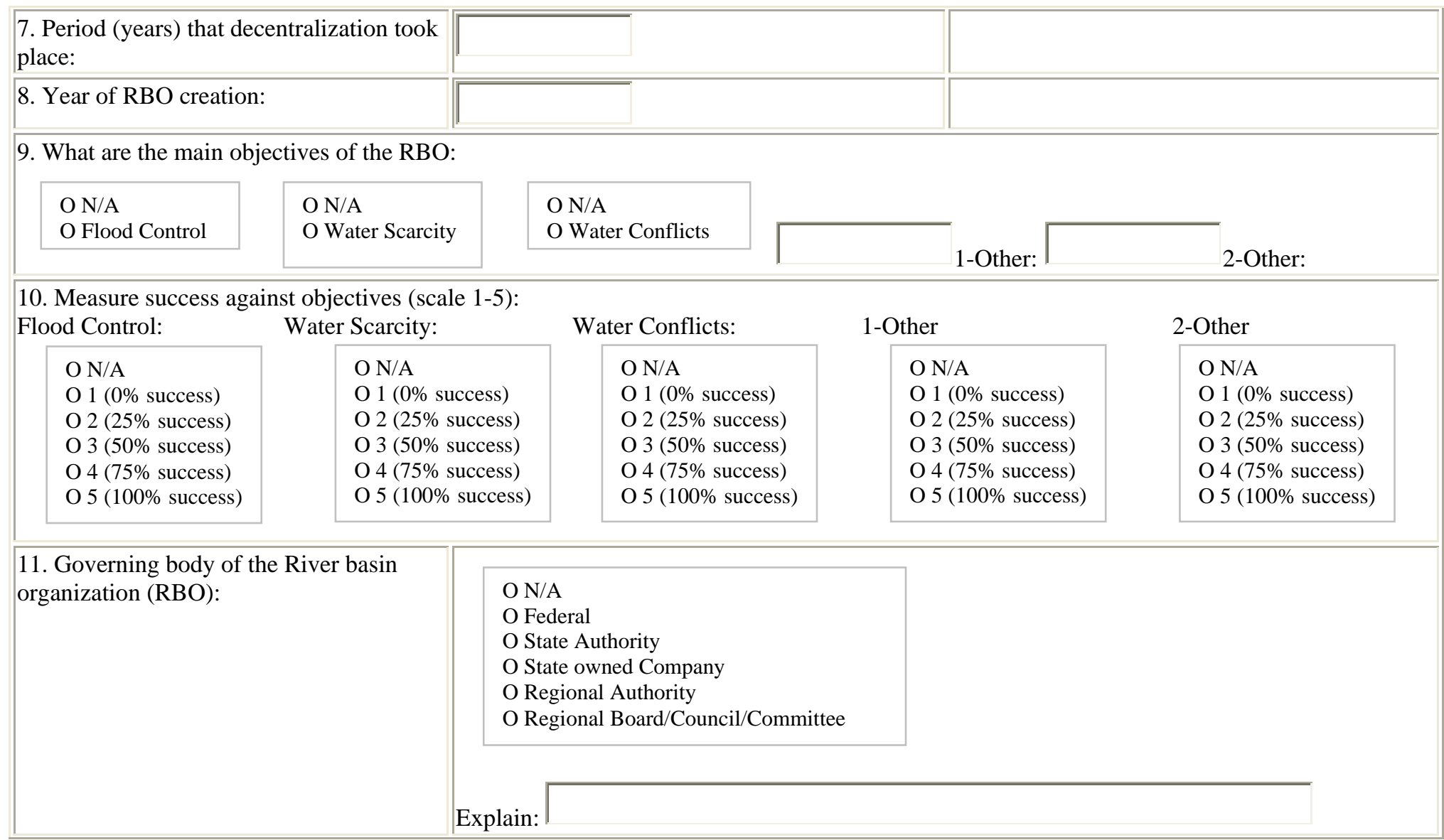




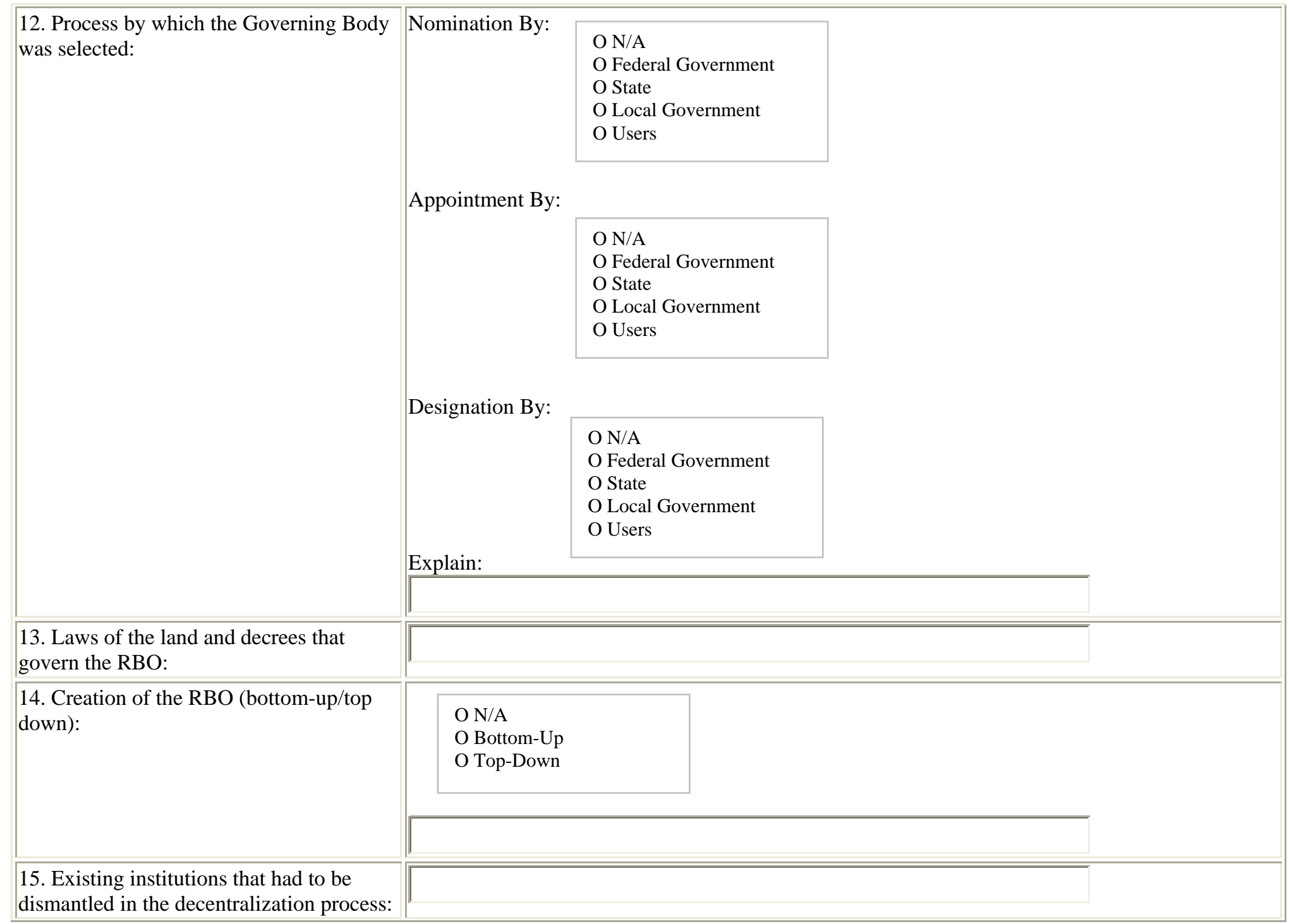




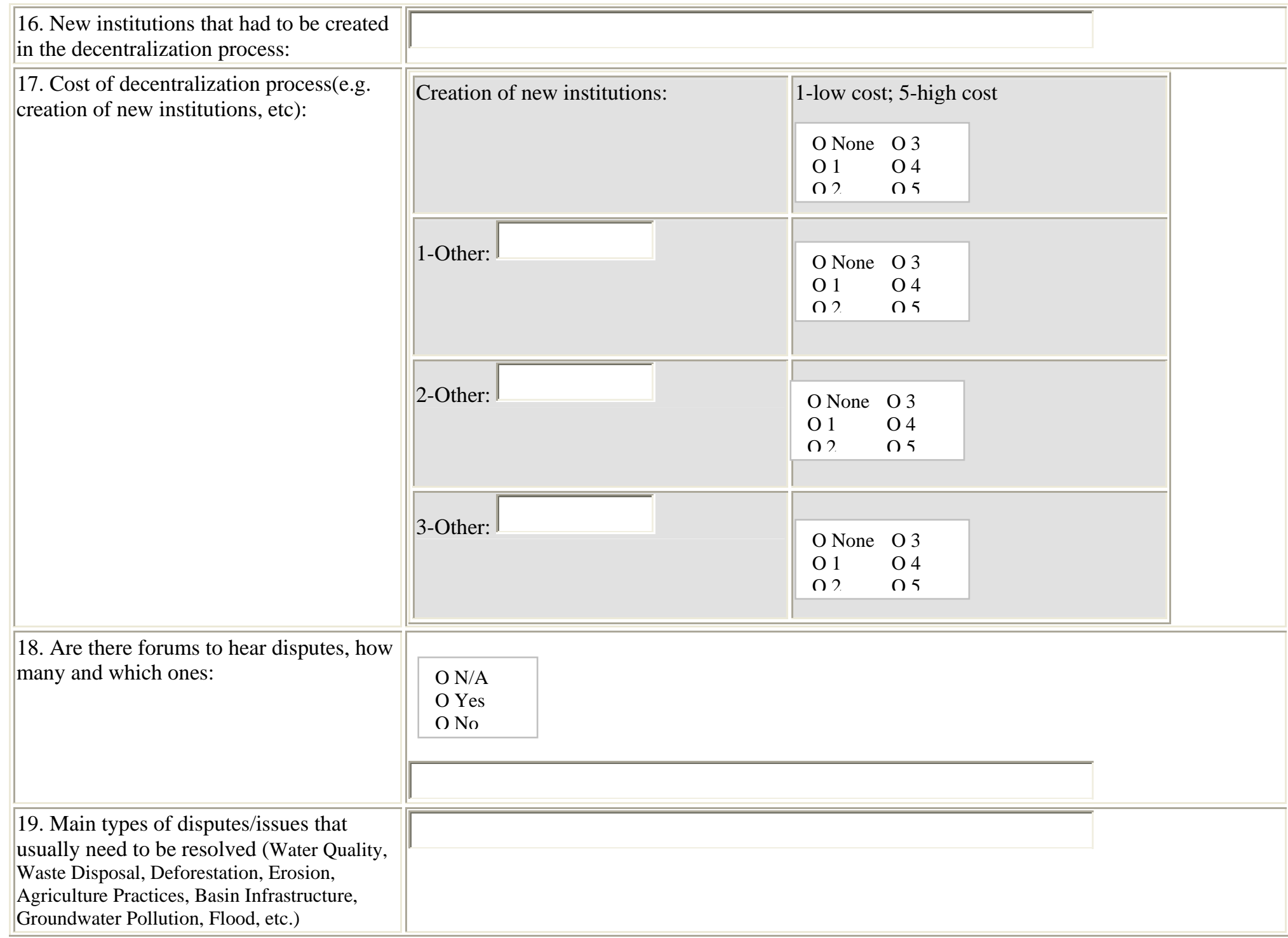




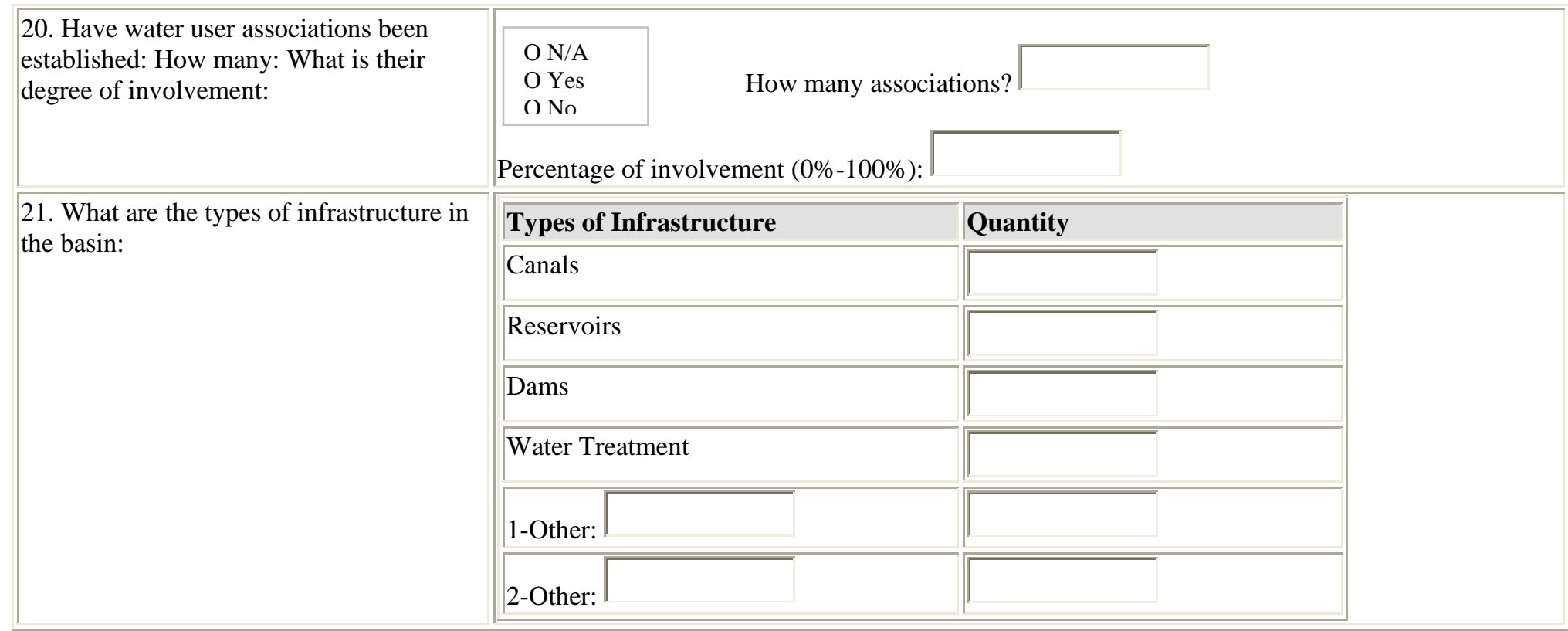

22. User types and share of use of the Basin's water:

\begin{tabular}{|l||l|}
\hline User Types & \multicolumn{1}{|c|}{ Share of Basin Water (0-100\%) } \\
\hline Irrigation: & \\
\hline Industrial: & \\
\hline Domestic: & \\
\hline Hydropower: & \\
\hline Environmental uses: \\
\hline 1-Other:
\end{tabular}




\begin{tabular}{|l|l|}
\hline 2-Other: & \multicolumn{1}{|}{} \\
3-Other: $\sqrt{\square}$ \\
\hline
\end{tabular}

23. Organigram - Please attached the RBO organigram. Attach your file here:

24. Share of types of water. Percentage (\%) of users that use:

\begin{tabular}{|l||l|}
\hline Types of Water & Percentage (0-100\%) \\
\hline Groundwater Only: & \\
\hline Surface Water Only: & \\
\hline Both Groundwater and Surface Water: & \\
\hline 1-Other: & \\
\hline 3-Other: & \\
\hline 3-Other:
\end{tabular}


25. Indicators of problems before and after establishment of the RBO (check all that apply):

\begin{tabular}{|c|c|c|}
\hline Water Resources Problems in the Basin & Before & After \\
\hline Water scarcity & $\begin{array}{l}\text { O No response } \\
\text { O No problem } \\
\text { O Some problem } \\
\text { O Severe problem }\end{array}$ & $\begin{array}{l}\text { O No response } \\
\text { O Situation same } \\
\text { O Situation improved } \\
\text { O Situation worsened }\end{array}$ \\
\hline Floods & $\begin{array}{l}\text { O No response } \\
\text { O No problem } \\
\text { O Some problem } \\
\text { O Severe problem }\end{array}$ & $\begin{array}{l}\text { O No response } \\
\text { O Situation same } \\
\text { O Situation improved } \\
\text { O Situation worsened }\end{array}$ \\
\hline Environmental Quality & $\begin{array}{l}\text { O No response } \\
\text { O No problem } \\
\text { O Some problem } \\
\text { O Severe problem }\end{array}$ & $\begin{array}{l}\text { O No response } \\
\text { O Situation same } \\
\text { O Situation improved } \\
\text { O Situation worsened }\end{array}$ \\
\hline Land Degradation & $\begin{array}{l}\text { O No response } \\
\text { O No problem } \\
\text { O Some problem } \\
\text { O Severe problem }\end{array}$ & $\begin{array}{l}\text { O No response } \\
\text { O Situation same } \\
\text { O Situation improved } \\
\text { O Situation worsened }\end{array}$ \\
\hline Water Conflicts & $\begin{array}{l}\text { O No response } \\
\text { O No problem } \\
\text { O Some problem } \\
\text { O Severe problem }\end{array}$ & $\begin{array}{l}\text { O No response } \\
\text { O Situation same } \\
\text { O Situation improved } \\
\text { O Situation worsened }\end{array}$ \\
\hline Development Issues & $\begin{array}{l}\text { O No response } \\
\text { O No problem } \\
\text { O Some problem } \\
\text { O Severe problem }\end{array}$ & $\begin{array}{l}\text { O No response } \\
\text { O Situation same } \\
\text { O Situation improved } \\
\text { O Situation worsened }\end{array}$ \\
\hline
\end{tabular}




\begin{tabular}{|c|c|c|}
\hline Other: & $\begin{array}{l}\text { O No response } \\
\text { O No problem } \\
\text { O Some problem } \\
\text { O Severe problem }\end{array}$ & $\begin{array}{l}\text { O No response } \\
\text { O Situation same } \\
\text { O Situation improved } \\
\text { O Situation worsened }\end{array}$ \\
\hline
\end{tabular}

26. Responsibilities for decision making Before and After the creation of the RBO. Please indicate the share of decision making for the following areas (0$100 \%)$ :

\begin{tabular}{|c|c|c|c|c|c|c|c|c|}
\hline \multirow{2}{*}{$\begin{array}{l}\text { Responsibility } \\
\text { for: }\end{array}$} & \multicolumn{4}{|c|}{ Before the creation of the RBO } & \multicolumn{4}{|c|}{ After the creation of the RBO } \\
\hline & $\begin{array}{c}\text { \% at local level } \\
\text { (e.g } \\
\text { municipality) }\end{array}$ & $\%$ at Basin level & $\begin{array}{c}\% \text { at state/ } \\
\text { provin-cial gov. } \\
\text { level }\end{array}$ & $\begin{array}{c}\% \text { at national } \\
\text { gov. level }\end{array}$ & $\begin{array}{c}\text { \% at local level } \\
\text { (e.g } \\
\text { municipality) }\end{array}$ & $\%$ at Basin level & \begin{tabular}{|c|}
$\%$ at \\
state/provincial \\
gov. level
\end{tabular} & $\begin{array}{l}\quad \% \text { at } \\
\text { national } \\
\text { gov. level }\end{array}$ \\
\hline $\begin{array}{c}\text { Water } \\
\text { Administration }\end{array}$ & $\begin{array}{ll}\text { O N/A } & \text { O } 50 \% \\
\text { O } 0 \% & \text { O } 60 \% \\
\text { O } 10 \% & \text { O } 70 \% \\
\text { O 20\% } & \text { O } 80 \% \\
\text { O 30\% } & \text { O } 90 \% \\
\text { O } 40 \% & \text { O } 100 \%\end{array}$ & $\begin{array}{ll}\text { O N/A } & \text { O } 50 \% \\
\text { O 0\% } & \text { O 60\% } \\
\text { O 10\% } & \text { O 70\% } \\
\text { O 20\% } & \text { O } 80 \% \\
\text { O 30\% } & \text { O } 90 \% \\
\text { O } 40 \% & \text { O } 100 \%\end{array}$ & $\begin{array}{ll}\text { O N/A } & \text { O } 50 \% \\
\text { O 0\% } & \text { O 60\% } \\
\text { O 10\% } & \text { O 70\% } \\
\text { O 20\% } & \text { O } 80 \% \\
\text { O 30\% } & \text { O } 90 \% \\
\text { O } 40 \% & \text { O } 100 \%\end{array}$ & $\begin{array}{lll}\text { O N/A } & \text { O } 50 \% \\
\text { O } 0 \% & \text { O } 60 \% \\
\text { O } 10 \% & \text { O } 70 \% \\
\text { O 20\% } & \text { O } 80 \% \\
\text { O 30\% } & \text { O } 90 \% \\
\text { O } 40 \% & \text { O } 100 \%\end{array}$ & $\begin{array}{lll}\text { O N N/A } & \text { O } 50 \% \\
\text { O } 0 \% & \text { O } 60 \% \\
\text { O } 10 \% & \text { O } 70 \% \\
\text { O } 20 \% & \text { O } 80 \% \\
\text { O 30\% } & \text { O } 90 \% \\
\text { O } 40 \% & \text { O } 100 \%\end{array}$ & \begin{tabular}{|lll} 
O N N & O $50 \%$ \\
O $0 \%$ & O $60 \%$ \\
O 10\% & O $70 \%$ \\
O $20 \%$ & O $80 \%$ \\
O 30\% & O $90 \%$ \\
O $40 \%$ & O $100 \%$
\end{tabular} & $\begin{array}{lll}\text { O N/A } & \text { O } 50 \% \\
\text { O } 0 \% & \text { O } 60 \% \\
\text { O } 10 \% & \text { O } 70 \% \\
\text { O } 20 \% & \text { O } 80 \% \\
\text { O } 30 \% & \text { O } 90 \% \\
\text { O } 40 \% & \text { O } 100 \%\end{array}$ & $\begin{array}{ll}\text { O N/A } & \text { O } 50 \% \\
\text { O } 0 \% & \text { O } 60 \% \\
\text { O } 10 \% & \text { O } 70 \% \\
\text { O } 20 \% & \text { O } 80 \% \\
\text { O } 30 \% & \text { O } 90 \% \\
\text { O } 40 \% & \text { O } 100 \%\end{array}$ \\
\hline $\begin{array}{l}\text { Infrastructure } \\
\text { Financing }\end{array}$ & $\begin{array}{lll}\text { O N/A } & \text { O } 50 \% \\
\text { O 0\% } & \text { O } 60 \% \\
\text { O } 10 \% & \text { O } 70 \% \\
\text { O 20\% } & \text { O } 80 \% \\
\text { O 30\% } & \text { O } 90 \% \\
\text { O 40\% } & \text { O } 100 \% \\
\end{array}$ & $\begin{array}{ll}\text { O N/A } & \text { O } 50 \% \\
\text { O 0\% } & \text { O } 60 \% \\
\text { O } 10 \% & \text { O } 70 \% \\
\text { O 20\% } & \text { O } 80 \% \\
\text { O 30\% } & \text { O } 90 \% \\
\text { O } 40 \% & \text { O } 100 \%\end{array}$ & $\begin{array}{ll}\text { O N/A } & \text { O } 50 \% \\
\text { O 0\% } & \text { O } 60 \% \\
\text { O 10\% } & \text { O 70\% } \\
\text { O 20\% } & \text { O } 80 \% \\
\text { O 30\% } & \text { O } 90 \% \\
\text { O 40\% } & \text { O } 100 \%\end{array}$ & $\begin{array}{ll}\text { O N/A } & \text { O } 50 \% \\
\text { O 0\% } & \text { O } 60 \% \\
\text { O } 10 \% & \text { O } 70 \% \\
\text { O 20\% } & \text { O } 80 \% \\
\text { O 30\% } & \text { O } 90 \% \\
\text { O } 40 \% & \text { O } 100 \%\end{array}$ & $\begin{array}{ll}\text { O N N/A } & \text { O } 50 \% \\
\text { O 0\% } & \text { O } 60 \% \\
\text { O } 10 \% & \text { O } 70 \% \\
\text { O } 20 \% & \text { O } 80 \% \\
\text { O } 30 \% & \text { O } 90 \% \\
\text { O } 40 \% & \text { O } 100 \%\end{array}$ & \begin{tabular}{|lll} 
O N N & O $50 \%$ \\
O $0 \%$ & O $60 \%$ \\
O 10\% & O 70\% \\
O 20\% & O $80 \%$ \\
O 30\% & O $90 \%$ \\
O 40\% & O $100 \%$
\end{tabular} & $\begin{array}{lll}\text { O N N/A } & \text { O } 50 \% \\
\text { O } 0 \% & \text { O } 60 \% \\
\text { O } 10 \% & \text { O } 70 \% \\
\text { O } 20 \% & \text { O } 80 \% \\
\text { O } 30 \% & \text { O } 90 \% \\
\text { O } 40 \% & \text { O } 100 \%\end{array}$ & $\begin{array}{lll}\text { O N/A } & \text { O } 50 \% \\
\text { O 0\% } & \text { O } 60 \% \\
\text { O } 10 \% & \text { O } 70 \% \\
\text { O 20\% } & \text { O } 80 \% \\
\text { O 30\% } & \text { O } 90 \% \\
\text { O 40\% } & \text { O } 100 \%\end{array}$ \\
\hline $\begin{array}{l}\text { Water quality } \\
\text { enforcement }\end{array}$ & $\begin{array}{ll}\text { O N/A } & \text { O } 50 \% \\
\text { O 0\% } & \text { O 60\% } \\
\text { O 10\% } & \text { O 70\% } \\
\text { O 20\% } & \text { O } 80 \% \\
\text { O 30\% } & \text { O } 90 \% \\
\text { O } 40 \% & \text { O } 100 \%\end{array}$ & $\begin{array}{ll}\text { O N/A } & \text { O } 50 \% \\
\text { O 0\% } & \text { O } 60 \% \\
\text { O } 10 \% & \text { O } 70 \% \\
\text { O } 20 \% & \text { O } 80 \% \\
\text { O 30\% } & \text { O } 90 \% \\
\text { O } 40 \% & \text { O } 100 \%\end{array}$ & $\begin{array}{lll}\text { O N/A } & \text { O } 50 \% \\
\text { O 0\% } & \text { O } 60 \% \\
\text { O } 10 \% & \text { O } 70 \% \\
\text { O } 20 \% & \text { O } 80 \% \\
\text { O 30\% } & \text { O } 90 \% \\
\text { O } 40 \% & \text { O } 100 \%\end{array}$ & $\begin{array}{lll}\text { O N/A } & \text { O } 50 \% \\
\text { O 0\% } & \text { O } 60 \% \\
\text { O } 10 \% & \text { O } 70 \% \\
\text { O } 20 \% & \text { O } 80 \% \\
\text { O } 30 \% & \text { O } 90 \% \\
\text { O } 40 \% & \text { O } 100 \%\end{array}$ & $\begin{array}{lll}\text { O N N/A } & \text { O } 50 \% \\
\text { O 0\% } & \text { O } 60 \% \\
\text { O } 10 \% & \text { O } 70 \% \\
\text { O } 20 \% & \text { O } 80 \% \\
\text { O } 30 \% & \text { O } 90 \% \\
\text { O } 40 \% & \text { O } 100 \%\end{array}$ & \begin{tabular}{|lll} 
O N N & O $50 \%$ \\
O 0\% & O $60 \%$ \\
O $10 \%$ & O $70 \%$ \\
O $20 \%$ & O $80 \%$ \\
O $30 \%$ & O $90 \%$ \\
O $40 \%$ & O $100 \%$
\end{tabular} & $\begin{array}{lll}\text { O N N/A } & \text { O } 50 \% \\
\text { O 0\% } & \text { O } 60 \% \\
\text { O } 10 \% & \text { O } 70 \% \\
\text { O } 20 \% & \text { O } 80 \% \\
\text { O } 30 \% & \text { O } 90 \% \\
\text { O } 40 \% & \text { O } 100 \%\end{array}$ & $\begin{array}{ll}\text { O N/A } & \text { O } 50 \% \\
\text { O } 0 \% & \text { O } 60 \% \\
\text { O } 10 \% & \text { O } 70 \% \\
\text { O } 20 \% & \text { O } 80 \% \\
\text { O } 30 \% & \text { O } 90 \% \\
\text { O } 40 \% & \text { O } 100 \%\end{array}$ \\
\hline
\end{tabular}




\begin{tabular}{|c|c|c|c|c|c|c|c|c|}
\hline $\begin{array}{c}\text { Setting water } \\
\text { quality standards }\end{array}$ & $\begin{array}{ll}\text { O N/A } & \text { O } 50 \% \\
\text { O 0\% } & \text { O } 60 \% \\
\text { O } 10 \% & \text { O } 70 \% \\
\text { O 20\% } & \text { O } 80 \% \\
\text { O 30\% } & \text { O } 90 \% \\
\text { O } 40 \% & \text { O } 100 \%\end{array}$ & $\begin{array}{ll}\text { O N/A } & \text { O } 50 \% \\
\text { O 0\% } & \text { O } 60 \% \\
\text { O } 10 \% & \text { O } 70 \% \\
\text { O } 20 \% & \text { O } 80 \% \\
\text { O 30\% } & \text { O } 90 \% \\
\text { O } 40 \% & \text { O } 100 \%\end{array}$ & $\begin{array}{ll}\text { O N/A } & \text { O } 50 \% \\
\text { O 0\% } & \text { O } 60 \% \\
\text { O } 10 \% & \text { O } 70 \% \\
\text { O } 20 \% & \text { O } 80 \% \\
\text { O 30\% } & \text { O } 90 \% \\
\text { O } 40 \% & \text { O } 100 \%\end{array}$ & $\begin{array}{ll}\text { O N/A } & \text { O } 50 \% \\
\text { O 0\% } & \text { O } 60 \% \\
\text { O } 10 \% & \text { O } 70 \% \\
\text { O 20\% } & \text { O } 80 \% \\
\text { O 30\% } & \text { O } 90 \% \\
\text { O 40\% } & \text { O } 100 \%\end{array}$ & $\begin{array}{ll}\text { O N N/A } & \text { O } 50 \% \\
\text { O } 0 \% & \text { O } 60 \% \\
\text { O } 10 \% & \text { O } 70 \% \\
\text { O } 20 \% & \text { O } 80 \% \\
\text { O 30\% } & \text { O } 90 \% \\
\text { O } 40 \% & \text { O } 100 \%\end{array}$ & $\begin{array}{ll}\text { O N N/A } & \text { O } 50 \% \\
\text { O 0\% } & \text { O } 60 \% \\
\text { O } 10 \% & \text { O } 70 \% \\
\text { O } 20 \% & \text { O } 80 \% \\
\text { O 30\% } & \text { O } 90 \% \\
\text { O } 40 \% & \text { O } 100 \%\end{array}$ & $\begin{array}{ll}\text { O N/A } & \text { O } 50 \% \\
\text { O } 0 \% & \text { O } 60 \% \\
\text { O } 10 \% & \text { O } 70 \% \\
\text { O } 20 \% & \text { O } 80 \% \\
\text { O } 30 \% & \text { O } 90 \% \\
\text { O } 40 \% & \text { O } 100 \%\end{array}$ & $\begin{array}{lll}\text { O N/A } & \text { O } 50 \% \\
\text { O } 0 \% & \text { O } 60 \% \\
\text { O } 10 \% & \text { O } 70 \% \\
\text { O } 20 \% & \text { O } 80 \% \\
\text { O 30\% } & \text { O } 90 \% \\
\text { O } 40 \% & \text { O } 100 \%\end{array}$ \\
\hline $\begin{array}{l}\text { Other (please } \\
\text { explain) }\end{array}$ & $\begin{array}{ll}\text { O N/A } & \text { O } 50 \% \\
\text { O 0\% } & \text { O } 60 \% \\
\text { O 10\% } & \text { O 70\% } \\
\text { O 20\% } & \text { O } 80 \% \\
\text { O 30\% } & \text { O } 90 \% \\
\text { O 40\% } & \text { O } 100 \%\end{array}$ & $\begin{array}{ll}\text { O N/A } & \text { O } 50 \% \\
\text { O 0\% } & \text { O } 60 \% \\
\text { O } 10 \% & \text { O } 70 \% \\
\text { O 20\% } & \text { O } 80 \% \\
\text { O 30\% } & \text { O } 90 \% \\
\text { O } 40 \% & \text { O } 100 \%\end{array}$ & $\begin{array}{lll}\text { O N/A } & \text { O } 50 \% \\
\text { O 0\% } & \text { O } 60 \% \\
\text { O } 10 \% & \text { O } 70 \% \\
\text { O } 20 \% & \text { O } 80 \% \\
\text { O 30\% } & \text { O } 90 \% \\
\text { O } 40 \% & \text { O } 100 \%\end{array}$ & $\begin{array}{lll}\text { O N/A } & \text { O } 50 \% \\
\text { O 0\% } & \text { O 60\% } \\
\text { O 10\% } & \text { O 70\% } \\
\text { O 20\% } & \text { O } 80 \% \\
\text { O 30\% } & \text { O } 90 \% \\
\text { O } 40 \% & \text { O } 100 \%\end{array}$ & $\begin{array}{ll}\text { O N N/A } & \text { O } 50 \% \\
\text { O } 0 \% & \text { O } 60 \% \\
\text { O } 10 \% & \text { O } 70 \% \\
\text { O } 20 \% & \text { O } 80 \% \\
\text { O 30\% } & \text { O } 90 \% \\
\text { O } 40 \% & \text { O } 100 \%\end{array}$ & $\begin{array}{lll}\text { O N N/A } & \text { O } 50 \% \\
\text { O 0\% } & \text { O 60\% } \\
\text { O 10\% } & \text { O 70\% } \\
\text { O 20\% } & \text { O } 80 \% \\
\text { O 30\% } & \text { O } 90 \% \\
\text { O } 40 \% & \text { O } 100 \%\end{array}$ & $\begin{array}{lll}\text { O N N/A } & \text { O } 50 \% \\
\text { O } 0 \% & \text { O } 60 \% \\
\text { O } 10 \% & \text { O } 70 \% \\
\text { O } 20 \% & \text { O } 80 \% \\
\text { O } 30 \% & \text { O } 90 \% \\
\text { O } 40 \% & \text { O } 100 \%\end{array}$ & $\begin{array}{lll}\text { O N/A } & \text { O } 50 \% \\
\text { O 0\% } & \text { O } 60 \% \\
\text { O } 10 \% & \text { O } 70 \% \\
\text { O } 20 \% & \text { O } 80 \% \\
\text { O 30\% } & \text { O } 90 \% \\
\text { O } 40 \% & \text { O } 100 \%\end{array}$ \\
\hline
\end{tabular}


3. Water Resource Management Instruments

Compare the situation before and after the existence of the RBO:

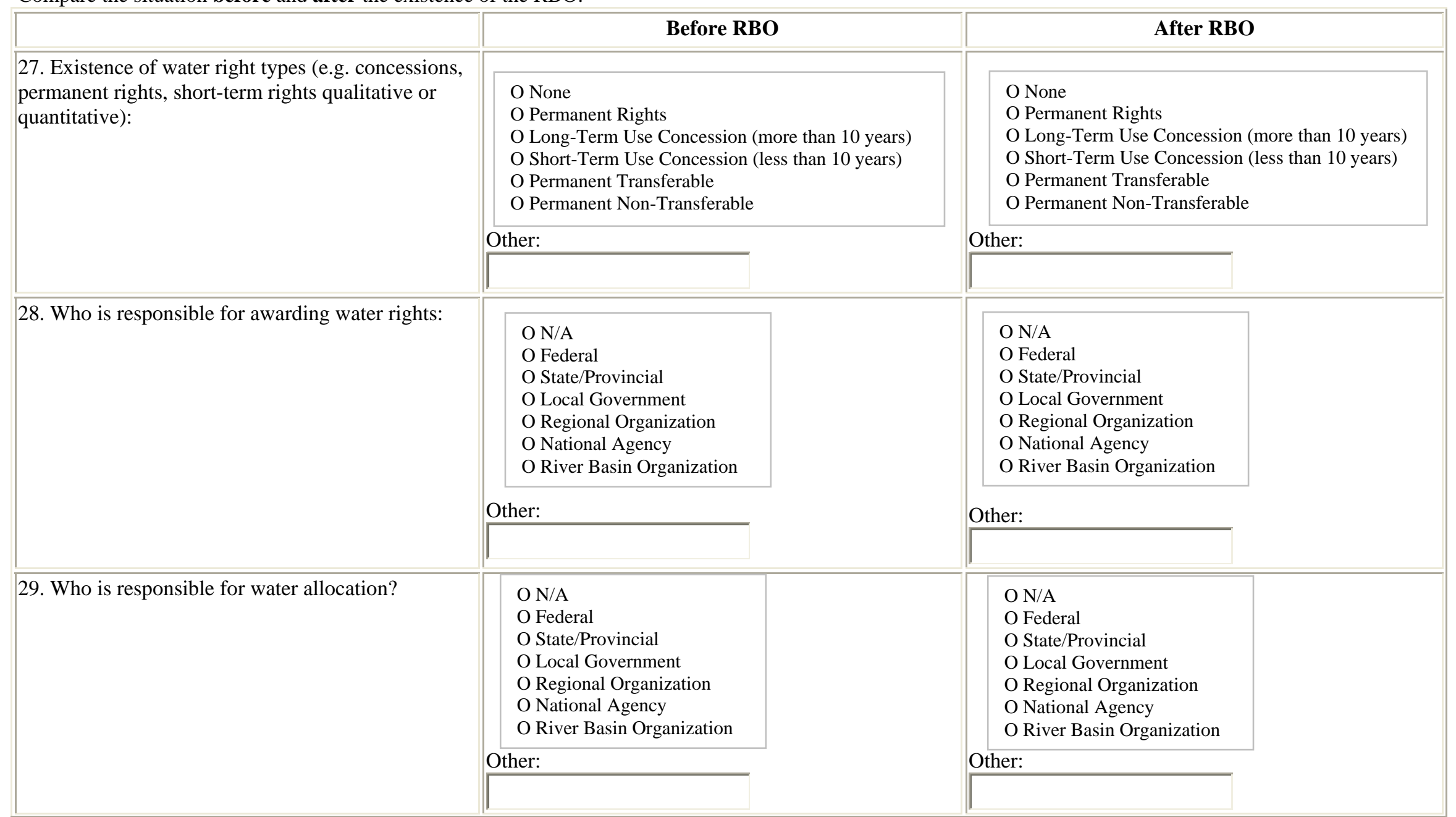




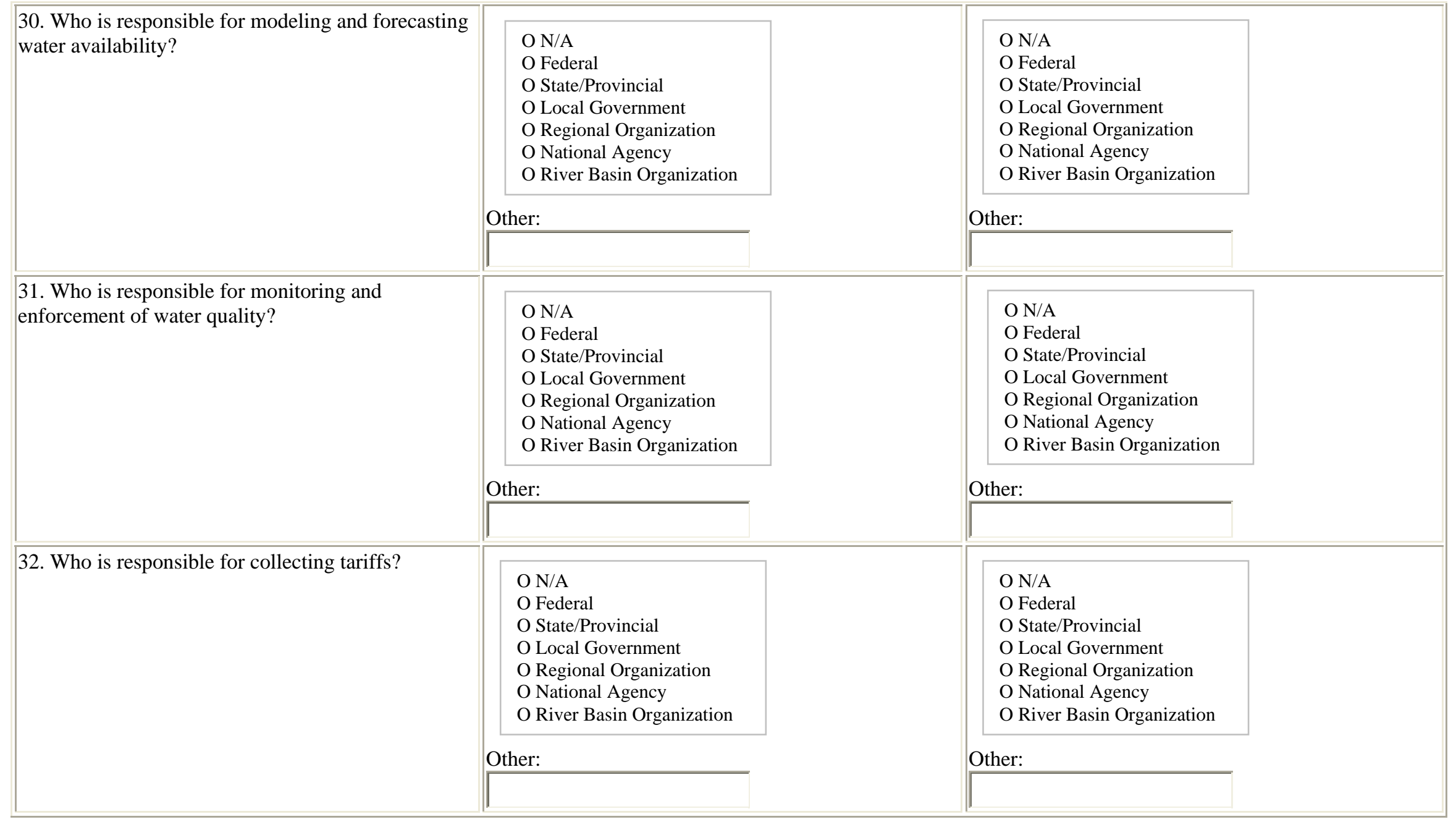


33. Water Tariff (if possible provide rates for various major uses):

\begin{tabular}{|l||l|}
\hline User Group & Water Tariff \\
\hline Irrigation & \\
\hline Industry & \\
\hline 1-Other: & \\
\hline 2-Other: & \\
\hline 3-Other: & \\
\hline
\end{tabular}

34. Percent of users paying tariffs:

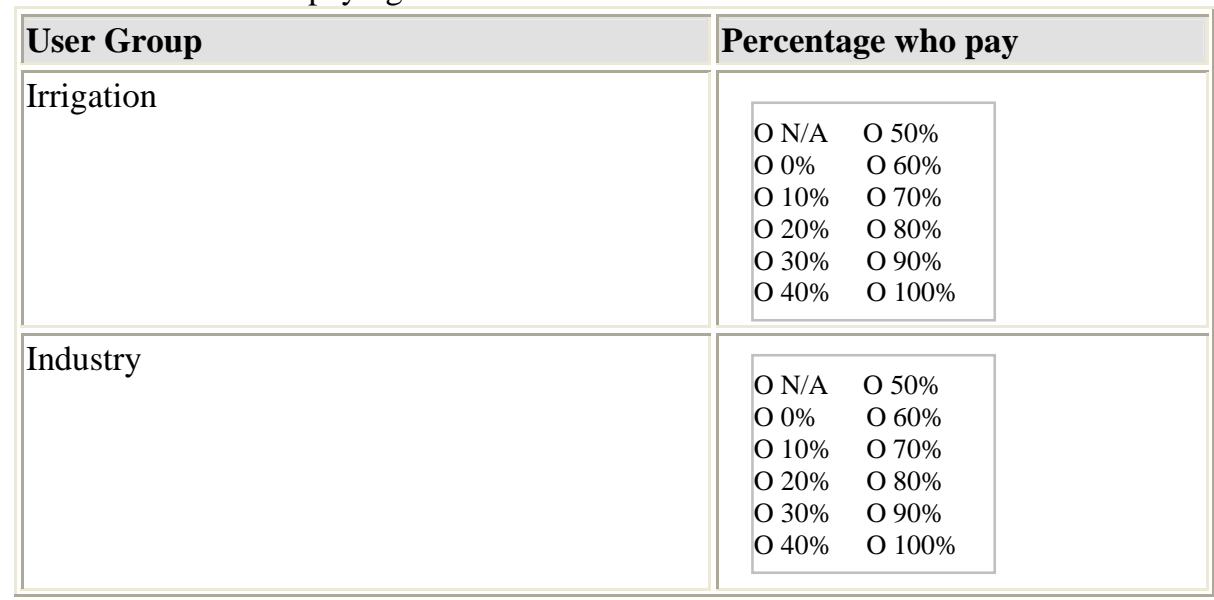




\begin{tabular}{|c|c|c|}
\hline Domestic & $\begin{array}{l}\text { O N/A } \\
\text { O 0\% } \\
\text { O 10\% } \\
\text { O } 20 \% \\
\text { O 30\% } \\
\text { O 40\% }\end{array}$ & $\begin{array}{l}\text { O } 50 \% \\
\text { O } 60 \% \\
\text { O 70\% } \\
\text { O 80\% } \\
\text { O 90\% } \\
\text { O 100\% }\end{array}$ \\
\hline 1-Other: & $\begin{array}{l}\text { O N/A } \\
\text { O 0\% } \\
\text { O } 10 \% \\
\text { O } 20 \% \\
\text { O 30\% } \\
\text { O } 40 \%\end{array}$ & $\begin{array}{l}\text { O } 50 \% \\
\text { O 60\% } \\
\text { O } 70 \% \\
\text { O 80\% } \\
\text { O 90\% } \\
\text { O 100\% }\end{array}$ \\
\hline 2-Other: & $\begin{array}{l}\text { O N/A } \\
\text { O 0\% } \\
\text { O } 10 \% \\
\text { O } 20 \% \\
\text { O 30\% } \\
\text { O } 40 \%\end{array}$ & $\begin{array}{l}\text { O } 50 \% \\
\text { O 60\% } \\
\text { O 70\% } \\
\text { O 80\% } \\
\text { O 90\% } \\
\text { O 100\% }\end{array}$ \\
\hline 3-Other: & $\begin{array}{l}\text { O N/A } \\
\text { O } 0 \% \\
\text { O } 10 \% \\
\text { O } 20 \% \\
\text { O 30\% } \\
\text { O } 40 \%\end{array}$ & $\begin{array}{l}\text { O } 50 \% \\
\text { O 60\% } \\
\text { O 70\% } \\
\text { O 80\% } \\
\text { O 90\% } \\
\text { O 100\% }\end{array}$ \\
\hline
\end{tabular}


35. Which percentage of the tariff payments stays in the basin and which percentage goes to other destinations? Which destinations?

$\begin{array}{lll}\text { Stays in the Basin: } & \text { O N/A } & \text { O 50\% } \\ & \text { O 0\% } & \text { O 60\% } \\ \text { O 10\% } & \text { O 70\% } \\ \text { O 20\% } & \text { O 80\% } \\ \text { O 30\% } & \text { O 90\% } \\ \text { O 40\% } & \text { O 100\% }\end{array}$

\section{Other Destinations: O N/A O $50 \%$ \\ O $0 \% \quad$ O $60 \%$ \\ O $10 \% \quad$ O $70 \%$ \\ O 20\% O $80 \%$ \\ O $30 \% \quad$ O $90 \%$ \\ O $40 \% \quad$ O $100 \%$}

\section{Which Destination:}

36. Extent/activities of private sector involvement in basin investments (e.g. water supply, water treatment, reservoir construction, basin infrastructure maintenance):

Percent Private Involvement:

\begin{tabular}{|ll}
\hline O N/A & O 50\% \\
\hline O 0\% & O 60\% \\
O 10\% & O 70\% \\
O 20\% & O 80\% \\
O 30\% & O 90\% \\
O 40\% & O 100\% \\
\hline
\end{tabular}

Explain:

37. Information sharing among all stakeholders (meetings, annual reports, websites):

38. Capacity building for stakeholders (e.g. training courses, seminars, study tours): 


\section{Financing:}

\begin{tabular}{|r|r|}
\hline 39. Annual Budget (million dollars per year): \\
\hline \% budget allocated by external (government) \\
\hline Provide name of external agency: \\
\hline \% budget derived from stakeholders in river \\
\% basins:
\end{tabular}

40. \% budget used for investment in the Basin:

41. \% budget used for other development activities:

42. \% budget used for O\&M:

43. \% budget used for water quality activities:

44. \% budget used for other:

\begin{tabular}{|l|}
$\sqrt{15}$ \\
$\sqrt{\square}$ \\
$\sqrt{\square}$
\end{tabular}




\section{Performance Indicators}

45. Do you measure your basin's GDP?

C Yes No

If Yes, please indicate the basin's yearly GDP (million US dollars per year):

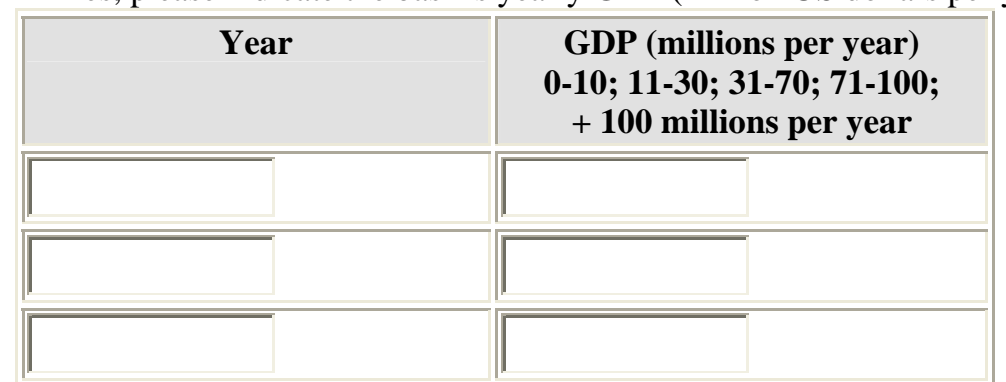

46. Basin land area utilized by various sectors:

\begin{tabular}{|l||l|}
\hline \multicolumn{1}{|c|}{ Sector } & Basin Area (km2) \\
\hline Agriculture & \multicolumn{1}{|c|}{} \\
\hline Forests & \\
\hline Urban Zones & \\
\hline Open Land & \\
\hline 1-Other: & \\
\hline 2-Other: & \\
\hline 3-Other: & \\
\hline
\end{tabular}


47. Various water quality indicators used in your Riverbasin:

\begin{tabular}{|l||l|l|}
\hline \multicolumn{2}{|c|}{ Indicator } & \multicolumn{1}{|c|}{ Value (units) } \\
\hline Dissolved Oxygen & \\
\hline Conductivity & \\
\hline Suspended Solids & \\
\hline 1-Other: & \\
\hline 2-Other: & \\
\hline 3-Other: & \\
\hline
\end{tabular}

48. Reduction in loss of production or productivity due to water scarcity or flooding: Describe verbally for the various sectors the situation before and after decentralization:

49. Number of disputes over water allocations or water quality before and after creation of the RBO:

50.Any other comments or clarifications including annexed material you think may be of value: 